\title{
2 Heimatrecht
}

Heimat war über Jahrhunderte hinweg ein juristischer Begriff, dem eine konkrete Rechtspraxis entsprach - diese Vorgeschichte der modernen Heimatsemantik ist heute fast vollständig in Vergessenheit geraten. Bis zum Ende des 19. Jahrhunderts war die rechtliche Bedeutung im Alltagsverständnis aber noch präsent - schlicht deshalb, weil das Heimatrecht noch galt und weitreichende, oft existentielle Konsequenzen für die armen Bevölkerungsschichten barg. Die im Heimatrecht enthaltene rechtliche Heimatlosigkeit war etwa in der Schweiz ein brennendes soziales Problem. Das musste im Jahrhundert des sentimentalen Heimatbegriffs notwendig zu Reibungen führen und insbesondere die Literatur verfügt über Möglichkeiten, diese Reibungen produktiv zu machen.

Heimat bezeichnet im juristischen Sinn die kleinste dem Rechtssubjekt zuzuordnende räumlich-administrative Einheit, die eng mit den Regelungen des Armen- und Abschieberechts (des sogenannten ,Schubwesens'), dem Recht auf Aufenthalt und Niederlassung und dem Eherecht zusammenhängt. Das Heimatrecht ist unteilbar, jeder Landeseinwohner kann also nur eine Heimat haben. Nur hier genießt er Aufenthaltsrecht. ${ }^{1}$ Im eng ausgelegten Sinn begründet das Heimatrecht die Zuständigkeit einer Gemeinde für die öffentliche Armenfürsorge der Gemeindeangehörigen. ${ }^{2}$ Das deutsche, österreichische und schweizerische Heimatrecht regelte neben dieser Zuständigkeiten auch das Recht zur Abschiebung von Bettlern, Straffälligen und ,Ausländern` - als Ausländer galt bis 1866 auch der Hannoveraner in Preußen und bis 1871 der Bayer in Hessen.

Das Heimatrecht basiert im 19. Jahrhundert auf der Annahme einer weitgehenden Stabilität des Lebensortes. Es geht von der Erwartung aus, dass Geburtsund Aufenthaltsort identisch sind. Jeder Bedürftige erhält Fürsorge nur in der Heimat, jeder Straffällige darf von allen Gemeinden, die nicht seine Heimat sind, abgeschoben werden. Im gesamten 19. Jahrhundert gilt dieses Heimatrecht für weite Teile des deutschsprachigen Raums, es versagt aber unter den Bedingungen wachsender Mobilität zunehmend. Die sich verschärfenden Diskrepanzen von Recht und Lebensrealität werden aus juristischer Sicht rege diskutiert und führen

1 „Der Inhalt des Aufenthaltsrechts ist ein negativer: aus dem Bezirke der Gemeinde nicht weggewiesen zu werden. Ein polizeiliches Verbot des Aufenthaltes in einer Gemeinde darf sich nicht gegen den in ihr Beheimateten richten.“ Kutzer 1904, S. 46.

2 In diesem engeren Sinn wird das Heimatrecht daher teilweise als Recht auf Verpflegung im Falle der Verarmung verstanden. In Heinrich Zoepfls Grundsätzen des gemeinen deutschen Staatsrechts wird diese Definition gewählt: „das Recht auf Armenverpflegung im Falle der Verarmung für sich und seine Kinder (sog. Heimathsrecht im engeren Sinne)“. Zoepfl 1863, S. 56.

๑ OpenAccess. () 2021 Anja Oesterhelt, publiziert von De Gruyter. (cc))BY-ND Dieses Werk ist lizenziert unter der Creative Commons Attribution-NonCommercial-NoDerivatives 4.0 Lizenz.

https://doi.org/10.1515/9783110707847-005 
zu zahlreichen Präzisierungen und Reformen, insgesamt aber scheitern die Versuche, das zahlreichen regionalen Sonderregelungen und einer widersprüchlichen Rechtspraxis unterliegende Heimatrecht einheitlich zu regeln. Erst zu Beginn des 20. Jahrhunderts - 1916, mitten im Ersten Weltkrieg - wird es im Deutschen Reich flächendeckend abgeschafft. Seitdem gilt der Grundsatz, dass für den Bedürftigen am Ort des tatsächlichen Wohnsitzes gesorgt wird; das Heimatrecht ist endgültig abgeschafft. In Österreich geschieht dies erst 1939, in der Schweiz besteht das Heimatrecht de jure bis heute, ist aber de facto von geringer praktischer Bedeutung.

Die rechtliche Dimension von Heimat und Heimatlosigkeit ist im 19. Jahrhundert Alltagswissen. In der Allgemeinen deutschen Real-Encyklopädie von 1845 oder in Meyers Neuem Konversations-Lexikon von 1867 befassen sich die Einträge $\mathrm{zu}$,Heimat' ausschließlich mit der rechtlichen Bedeutung - eine emphatische oder auch nur semantisch offenere Bedeutung wird nicht einmal benannt. ${ }^{3}$ Noch in Brockhaus’ Konversations-Lexikon von 1893 hat sich das nicht geändert: „Die H. ist im Gegensatz zum faktischen Aufenthalt und andererseits zur Staatsangehörigkeit die rechtlich anerkannte und rechtlich wirksame Zugehörigkeit zu einer Gemeinde, auf welcher die kommunalpol. Rechte und Pflichten beruhen; [...].“4 Diese Bedeutung habe der Begriff Heimat „bis in die neueste Zeit beibehalten“. 5 Weiterhin wird auf den eigenen Artikel ,Heimatrecht‘ verwiesen.

In Anbetracht des emphatischen Heimatverständnisses seit 1800 und seiner zunehmenden Sentimentalisierung in der Populärkultur des 19. Jahrhunderts muss diese Diskrepanz, muss dieses doppelte Alltagswissen um Heimat und Heimatlosigkeit auffallen. Wie eklatant die sentimentale Heimat-Topik und die rechtlich-administrative Bedeutung des Heimatbegriffs einander widersprachen, kann die Figur des heimwehkranken Schweizer Söldners zeigen. Einerseits ist sie ein zentraler zeitgenössischer Topos der sentimentalen Heimat- und Heimweherzählungen. Kaum eine Familienzeitschrift des 19. Jahrhunderts ohne eine Anekdote oder ein Gedicht über einen Schweizer Soldaten, der fern von der Heimat an unerklärlichem Heimweh stirbt und so die Kraft der Heimatliebe beweist. ${ }^{6}$ Andererseits gehörten gerade die heimkehrenden Soldaten in der Schweiz

3 Vgl. Anonym 1845, S. 2 und Anonym 1867, S. 214.

4 Anonym: Heimat, 1893, S. 970.

5 Anonym: Heimat, 1893, S. 970.

6 Vgl. etwa einen entsprechenden Beitrag in der Zeitschrift Unterhaltungen am häuslichen Herd, Anonym: Schweizerheimweh, 1852. Schon im 17. Jahrhundert bindet die Medizin die Pathologie des Heimwehs an den hochalpinen Raum (und kommt zu teils abenteuerlichen Therapievorschlägen: Die Kranken sollten beispielsweise auf hohe Türme gestellt werden, vgl. Jaspers 2019) und belegt das Phänomen mit dem Namen morbus helveticus. Auch noch im 19. Jahrhundert ist 
zu derjenigen Bevölkerungsgruppe, der das Heimatrecht und damit die Versorgung durch die Gemeinde entzogen wurde und die daher massiv von Heimatlosigkeit im rechtlichen Sinn bedroht war. Für das 18. Jahrhundert geht man von bis zu 500.000 Männern aus den ländlichen Unterschichten aus, die als Söldner für die Armeen Frankreichs, Spaniens, Venedigs, Savoyens, Roms, der Niederlande, Österreichs oder Preußens Dienst taten, um so temporär Arbeit und Auskommen zu erlangen. ${ }^{7}$ Trotz verschiedener Beschränkungen war auch im 19. Jahrhundert der Kriegsdienst für fremde Mächte als Erwerbsmöglichkeit noch an der Tagesordnung, beispielsweise auch für England im Krimkrieg oder für das Königreich Neapel. Die längere Ortsabwesenheit nutzten Gemeinden teilweise, um sich der oft mittellos und nicht selten invalide Zurückkehrenden zu entledigen, indem sie ihnen ihre Heimatberechtigung wegen zu langer Abwesenheit aberkannten. ${ }^{8}$

Literarische Texte, die solche Widersprüche des Wissens um Heimat verarbeiten oder integrieren, finden sich ab den 1840er Jahren. Bezeichnenderweise hatte sich die schöne Literatur in der Phase der Emphatisierung von Heimat ab 1800 zunächst so gut wie an keiner Stelle auf das Heimatrecht bezogen, obwohl sich solch ein Bezug zeitgleich innerhalb anderer Textformen nachweisen lässt (so etwa in den pragmatischen Textsorten Justus Mösers, vgl. II.2.2). Erst in den 1840er Jahren spielt das Heimatrecht mit dem Einzug von realistischen Darstellungsweisen auch in literarischen Texten eine nennenswerte Rolle. Die literarische Neusemantisierung von Heimat ab den 1840er Jahren spiegelt sich also auch im Bezug auf den rechtlichen Aspekt von Heimat wider, wie die Hinwendung zu den ,Realien' in Form des Heimatrechts bei zahlreichen Autoren von Berthold Auerbach über Fritz Reuter, Gottfried Keller, Adalbert Stifter und Hermann Kurz,

diese Verbindung in medizinischen Abhandlungen zu finden, beispielsweise in Julius Heinreich Gottlieb Schlegels Schrift Das Heimweh und der Selbstmord (1835), das im Anhang die Noten und Liedtexte von „Der Kuhreihn“ und „Das Tyroler Heimweh“ enthält. Die Übergänge zwischen medizinischem und literarischem Diskurs sind fließend. Schön ist die um 1800 einsetzende Sentimentalisierung des ursprünglich pathologisch aufgefassten Phänomens an Clemens Brentanos Bearbeitung eines Fliegenden Blattes für Des Knaben Wunderhorn zu sehen. In der Vorlage, „Zu Straßburg auf der Schanz“, einem anonymen Text vom Ende des 18. Jahrhunderts, muss ein Deserteur sterben, der von den Franzosen zu den Preußen überlaufen wollte. In Brentanos Umarbeitung erhält der Text einen neuen Titel - „Der Schweizer“ - und ein Motiv für die Desertion: ein Alphorn, dessen Klang beim Soldaten solches Heimweh auslöst, dass er dem inneren Zwang erliegt, heimwärts zu laufen, und kurz vor seiner Erschießung klagt: „Der Hirtenbub ist schuld daran, / Das Alphorn hat mir's angetan, / Das klag ich an.“ Das Lied wurde im weiteren 19. Jahrhundert mehrfach variiert, beispielsweise von Salomon Mosenthal, in dessen „Zu Straßburg auf der langen Brück'“ dann der Begriff der Heimat mit dem Alphorn kombiniert auftritt. Zur Topik des heimwehkranken Soldaten und der medizinischen Vorgeschichte vgl. auch I.2.3.

7 Vgl. Meier/Wolfensberger 1998, S. 83.

8 Vgl. Meier/Wolfensberger 1998, S. 84. 
Gottfried Kinkel, Wilhelm Heinrich Riehl und Robert Schweichel bis hin zu Wilhelm Raabe, Friedrich Gerstäcker und Clara Viebig zeigt. Selbst bei dem Bestsellerautor Ludwig Ganghofer, der mit seinen Romanen, Erzählungen und Theaterstücken an den populären Gleichungen von Einfachheit und Redlichkeit, Unverbildetheit und Glaube, Gesundheit und Heimatliebe maßgeblich mitschuf ${ }^{9}$ (wenn auch das Ticket der Authentizität, mit dem Ganghofer so gut reiste, schon von Zeitgenossen in Frage gestellt wurde), ${ }^{10}$ ist das Wissen um die rechtliche Dimension von Heimat allerorten zu finden. ${ }^{11}$

Das Heimatrecht hat innerhalb literarischer Texte ab den 1840er Jahren stets auch die Funktion, zeitgenössische Lebenswelt abzubilden, ,realistisch ${ }^{6}$ zu sein. Teilweise wird dabei die gesellschaftliche Realität einer Kritik unterzogen: Kritik am individuellen und institutionellen Umgang mit Armut und sozialer Ungleichheit, an der strukturell produzierten Ohnmacht insbesondere der Armen gegenüber dem Verwaltungsstaat und seinen Trägern. Auch die im Zusammenhang mit dem Heimatrecht stehenden Themen erstens der Abschiebung, zweitens der massenhaften Auswanderung, insbesondere nach Übersee, und drittens der Heimatlosigkeit von Minoritäten, die als Fremde im eigenen Land leben, basieren auf gesellschaftlichen Realitäten der Zeit, die auch eine juristisch-administrative Seite haben. Der kritische Impuls eines Teils der literarischen Texte knüpft dabei nicht nur an die soziale Realität an, sondern auch an die Widersprüche eines Heimatbegriffs, der sowohl eine sentimentale als auch eine rechtliche Semantik in sich birgt.

Die folgende Einführung in die rechtliche Semantik des Begriffs wird recht breiten Raum einnehmen, da eine neuere rechtshistorische Darstellung für

9 Die zeitgenössische Rezeption beschreibt Ganghofer und sein Werk oft als Gegensatz zur zerrissenen Gegenwart. Ganghofer sei „ein Dichter, dem alles Problematische fehlte, der wußte, was er wollte und was er konnte, und der froh und zuversichtlich seines Weges ging, ganz und gar nicht zerrissen, sondern hell und heil und gesund, aus seiner Heimat strömten immer von neuem die Kräfte in sein Werk“. In diesem Sinn wird Ganghofer dann auch als Repräsentant des Deutschen verstanden, er sei „einer der deutschesten Dichter geworden, die sonnige Freude und der farbige Reichtum seiner Heimat, die in allen seinen Werken leuchten, [...] haben ganz Deutschland bezaubert“; Leyen 1925, S. 16-18.

10 Ein Rezensent des ganghoferschen Novellenbandes Aus Heimat und Fremde (1884) bemerkt, dass Ganghofers Ruhm wachse, je weiter die Leser vom angeblich authentisch geschilderten Schauplatz entfernt lebten. Nachzulesen in einem ausführlichen Zitat in der Ganghofer-Studie von Matthias Prangl, Prangl 1986, S. 71. Dass Ganghofers außergewöhnlicher Erfolg seine Ursprünge in Berlin hatte, geht auch aus Peter Mettenleiters Studie hervor; hier auch zur zentralen Rolle der Gartenlaube für die Verbreitung von Ganghofers Werk; vgl. Mettenleiter 1974, S. 367. 11 Die Waise Modei in Der Jäger von Fall (ursprünglich ein Volksstück, das dann in der Novellenfassung zu großer Popularität gelangte) meint ganz konkret ihren bei einem Brand verlorenen Hof, wenn sie sagt, sie habe weder Vater und Mutter noch Heimat (vgl. Ganghofer 1940, S. 134). 
Deutschland bisher nicht vorliegt. Anders sieht das für die Schweiz und Österreich aus, hier sind mit der Studie des Autorenpaars Thomas Dominik Meier und Rolf Wolfensberger und der Studie Harald Wendelins zwei exzellente, Sozial- und Rechtsgeschichte miteinander verbindende Darstellungen entstanden, ${ }^{12}$ die sich durch eine umfassende Aufarbeitung der Gesetzgebung und Rechtspraxis und deren soziale, ökonomische und politische Kontextualisierungen auszeichnen.

Für den Raum des späteren Deutschen Reiches liegen keine vergleichbaren Studien vor. Hier bieten die grundlegende und auch von zeitgenössischen Juristen als Standardwerk angesehene ${ }^{13}$ Arbeit von Emil von Riedel aus dem Jahr 1868 (bis 1881 in verschiedenen Auflagen aktualisiert ${ }^{14}$ sowie die Arbeiten von Max Seydel und anderen zeitgenössischen Juristen immer noch die besten Quellen. ${ }^{15}$ Diese beschränken sich, genau wie die zeitgenössischen Quellen zur K.-und-k.-Monarchie, ${ }^{16}$ auf die rechtsdogmatische Kommentierung von Gesetzestexten, ohne dass die Kodifikationen auch im Hinblick auf ihre soziokulturellen Bedeutungen gelesen würden. Die Forschung weist seit den 1970er und 1980er Jahren auf die rechtshistorische Dimension von Heimat hin. ${ }^{17}$ Zwei wichtige Aufsätze zum Thema Anfang der 1990er Jahre haben das Forschungsdefizit aufgezeigt ${ }^{18}$ und in jüngerer Zeit sind sehr gute, allerdings regional oder zeitlich eingegrenzte rechtsund sozialhistorische Einzelstudien im Umfeld des Themas entstanden. ${ }^{19}$

Es ist angesichts der relativ geringen Aufmerksamkeit der Fachhistoriker für das Heimatrecht kaum verwunderlich, dass auch die historisch arbeitende Lite-

12 Vgl. Meier/Wolfensberger 1998 und Wendelin 2000.

13 Vgl. etwa Max Seydels Rezension der sechsten Auflage von Riedels Schrift. Seydel 1892, S. $256-258$.

14 Im Folgenden wird nach der von Ludwig August von Möller überarbeiteten fünften Auflage zitiert, vgl. Riedel 1881.

15 Vgl. Seydel 1877; Seydel 1886; Seydel 1890; Seydel 1891.

16 Vgl. Swieceny 1861; Arailza 1889; Geller 1897; Giegl 1901; Langhoff 1920; Kanzian 1934.

17 Meist eher pauschale Hinweise auf die rechtliche Dimension von Heimat liefern kürzere Forschungsbeiträge der 1970er und 1980er Jahre. Für die Rechtswissenschaft vgl. Brintzinger 1981, S. 15; für die Volkskunde vgl. Greverus 1972, S. 28; Bausinger 1980, S. 13-14; für die Literaturgeschichte vgl. Jens 1985. Walter Jens datiert die Geltungskraft des Heimatrechts falsch: Es galt, entgegen seiner Darstellung, noch mehrere Jahrzehnte nach der „Mitte des neunzehnten Jahrhunderts“. Jens 1985, S. 14.

18 Tiefergehend verfolgen die rechtsgeschichtliche Dimension erstmals Harm-Peer Zimmermann und Barbara und Werner Hartung Anfang der 1990er Jahre (vgl. Zimmermann 1991; Hartung 1991); Andrea Bastians Studie widmet dann 1995 ein ganzes Kapitel dem Thema (vgl. Bastian 1995). 19 Vgl. die volkskundliche Studie Eva Maria Lerches, die sich auf die westfälische bzw. preußische Situation des Heimatrechts im Zeitraum 1844-1891 fokussiert: Lerche 2009. Die Historikerin Beate Althammer stellt in einem aktuellen Aufsatz die Debatte um Heimatrecht und Unterstützungswohnsitz um 1871 dar, vgl. Althammer 2021. 
raturwissenschaft dem Thema in der Regel keine Aufmerksamkeit schenkt. Das folgende Kapitel wird zeigen, dass es lohnend ist, es zu integrieren. In vielen Fällen gewinnt man so einen zeithistorisch interessanten Aufschluss auf der Ebene des Textkommentars, in anderen Fällen gibt sie einen hermeneutischen Schlüssel für das Textganze in die Hand - so in Kellers Romeo und Julia auf dem Dorfe -, und in wieder anderen Fällen wird sogar der Zugriff auf ganze Werkzusammenhänge eines Autors möglich, wie bei Auerbach.

Nach einer Einführung in die rechtliche Dimension von Heimat (II.2.1) wird diskutiert, mit welchem Gewinn sich auch die Literaturwissenschaft an der Rückeroberung dieses Wissens beteiligen kann (II.2.2). Dies wird für die Literatur zwischen den 1840er und 1910er Jahren anhand der Themenkomplexe Abschiebung (II.2.2.1), Auswanderung (II.2.2.2) und Heimatlosigkeit (II.2.2.3) ausgeführt. Nicht zufällig betreffen diese Themen fast immer nur die Ärmsten der Gesellschaft. Denn nur für den, der so arm ist, dass er sich selbst nicht ernähren kann, oder der wegen dieser Armut straffällig wird, ist das Heimatrecht relevant. Die Verfechter des Heimatrechts im 19. Jahrhundert betonen die Funktion der sozialen Bindung an die Heimatgemeinde und leiten daraus die Versorgungsfunktion der Gemeinde für die Armen ab. Ausgehend von der historischen Rekonstruktion der realen Rechtspraxis lässt sich aber das Heimatrecht mindestens ebenso plausibel als systematische Verweigerung von Versorgung beschreiben. Denn die Gemeinden waren unter ökonomischen Gesichtspunkten daran interessiert, ihre Versorgungsleistungen so gering wie möglich zu halten und also möglichst viele Versorgungsfälle abzuweisen. Die Verweigerung von Heimat gegenüber den Ärmsten seitens der Gemeindebürger ist somit eine historische Tatsache, die die ,Bürgerlichkeit' von Heimat unter einem rechtlichen Aspekt zeigt: Heimat ist ein nicht nur sentimentales, sondern auch ökonomisches Gut, das im Zeitalter des Bürgertums (vgl. I.2.5) nicht zuletzt deswegen zunehmend an Relevanz gewinnt, weil es nicht mehr Adel und Klerus sind, die die Versorgungsverantwortung zu übernehmen haben, sondern Institutionen des bürgerlichen Staates: die Gemeinden, die Landesarmenhäuser, die Arbeitshäuser. Heimat ist eine reglementierte Ressource, die das Bürgertum besonders ,nach unten' verteidigen muss. Literarische Texte zeigen das auf vielfältige Weise. 


\subsection{Heimat als Rechtsbegriff}

\section{Zur Vorgeschichte}

,Heimath' ist als Begriff seit dem 16. Jahrhundert in der Rechtssprache zu finden. ${ }^{20}$ Häufiger werden bis zum 18. Jahrhundert die Begriffe ,Domicilium‘, ,Indigenat“ ,Zuständigkeit‘ oder ,Zuständigkeitsobrigkeit‘ (in der Schweiz auch Bürgerort, Bürgergemeinde, Bürgerrecht) verwendet. Geregelt wurde mit allen diesen Begriffen die Zugehörigkeit der Landeseinwohner zu einer Gemeinde und die Zuständigkeit dieser Gemeinde im Fall von deren Hilfsbedürftigkeit.

Die sukzessive Ausbildung einer Armenunterstützungspflicht durch die Gemeinden ist eine gesamteuropäische Entwicklung, die sich zeitgleich um die Mitte des 16. Jahrhunderts auch in England und Frankreich vollzieht und mit den verschiedenen europäischen religiösen Reformationsbewegungen zusammenhängt, in deren Gefolge die Armenunterstützung schrittweise von der Kirche auf den Staat überging. ${ }^{21}$ In den verschiedenen deutschsprachigen Räumen gibt es zahlreiche regionale Abweichungen, im Ganzen zeigt sich aber ein ähnliches Bild: Die Polizeiordnung des Heiligen Römischen Reiches Deutscher Nation von 1530 bestimmt, ,daß auch die Oberkeit Versehung thue, daß eine jede Stadt und Commune ihre Armen selbst ernähren und unterhalten, und im Reiche nicht gestattet, Fremden an einem jeglichen Ort zu betteln“. ${ }^{22}$ Dabei geht es nicht um eine regelrechte ökonomische Unterstützung der Armen durch die Gemeinde und schon gar nicht um ein Recht auf solche Unterstützung, ${ }^{23}$ sondern um eine Regelung, wo die Armen betteln dürfen und wo nicht. Die Armenunterstützungspflicht der

20 Das Deutsche Rechtswörterbuch verzeichnet im Artikel ,Heimat‘ auch schon frühere Bedeutungen ab dem 12. Jahrhundert, die eingefriedetes Land oder im übertragenen Sinn die Umzäunung selbst meinen können, vgl. Anonym 1960. In der Rechtssprache kann Heimat bis ins 19. Jahrhundert auch den elterlichen Hof bedeuten, etwa im Zusammenhang mit der ,Heimatzuflucht‘. Hier handelt es sich um das für ein bis zwei Wochen geltende Zufluchtsrecht auf den elterlichen Hof für die weichenden Familienmitglieder in Notfällen; zunächst war dieses gewohnheitsrechtlich, seit Mitte des 19. Jahrhunderts durch Anerbengesetze gesetzlich geregelt. Vgl. den Artikel ,Heimatzuflucht‘ im Handwörterbuch zur deutschen Rechtsgeschichte: Amend-Traut 2012.

21 Zur gesamteuropäischen Dimension vgl. Althammer 2014, S. 315.

22 Ordnung und Reformation guter Polizey von 1530, Ziff. XXXIV, in: Sammlung „Aller des heiligen römischen Reichs Ordnungen, gehaltener Reichßtäge und Abschiedt. gedruckt in der churfürstlichen Statt Meyntz durch Franz Behem im Jahre 1566“, Thl. I, S. 234, hier zitiert nach: Riedel 1881, S. 2. In den späteren Reichspolizeiordnungen von 1548 und 1577 kehrt diese Bestimmung wieder.

23 „Allerdings wies diese Gemeindeangehörigkeit keinerlei Merkmale eines persönlichen Rechtes auf. Entsprechend dem polizeilichen Ursprunge jener Normen erschien die Gemeinde für solche Personen lediglich als polizeilicher Verweisungsort.“ Seydel 1886, S. 719. 
Gemeinden besteht also zunächst darin, den eigenen bedürftigen Armen das Almosensammeln innerhalb ihres Bezirks zu gewähren; hinzu kommt die Versorgung der armen Kranken in den (allerdings rar gesäten) öffentlichen Spitälern. In Frage steht damit für die Städte und Kommunen, welche Armen sie als die ihnen Zugehörigen anzuerkennen haben, da das Almosen selbst nun zu einem reglementierten Gut wird.

Auch in der Schweiz gab es vergleichbare Verordnungen: 1551 wurde von der Tagsatzung der Alten Eidgenossenschaft festgelegt, dass jede Schweizer Gemeinde für ihre eigenen Armen aufkommen solle; dies bildete die Grundlage für die weitere Gesetzgebung im Bereich des Armenrechts. ${ }^{24}$ Wurde ein Schweizer ,armengenössig‘, also unterstützungbedürftig, war die Bürger- bzw. Heimatgemeinde bzw. der Bürger- bzw. Heimatort zuständig. Heimat- und Bürgerrecht sind in der Schweiz synonym. ${ }^{25}$ Nur die vollberechtigten, alteingesessenen Bürger genossen die an diesen Ort geknüpften Rechte, dagegen waren die sogenannten Hintersassen und die sogenannten Heimatlosen ohne bürgerrechtlichen Status so gut wie vollständig rechtlos. ${ }^{26}$

In der Habsburgermonarchie legte die Polizeiordnung Ferdinands II. zuerst 1552 das später so genannte Heimatprinzip fest. ${ }^{27}$ Es bezeichnet auch hier das Recht jedes Einheimischen auf Versorgung im Falle der Armut durch die heimische Gemeinde. Und auch hier gilt, dass sich nur sehr bedingt ein Anrecht des Einzelnen auf Versorgung durch die Gemeinde hinter dem Heimatrecht verbirgt, da es in der Entscheidungsbefugnis der Gemeinde lag, ob und in welchem Umfang den Bedürftigen geholfen wurde. Deutlicher tritt in der Rechtspraxis die Verfügungsgewalt des Staates über seine Mitglieder zutage, insofern das Heimatrecht Abschiebungen mittels des sogenannten ,Schubwesens‘ legitimierte. Denn bis dato hatte grundsätzlich auch der Nichteinheimische Anspruch auf Versorgung, beispielsweise auf die Aufnahme in ein Armen- oder Krankenhaus, und durfte legal betteln. Ab diesem Zeitpunkt konnten arbeitsunfähige Arme, die bettelten, in die zuständige Gemeinde rücküberführt werden.

Die praktische Bedeutung der verschiedenen Heimatgesetzgebungen dürfte anfangs eher gering gewesen sein. Sozialfürsorge fand wohl kaum statt, da es noch keine definierte Versorgungspflicht der Gemeinden gab. Und die Bettelge-

24 So das Historische Lexikon der Schweiz im Artikel ,Bürgerrecht‘, vgl. Schweizer 2011; Meier/ Wolfensberger 1998 weisen auf einen vergleichbaren Tagsatzungsbeschluss schon von 1520 hin. 25 Vgl. Meier/Wolfensberger 1998, S. 98. Heimat- und Bürgerort bzw. -gemeinde sind in der Schweiz (bis heute) identische Begriffe. Zum Schweizer Heimatrecht vgl. auch den Artikel ,Bürgerrecht‘ im Historischen Lexikon der Schweiz: Schweizer 2011.

26 Vgl. Meier/Wolfensberger 1998.

27 Vgl. Wendelin 2000, S. 181. 
setzordnungen wurden vielfach unterlaufen: 1552 wurde etwa zugleich mit der Polizeiordnung Ferdinands II. festgelegt, dass Städte und Gemeinden Erlaubnisscheine für das Betteln außerhalb ihres Herrschaftsbereichs ausstellen durften, ${ }^{28}$ auch die bayerische Gesetzgebung sah die Befugnis für arme Gemeinden vor, die Armen mit einer entsprechenden Urkunde ausgestattet abzuschieben und so de facto auch das Betteln in anderen Gemeinden zu ermöglichen. ${ }^{29}$ Der Beginn der Heimat-Gesetzgebung kann als Beginn der Verstaatlichung der Sozialfürsorge gelten, weil Armut nicht mehr an christliche private Wohltätigkeit, sondern wenn auch zunächst nur auf dem Papier - an staatliche Fürsorge verwiesen wird. Wichtig für die aus dem Heimatrecht hervorgehenden Konflikte und sozialen Verwerfungen ist, dass diese staatliche Fürsorge nicht zentral, sondern lokal von den Gemeinden geregelt wird.

Im Lauf des 17. und 18. Jahrhunderts werden die Regelungen zur Gemeindezugehörigkeit, zum Betteln, zur Abschiebung und zur Fürsorge immer weiter präzisiert; die Administration gibt sogenannte Heimatscheine aus, die das Heimatrecht bezeugen. ${ }^{30}$ Exemplarisch sei dies an der bayerischen Landesgesetzgebung gezeigt. Die Landesgesetzgebung von 1616 unterscheidet zwischen fremden (also nicht-bayerischen) und inländischen (also bayerischen) Bettlern. Die fremden sollen ,gefänglich eingezogen, ausgeschafft, und für den Fall der Wiederkehr strengstens bestraft werden“. ${ }^{31}$ Nur den „Innlendern und Innwohnern“, welche wegen Alter, Krankheit oder anderer Gebrechen arbeitsunfähig sind, ist das Almosensammeln gestattet, allerdings nur an dem Ort, wo sie „geboren seynd oder bisher lang ihre Wohnung gehabt“. ${ }^{32}$ In der Polizeiordnung von 1616 taucht der Begriff der Heimat in Zusammenhang mit dem Abschieberecht der Gemeinden auf: Alle ,müssig gehende‘ Leute, „die nicht Haimat noch sich von den ihrigen zu unterhalten haben“, ${ }^{33}$ sollen ,ausgeschafft' und wie Bettler behandelt werden, sofern sie nicht zur Arbeit zu bewegen seien. ${ }^{34}$ Die bayerische Bettelordnung von 1726 präzisiert, dass Ausländer nach zehnjährigem Aufenthalt den Inländern

28 Bis ins 19. Jahrhundert war diese legale Umgehung der Pflicht der Gemeinden zur Armenversorgung oft geübte Praxis - auch wenn sie Mitte des 18. Jahrhunderts offiziell verboten wurde. Vgl. Wendelin 2000, S. 184.

29 Vgl. Riedel 1881, S. 3.

30 Genaueres zu Heimatscheinen vgl. Kutzer 1904.

31 Landrecht, Policey-, Gerichts-, Malefitz- und andere Ordnungen der Fürstenthumben Obernund Niedern Bayern. München 1616. Bayer. Landes- und Polizeiordnung von 1616, Buch V, Tit. V, Art. 1 und 2, zitiert nach Riedel 1881, S. 3.

32 Tit. V, Art. 3, zitiert nach Riedel 1881, S. 3.

33 Buch IV, Tit. XI, Art. 3, zitiert nach Riedel 1881, S. 3.

34 Buch IV, Tit. V, Art. 3, zitiert nach Riedel 1881, S. 3. 
gleichgestellt seien. ${ }^{35}$ Der Codex Maximilianeus Bavaricus Criminalis verordnet 1751, dass ausländische Bettler, „wenn sie im Lande nicht geboren oder erzogen worden, oder sonst das Domicilium nicht ersessen haben“ - hier ist der zehnjährige Aufenthalt gemeint -, das erste Mal „gegen geschworner Urfehd und Aufbrennung des Buchstabens B“36 ausgewiesen, im Wiederbetretungsfall aber hingerichtet werden sollen. Inländische Bettler, die nicht innerhalb ihrer Gemeinde betteln, sind „,an ihr Geburtsort anzuweisen“, ${ }^{37}$ bei Wiederholung unter Leibeszüchtigung für ein Jahr ins Arbeitshaus zu liefern. ${ }^{38}$ Wer an Nichteinheimische Almosen gibt, muss eine Strafe von 40 Reichstalern bezahlen. ${ }^{39}$ Im bayerischen Landrecht von 1756 (Codex Maximilianeus Bavaricus Civilis) finden sich weiterhin folgende Bestimmungen zum Domicilium: Keine freie Wahl des Domizils haben Leibeigene, Kinder und unverheiratete Frauen (die sich unter väterlicher Gewalt befinden), Ehefrauen (die sich unter der Gewalt des Ehemannes befinden) und Gefangene. Alle anderen Personen können abgesehen vom Domicilium qua Geburt auch ein neues Domizil erlangen, etwa durch den Erwerb eines Bürgerrechts, das durch Ratifikation der Staatsbehörde und Erstattung einer Bürgeraufnahmegebühr erteilt werden kann, sofern der Bewerber eigenen Besitz und die Fähigkeit, sich und seine Familie $\mathrm{zu}$ ernähren, nachweisen kann. ${ }^{40}$ Demnach kann nur der Besitzende ein neues Domizil erlangen, der Nichtbesitzende hingegen nicht. ${ }^{41}$ Hat der Vater kein domicilium fixum, ist als Domizil der Kinder deren Geburtsort festgeschrieben. Eine Veränderung des Domizils muss immer bewiesen werden, das frühere Domizil geht erst durch den förmlichen Erwerb eines neuen, niemals durch bloßen Aufenthalt an einem anderen Ort verloren.

In den bayerischen Bettelmandaten von 1770 und 1780 ist festgehalten, dass ausländische Bettler auszuweisen und zu bestrafen seien, die inländischen sich innerhalb vierzehn Tagen an ihren Geburtsort oder rechtmäßiges Domizil begeben müssten. „Die über das ursprüngliche Aufenthaltsort vielfältig entstandenen Zweifel“ werden dahingehend erläutert, „daß unter dem Domicilio originario nicht sowohl der Ort, wo man geboren ist, als vorzüglich der Ort, wo der Vater domicilirt war, verstanden ist, und sich dieses domicilii Jedermann zu erfreuen

35 Bettelordnung von 1726, § 20, hier nach Riedel 1881, S. 7.

36 Beide Zitate Cod. Max. crimin. Th. I, Cap. XI, § 1, hier zitiert nach Riedel 1881, S. 7-8.

37 Cod. Max. crimin. Th. I, Cap. XI, §4, hier zitiert nach Riedel 1881, S. 8.

38 Vgl. Riedel 1881, S. 8.

39 Vgl. Riedel 1881, S. 8, § 6.

40 Landrecht Th. V, Cap 25, § 6, vgl. Riedel 1881, S. 9.

41 Vgl. Riedel 1881, S. 13. Nach Riedels Auslegung treten die Heimatrechte sofort nach Erwerb der Bürgerrechte in Kraft und nicht erst nach Ablauf von zehn Jahren oder einer anderen Frist. 
hat, bis er gleichwohl in einem andern Ort ein Domicil gemäß der Rechten und Landesgesetzen erlangte.“ Es habe daher „keine Gemeinde - noch minder eine Obrigkeit - Jemanden das domicilium originarium $\mathrm{zu}$ verweigern, der nicht rechtmäßiger Weis anderer Orten eins erhalten, wenn er schon 10, 20 und noch mehre Jahre von seinem ursprünglichen Aufenthaltsort abwesend gewesen“. ${ }^{42}$ Was hier positiv formuliert eine Pflicht der Gemeinde ist, das Heimatrecht auch an Personen zu vergeben, die möglicherweise nie in dieser Gemeinde gelebt haben (denn es gilt das Domizil des Vaters, wenn nicht ein eigenes Domizil erworben wurde), bedeutet negativ formuliert, dass ein in Armut Gefallener von einer Gemeinde abgeschoben werden kann, in der er über zwanzig Jahre gelebt, aber aus ökonomischen Gründen nicht die Bürgerrechte erworben bzw. sich ansässig gemacht hat.

In den Bettelmandaten findet sich auch eine genaue Festschreibung für den Umgang mit Findelkindern, unehelichen Kindern, Dienstboten. Für Letztere gilt etwa, dass eine Gemeinde erst dann für sie versorgungspflichtig wird, wenn sie zwanzig (1770) bzw. fünfzehn (1780) Jahre in dieser Gemeinde Dienste geleistet haben, da sie erst dann zu ihrem rechtmäßigen Aufenthaltsort geworden sei. Tagelöhner also, die nicht in regelmäßigem Dienst standen, haben nach gleicher Aufenthaltsdauer diesen Ort nicht zu ihrem rechtmäßigen Aufenthaltsort gemacht und demnach auch keinen Anspruch auf Versorgung. ${ }^{43}$

Abweichend vom älteren Recht wird den Gemeinden im Lauf des 18. Jahrhunderts insgesamt eine explizitere Verbindlichkeit zur Armenfürsorge auferlegt. Alle Armen, die wegen Alters oder anderer Gebrechen nicht arbeiten können, sind demnach genauso wie Arme, die von ihrer Arbeit nicht die ganze Familie ernähren können, zu unterstützen. Arme arbeitsfähige Kinder sind zur Arbeit anderswo unterzubringen. ${ }^{44}$

In der Schweiz des 18. Jahrhunderts hat die Heimatgesetzgebung die eklatantesten negativen Auswirkungen für die Ärmsten. Denn in der Schweiz war der Entzug des Heimatrechts ein probates Mittel der Strafe; die rechtliche Heimatlosigkeit großer Bevölkerungsgruppen wurde so zu einem strukturellen Problem, das bis zu zehn Prozent der Bevölkerung einer Gemeinde betreffen konnte. ${ }^{45}$ Der fehlende bürgerrechtliche Status der Heimatlosen betraf sämtliche politische,

42 Beide Meyer's Generaliensammlung von 1784, Bd. II, S. 948, Ziff. 6 und Ziff. 7, hier zitiert nach Riedel 1881, S. 10.

43 Vgl. Meyer's Generaliensammlung von 1784, Bd. II, S. 948, Ziff. 9.

44 Vgl. Meyer's Generaliensammlung von 1784, Bd. II, S. 948, Ziff. 15 und 16, vgl. Riedel 1881, S. 11. 45 Vgl. Meier/Wolfensberger 1998. In manchen Schweizer Gemeinden waren noch im 19. Jahrhundert bis zu zehn Prozent der Bevölkerung heimatlos - Nicht-Sesshafte, Obdachlose und schlicht Arme ohne entsprechenden Nachweis: Für diese war niemand zuständig. 
soziale und ökonomische Rechte des Individuums: Das Recht auf Niederlassung und gewerbliche Betätigung, auf Armenunterstützung, auf Besitz immobiler Güter, auf Eheschließung war Heimatlosen verwehrt. Heimatlosigkeit und vagierende Lebensweise standen aufgrund dieser Regelungen in kausalem Zusammenhang. ${ }^{46}$ Denn ohne Bürgerrechte wurden die Heimatlosen in der Regel in die Nicht-Sesshaftigkeit getrieben, so wie andersherum Nicht-Sesshaftigkeit in der Regel die rechtliche Heimatlosigkeit nach sich zog. ${ }^{47}$

Heimatlosigkeit war in der Schweiz daher zum überwiegenden Teil ein Produkt der Gesetzgebung selbst. Die Strafnorm der Aberkennung des Heimatrechts war im Eherecht, im Armenrecht und in der konfessionellen Gesetzgebung enthalten; ferner wurden beispielsweise Desertion, Hochverrat und politische Verschwörung mit Heimatrechtsverlust bestraft. In einem Gutachten der Berner Almosenkammer aus dem Jahr 1744 werden nach Maßgabe der Entstehungsgründe folgende Personengruppen als Heimatlose aufgeführt:

1) Diejenigen, welche wegen Nichtbezahlung von Einzuggeldern, wegen langer Abwesenheit, wegen Negligentz oder auch wegen Verbrechen der Eltern und Verbannung derselben in den Städten und auf dem Lande ihr Heimatrecht verloren und nicht als Angehörige anerkannt und gehalten werden.

2) Die Proselyten und ihre Nachkommen, diejenigen, welche Naturalisationsbriefe erhalten, nicht aber ein Burger- oder Gemeinderecht, die französischen und pragellanischen Religionsflüchtigen oder Refugirten und deren Nachkommen, die sich nirgends verburgrechtet.

3) Uneheliche, deren Mütter fremde, unbekannte, oder weggezogenen Menschen als Väter angaben und die nach der ältern Chorgerichtssatzung heimat- und vaterlos wurden.

4) Fündeli (Findelkinder) und die sozusagen ewigen Heimatlosen und solche, deren Voreltern vielleicht auch von ausgesetzten Kindern herstammten. ${ }^{48}$

Deutlich wird im Punkt „Proselyten und ihre Nachkommen“, dass Heimatlosigkeit und Konfessionskampf in der Schweiz zusammenhängen. Mit Verbreitung der Reformation im 16. Jahrhundert wurde das Heimatrecht als Mittel im Kampf um Konvertiten eingesetzt. Die reformierten Kantone sicherten den Konversionswilligen die vollen Bürgerrechte zu, die katholischen bewilligten ihnen in der Regel lediglich den Aufenthalt. Alle katholischen und ein Teil der reformierten Kantone bestraften eine Konversion in die ,falsche“ Richtung mit Heimatrechtsverlust. 1803 setzten die konfessionell begründeten Vertreibungen nach der kurzen, Religi-

46 Vgl. Meier/Wolfensberger 1998, S. 33.

47 Vgl. Meier/Wolfensberger 1998, S. 33.

48 Geiser 1894, S. 247. 
onsfreiheit garantierenden Unterbrechung der Helvetik wieder ein. ${ }^{49}$ Konvertiten verloren in der Regel wieder ihre Heimatberechtigung.

Deutlich wird außerdem, dass sich Heimatlosigkeit auf die Nachkommen vererbt. So resultiert das manifeste Problem einer ganze Familienverbände umfassenden Heimatlosigkeit Mitte des 19. Jahrhunderts aus Heimatsrechtsverlusten, die im 17. und 18. Jahrhundert eingetreten waren und von da an weitervererbt wurden. Im 19. Jahrhundert enthielt das Armenrecht nur noch wenige Bestimmungen, die direkt zu einer Aberkennung des Heimatrechts führten. ${ }^{50}$ Aber das Folgeproblem des vererbten Heimatverlusts war trotzdem so groß wie nie zuvor.

\section{Heimatrecht im 19. Jahrhundert}

Mit Beginn des 19. Jahrhunderts hat sich ein Verständnis des Staates herausgebildet, nach dem der Staat einerseits die Verantwortung für seine Einwohner übernimmt, andererseits auch jeder Arme in die Verantwortung genommen wird, arbeitsam zu sein und folglich dem Staat nicht zur Last zu fallen. ${ }^{51}$ Sozialpolitik und Monopolisierung der Staatsgewalt gehen Hand in Hand..$^{52}$ Privatwohltätigkeit

49 Meier/Wolfensberger 1998, S. 35.

50 Vgl. Meier/Wolfensberger 1998, S. 69.

51 Vgl. Wendelin 2000, S. 189 und Kaschuba 1988, insbesondere das Kapitel „Armenhülfe‘: Arbeitserziehung als neue Sozialpolitik“, S. 114-122.

52 Dies könnte auch erklären helfen, warum der Staat dieses - bezogen auf die Betroffenen ineffiziente und nicht selten inhumane System so lange aufrechterhielt. Nicht primär Sozialpolitik, sondern der Erwerb von demographischen Informationen ist das handlungsleitende staatliche Interesse, so die These von Wendelin 2000, S. 228. Schon ab der zweiten Hälfte des 18. Jahrhunderts verlangten die Landesfürsten Zugriffsrechte auf die Kirchenbücher. Das Konskriptionswesen, also die systematische Volkszählung, entsteht, nachdem sich ab 1770 die Heere nicht mehr aus der Anwerbung von Soldaten, sondern der allgemeinen Militärpflicht aller männlichen Untertanen rekrutierten. Um einen Überblick über die Militärpflichtigen zu schaffen, wird 1781 das Konskriptionssystem eingeführt. Das Konskriptionspatent von 1804 erhob dann bereits nicht nur Militärpflichtige, sondern alle Einwohner; zugleich wurden erstmals Ortstafeln (auf denen Orts- und Kreisname und Bezirksnummer stehen sollten) und Hausnummern eingeführt, 1857 gab es die erste Volkszählung (vgl. Wendelin 2000, S. 191-194). Die Bestimmungen des Konskriptionspatents von 1804 wurden herangezogen, um strittige Fragen des Heimatrechts zu klären, denn hier wurde explizit festgelegt, wer als einheimisch und wer als fremd zu gelten hatte (vgl. Wendelin 2000, S. 194). „Erst die Bestimmungen des Heimatrechtes normierten jene Kriterien, die es erlaubten, eine systematische Unterscheidung zwischen Einheimischen und Fremden $\mathrm{zu}$ treffen. Eine Abschiebung war stets die Umsetzung heimatrechtlicher Normen, die in der Zuweisung des Attributs ,fremd' mündete. Im bürokratischen Diskurs wurde der Schub nicht als Strafe verstanden, er sollte vielmehr ein Mittel darstellen, Individuen an jenen Ort zu transportieren, den die heimatrechtlichen Bestimmungen als ihre Heimat definierten.“ Die rechtliche Definition von einheimisch und fremd unterscheidet sich kategorial von der heutigen, die le- 
spielte gegenüber der öffentlichen Armenpflege eine untergeordnete Rolle; ${ }^{53}$ dasselbe gilt für die sogenannte Heimatfremdenfürsorge der Kirche. ${ }^{54}$ Für den gesamten deutschsprachigen Raum des 19. Jahrhunderts kann aus unterschiedlichen Gründen von einer Zuspitzung der mit dem Heimatrecht verbundenen administrativen Hürden und sozialen Verwerfungen gesprochen werden. Das Hauptproblem ergibt sich daraus, dass die ans Heimatrecht geknüpfte Armenfürsorge auch unter den neuen, in diesem Umfang bisher unbekannten Mobilitätsbedingungen Sache der Gemeinden bleibt, auch in allen anderen westeuropäischen Staaten. ${ }^{55}$ Die Konsequenzen des zunehmend dysfunktionalen Heimatrechts werden unter den Bedingungen einer rasant wachsenden Bevölkerung auch schlicht quantitativ spürbar. Legt man die Grenzen des Deutschen Reiches von 1871 zugrunde, so lebten 1816 auf diesem Gebiet vierundzwanzig Millionen Menschen, 1875 waren es dreiundvierzig und 1910 fünfundsechzig Millionen. ${ }^{56}$ Diese zunehmende Menge von Menschen musste immer mobiler werden, um den Anforderungen eines sich wandelnden Arbeitsmarktes zu genügen, blieb aber durch ein anachronistiches Heimatrecht gebunden, das Versorgung nur an einem Herkunftsort bot, der längst verlassen wurde.

Schon in der ersten Hälfte des 19. Jahrhunderts verändern sich die Migrationsbedingungen für die armen Bevölkerungsschichten durch die sukzessive Aufhebung der Leibeigenschaft, die sich in weiten Teilen des deutschsprachigen Raums im ersten Drittel des Jahrhunderts vollzieht. Sehr viel früher verlor die Leibeigenschaft in der Schweiz (offiziell wurde sie 1789 abgeschafft, war aber schon seit dem 17. Jahrhundert de facto keine Praxis mehr) ${ }^{57}$ und in Österreich (1782 wurde sie für ganz Österreich aufgehoben, für einzelne Landesteile schon

diglich auf Staatsgrenzen Bezug nimmt. „Je größer der Raum wurde, innerhalb dessen man zu den Einheimischen gezählt wurde, desto weiter war die Konsolidierung des Herrschaftsraumes fortgeschritten." Beide Zitate Wendelin 2000, S. 175.

53 Vgl. Sachße/Tennstedt 1980, S. 222-244.

54 Die sogenannten ,Herbergen zur Heimat', 1854 initiiert durch Clemens Perthes, „waren eine Einrichtung der Inneren Mission“ und ursprünglich für reisende Handwerksburschen gedacht, enwickelten sich aber zunehmend zu „Fürsorgestätten für Wanderarme“ (Mahling 1928, Sp. 1765). Die Idee der sogenannten ,Arbeiterkolonien“ und ,Heimatkolonien“ zur Resozialisierung NichtSeßhafter geht auf Wilhelm von Bodelschwingh zurück, wobei erstere kurzfristigere, letztere längerfristige Aufenthalte ermöglichten: „An die Arbeiterkolonie schließt sich die eine oder andere Heimatkolonie an zu längerem Aufenthalt für die, die draußen im Leben allein für sich nicht mehr fortkommen können“ (Mahling 1928, Sp. 1767).

55 Zur gesamteuropäischen Dimension vgl. Althammer 2014, S. 315.

56 Vgl. Helbich 1985, S. 16.

57 Vgl. den Artikel ,Bürgerrecht‘ von Rainer J. Schweizer im Historischen Lexikon der Schweiz: Schweizer 2011. 
weit früher) ihre Bedeutung; auch in Bayern wurde die Leibeigenschaft bereits 1783 aufgehoben. Der Großteil des später im Deutschen Reich aufgehenden Gebietes erlebte die Aufhebung der Leibeigenschaft aber erst nach der Jahrhundertwende: 1808 Westfalen, 1810 Preußen, 1813 Hessen, 1817 Württemberg, 1822 Mecklenburg, 1832 Sachsen, 1833 Hannover. Die Befreiung der Leibeigenen bedeutete auch eine Befreiung der Herrschaft von der Versorgungspflicht. Die Gemeinden mussten nun diese Versorgung übernehmen - das bildet noch den Erzählhintergrund für Marie von Ebner-Eschenbachs Gemeindekind (1887). Allerdings wird die sogenannte Ansässigmachung, also Niederlassung, von vielen Gemeinden verhindert, so dass gerade die Armen zwar theoretisch frei in ihrer Mobilität waren (sofern das Freizügigkeitsrecht schon galt), ${ }^{58}$ sich de facto aber nirgendwo ansiedeln konnten.

Ernst Moritz Arndt, dessen Vater selbst Leibeigener war, schlägt 1803 in seiner Schrift gegen die Leibeigenschaft mit Blick auf die Folgen der Freiheit verschiedene Vorgehensweisen vor, um eine unkontrollierte Mobilität zu verhindern, etwa, nur eine bestimmte Anzahl von Umzügen zuzulassen oder die Freilassung der Leibeigenen progressiv durchzuführen. ${ }^{59}$ In Mecklenburg, auf das sich Arndts Schrift bezieht, kam es nach Abschaffung der Leibeigenschaft 1822 tatsächlich zu einer objektiven Verschlechterung der Situation der befreiten Bauern, weil die Versorgung durch die ehemaligen Herrschaften wegfiel, ohne dass das Niederlassungsrecht angepasst wurde. Das Fehlen des sogenannten Freizügigkeitsrechts (freie Niederlassungswahl) verhinderte, dass die Bauern wirtschaftliche Selbständigkeit erlangen konnten. ${ }^{60}$

Zum Massenphänomen wird die Binnenmigration in den späten 1860er Jahren und bleibt es bis zum Beginn des 20. Jahrhunderts; sie gilt als die größte Massenbewegung der deutschen Geschichte überhaupt. ${ }^{61}$ „Heimatlosigkeit wurde

58 Zum Freizügigkeitsrecht vgl. Klippel/Dehmer 2006 und Hitzer 2016; hier ab S. 274 auch zum sogenannten Heimatprinzip.

59 „Manche Dienstleute würden auch, in der ersten Luft und Ungewohnheit der Freiheit, wohl alle Jahre anfangs den Ort verändern, und also den Herren manche Verlegenheiten und Unbequemlichkeiten verursachen. Hier müsste nun durch gute Polizeiordnungen verfügt werden, z. B. daß die Arbeiter in den ersten 10, 20 Jahren der Freiheit etwa alle 2, 3 Jahre nur umziehen dürften; daß in den Gegenden, wo man vorzüglich Mangel an Leuten fürchten müßte, die Freilassung etwa mehr progressive geschähe und nicht auf einmal, daß man, wie in anderen Ländern geschehen ist, nach den verschiedenen Altern Termine von 5, 10, 15 Jahren setzte, wo sie erst die volle Freiheit ansprechen könnten, damit die Besitzer Zeit hätten Einrichtungen zu treffen, um die Leute durch Wohlthaten und durch Hoffnungen für die Zukunft fest zu halten.“ Arndt 1803, S. 266-267.

60 Vgl. Koch 1997, S. 79-85; Pade 2004, S. 61-75, Verweis aufs Heimatrecht S. 62.

61 Vgl. Köllmann 1976, S. 9. 
Signatur der Epoche“, fasst Michael Stürmer zusammen. ${ }^{62}$ Die ländliche Abwanderung in die Städte führte dazu, dass 1907 von 60,4 Millionen im Deutschen Reich Geborenen 29 Millionen, also 48 Prozent, außerhalb der Gemeinde ihrer Geburt lebten. ${ }^{63}$ Weniger bekannt ist, dass die Migration in zwei Richtungen verlief: Die Arbeitssuchenden zogen in die Städte, die nicht mehr Arbeitsfähigen und Versorgungsbedürftigen zogen zurück aufs Land, wenn sie Fürsorge in Anspruch nehmen mussten. Der preußische Verwaltungsjurist Gustav von Bonin stellt schon 1855 fest, dass die Städte vom Land „,in der Mehrzahl der Fälle nur solche Personen an sich“ ziehen, „die noch in voller Kraft stehen, vollständig arbeitsfähig sind für alle Arten von Arbeiten“. Was, so fragt er, „geben sie dem Lande zurück? Nur das, was sich in den Städten nicht halten kann, verbrauchte Kräfte, heruntergekommene Handwerker, Krämer u.dgl. “64 Der Gründerkrach von 1873 potenzierte diese Situation: Ein Heer von Erwerbslosen wurde freigesetzt, die teilweise in den Heimatgemeinden nicht mehr aufgenommen wurden und so zu den rechtlich Heimatlosen zählten. ${ }^{65}$

Für die Habsburgermonarchie liegen dank einer speziell sich den Auswirkungen des Heimatrechts widmenden Studie von Silvia Hahn statistische Daten vor, die die rasanten Entwicklungen in der zweiten Jahrhunderthälfte deutlich zeigen. In Niederösterreich (inklusive Wien) schnellte der Bevölkerungsanteil ohne Heimatrecht am Aufenthaltsort von 20 Prozent im Jahr 1851 auf 60 Prozent im Jahr 1900 in die Höhe, in Oberösterreich in demselben Zeitraum von 5 Prozent auf 57 Prozent, in Böhmen von 5 Prozent auf 56 Prozent. ${ }^{66}$ In den Städten ist der Anteil der Bevölkerung ohne Heimatrecht teilweise noch höher: In Graz liegt er im Jahr 1869 bei 64,3 Prozent und im Jahr 1900 bei 80,8 Prozent, in Prag in denselben Jahren erst bei 64,3 Prozent und dann bei 79,3 Prozent, in Marburg (Steiermark) erst bei 68,7 Prozent, dann bei 89,7 Prozent. ${ }^{67}$

62 Stürmer 1994, S. 60.

63 Vgl. Sachße/Tennstedt 1980, S. 195; hier mit weiteren Quellen.

64 Alle zitiert nach: Sachße/Tennstedt 1980, S. 195.

65 „Die Gemeinde, die alte Heimat, war unwiederbringlich dahin, und die städtischen Ballungszentren boten einstweilen ein Bild von Armut, Elend und Verwahrlosung, das kaum Heimat genannt werden konnte. Hier wurde offenkundig, daß Industrie und Markt nicht Harmonie und Wohlstand für alle hervorgebracht hatten, sondern eine bedrohliche Spaltung der Gesellschaft, eine neue gesellschaftliche Unterschicht, die die Angst des Bürgertums vor Aufruhr und Chaos geradezu neurotisch reizte.“ Sachße/Tennstedt 1980, S. 15.

66 Vgl. Hahn 2005, S. 30. Hahn erstellt auf Grundlage der Volkszählungsergebnisse und anderer statistischer Daten differenzierte Datentabellen zum Thema.

67 Vgl. Hahn 2005, S. 33. 
Das Heimatrecht steht auch im Zusammenhang mit der Migration nach Übersee, insofern die Auswanderer ihr Heimatrecht teilweise durch die Auswanderung verloren. ${ }^{68}$ Die deutsche Auswanderung nach Amerika begann gegen Ende des 17. Jahrhunderts. Aber erst das Hungerjahr 1816/17 brachte in Deutschland eine erste quantitativ relevante Auswanderungswelle in Südwestdeutschland hervor, die folgenden Wellen breiteten sich dann bis Mitte der 1850er Jahre auf ganz Deutschland aus (wenn auch regional weiterhin sehr unterschiedlich). Die schlechten lokalen Wirtschaftsbedingungen sind der Hauptanlass für die Auswanderung: der Niedergang der Heimgewerbe infolge maschineller Konkurrenz, Missernten und steigende Lebensmittelpreise. Von den geschätzten fünfzig Millionen Menschen, die im Verlauf des 19. Jahrhunderts aus Europa emigrierten, stammt ein großer Teil aus deutschsprachigen Gebieten. Im Zeitraum zwischen 1820 und 1920 verließen 5,5 Millionen Auswanderer allein mit dem Ziel USA jenes Gebiet, das 1871 das Deutsche Reich bildet (vgl auch das Kapitel ,Heimat und Fremde als Erfahrung von Migration' in I.2.4). ${ }^{69}$

Die Migration hat viele Gesichter; ob es sich aber um Auswanderung in andere Länder, um Binnenmigration vom Land in die Städte oder nur von einer Gemeinde in die Nachbargemeinde handelte, ist für Fragen des Heimatrechts nebensächlich, da nicht die einzelnen Länder und Staaten, sondern die Gemeinden für das Heimatrecht zuständig waren. Es sei leichter, in Heimatrechtsstreitigkeiten zwischen Mecklenburg und einem fremden Staat zu einem Ergebnis zu kommen, als innerhalb der verschiedenen Landesteile Mecklenburgs, heißt es bei Fritz Reuter. ${ }^{70}$ Auch in der Schweiz funktioniert das föderale Kantonswesen nicht nach dem solidarischen Prinzip, jedenfalls nicht in Bezug auf die Ärmsten. In einer Ausgabe des Schweizer Boten von 1837 findet sich folgende Zeitungsnotiz:

Wie lange wird wohl noch in unserm schönen, freien, glücklichen Vaterlande jene unglückliche Menschenklasse der Heimathlosen herum irren müssen? Wie lange wird sie noch von Kanton zu Kanton gepeitscht werden, auf die unmenschlichste, grausamste Weise? - Ein neues Beispiel dieser unserer Barbarei und Unbarmherzigkeit gegen diese unsere Mitmenschen kam mir vor kurzem wieder zu Gesicht. Ein etwa 14 Jahre altes, heimathloses Mädchen traf ich, das an einem häßlichen Nasenkrebse leidet, welcher schon einen Theil dieses Ge-

68 Württemberg erließ 1816 ein Rückkehrverbot für Auswanderer und war in den Folgejahren mit den dennoch zurückkehrenden, gescheiterten Auswanderern mit dem Problem der Heimatlosigkeit dieser Bevölkerungsgruppe konfrontiert, vgl. Behringer 2015, S. 213-215.

69 Vgl. Bade 2003; Plaß 2016.

70 „[...] denn Mecklenburg scheidet sich in drei Landesteile, großherzogliches Domanium, Ritterschaft und Städte, die unter sich vice versa die Heimatsgesetzgebung energischer aufrecht erhalten, als dies sogar einem fremden Staate gegenüber geschieht [...]. “ Reuter: Ein Heimatloser, 1904, S. 28. 
bildes [sic] zerstört hat und anfängt sich auf der Lippe auszubreiten. [...] Ich fragte sie, warum sie nicht suche in ein Spital zu kommen, um sich heilen zu lassen? Ach, weinte sie, ich bin heimathlos und in keinem Kanton geduldet. An vielen Orten suchte ich vergebens Hilfe. Aus Bern, Aarau, Basel, Zürich und Luzern wurde ich vertrieben, man drohte sogar bisweilen mich wegprügeln zu lassen, wenn ich den Kanton nicht sogleich verlasse. ${ }^{71}$

Für das Gebiet zwischen Mecklenburg und der Schweiz gilt: Das Heimatrecht wird nicht angemessen an die geänderten Rahmenbedingungen einer immer mobiler werdenden Bevölkerung angepasst. Immer wieder wird um eine einheitliche Regelung gerungen, doch vergeblich. ${ }^{72}$ Selbst eine systematische Darstellung der herrschenden Rechtslage ist aufgrund der widersprüchlichen regionalen Gesetzgebungen und vielfältigen Änderungen schon den zeitgenössischen Juristen unmöglich. ${ }^{73} 1850$ scheitert eine Zusammenfassung aller Bestimmungen über das Heimatrecht für die Habsburgermonarchie an zu vielen Fehlern und muss zurückgezogen werden. ${ }^{74}$ Der Verwaltungsrechtler Lorenz von Stein konstatiert 1866 für die deutschen Verhältnisse, die „Verwirrung“ über Inhalt, Bedeutung und Stellung des „Heimathswesens“ sei „vollständig“. ${ }^{75}$

Eine Rekonstruktion des Heimatrechts kann für das 19. Jahrhundert vor allem mithilfe von Handbüchern zum praktischen Gebrauch immerhin leitende Prinzipien herausarbeiten. ${ }^{76}$ Das oberste Prinzip ist demnach, dass jeder Bürger nur einer Gemeinde angehören kann. Die Geburtszuständigkeit ist maßgeblich, solange nicht ein anderer Fall eintritt, etwa die ausdrückliche Aufnahme durch eine andere Gemeinde, die Ausübung bestimmter Berufe, die automatisch das Heimatrecht neu zuweisen (Staatsbeamte, Seelsorger, Offiziere) - hier wird von „sogen. Beamtenheimat“77 gesprochen -, die Verehelichung (die Frau wechselt zur Heimat des Mannes), die Annahme von Bedienstung oder Amt, Antritt von Bürger- oder Meisterrecht, die häusliche Niederlassung, die Erlangung eines die

71 Anonym 1837, S. 108.

72 Heinrich Zoepfl verweist 1863 darauf, dass „,die Feststellung allgemeiner für ganz Deutschland giltiger Normen bezüglich der Heimathsverhältnisse, beziehungsweise die gegenseitige Uebernahme der Ausgewiesenen und Heimathlosen“ bisher nicht verwirklicht sei. Zoepfl 1863, S. 354, $\S 145$.

73 Für den K.-u.-k.-Raum vgl. Herzog 1837, S. VIII; Scheda 1861, S. IV (auf diese Quellen macht Harald Wendelin aufmerksam, vgl. Wendelin 2000, S. 196), für Deutschland vgl. Riedel 1881.

74 Vgl. Wendelin 2000, S. 196.

75 Alle Zitate Stein 1866, S. 341. Harm-Peer Zimmermann nimmt ausführlich auf Steins Erörterungen zum Heimatrecht Bezug, vgl. Zimmermann 1991.

76 Vgl. Riedel 1881 und Wendelin 2000, S. 198, dieser verwendet insbesondere das Handbuch zum Heimatrecht von Johann Jegierek, vgl. Jegierek 1894.

77 Kutzer 1904, S. 50. 
Ansässigkeit bedingenden Besitztums oder der ununterbrochene zehnjährige Aufenthalt. Kann der Geburtsort nicht eruiert werden und trifft keiner der vorigen Punkte zu, dann gilt die Zugehörigkeit zum Ort des längsten Aufenthalts.

In der Praxis wird gegen diese leitenden Prinzipien immer wieder verstoßen; auch läuft das regionale Recht teilweise quer zu diesen Prinzipien. Es wird immer deutlicher, dass ein Armenversorgungssystem, das auf dem Idealfall einer Identität von Geburts- und Lebensort beruht und alles andere nur als Abweichung begreift, mit zunehmender Mobilität an seine Grenzen stoßen muss. Die Widersprüche zur Lebensrealität im Zeitalter der Industrialisierung zeigen sich exemplarisch in einem Fallbeispiel aus dem Jahr 1847/48, das Harald Wendelin in seiner Studie zum Heimatrecht der Habsburgermonarchie aufarbeitet. Die Härte des Falls nahmen schon die zeitgenössischen Behörden zur Kenntnis, ohne allerdings mildernd einzuschreiten:

Die fünfundzwanzigjährige Eva Maria Krause, Mutter von drei Kindern im Alter von vier, zwei und einem halben Jahr, deren Mann, ein Schlossergeselle, an Typhus gestorben war, ersuchte die Wiener Behörden um finanzielle Unterstützung, da sie sich und ihre Kinder nicht von ihrer Arbeit als Tuchmacherin ernähren könne und das jüngste Kind gefährlich krank sei. Der verstorbene Ehemann hatte zwar siebzehn Jahre mit magistratischem Konsens ein Schlossergewerbe in Wien betrieben, der Magistrat hatte jedoch bei der Erteilung des Konsenses ausdrücklich festgehalten, dass er dadurch nicht die Zuständigkeit (also eben: das Heimatrecht) erwerbe. Obwohl Eva Maria Krause seit ihrem zwölften Lebensjahr in Wien gelebt hatte, ihre Eltern und Geschwister sämtlich in Wien lebten und sie selbst nie in Altenbuch in Böhmen (dem Geburtsort und damit der Heimat des verstorbenen Mannes) gewesen war, noch mit irgendjemandem dort bekannt war, als gelernte Tuchmacherin dort auch keine Aussicht auf Erwerbstätigkeit hat, wurde sie mit ihren Kindern gegen ihren Willen und trotz eines Gnadengesuchs eben dorthin abgeschoben - mit der korrekten Begründung, dass die Ehefrau mit der Heirat die Heimat des Mannes erwerbe. Die Akte mit den Stellungnahmen der Gemeinde in Böhmen und verschiedenen Wiener Verwaltungsbeamten schwoll im Lauf eines halben Jahres beträchtlich an; das letzte Dokument der Akte hält fest, dass das kleinste Kind der Eva Maria Krause in der Zwischenzeit gestorben sei; sie wurde also nur noch mit zwei Kindern auf den Schub geschickt und die ihr unbekannte Heimat hatte nur noch drei Mäuler zu stopfen. ${ }^{78}$

Das Heimatprinzip, nach dem für Witwen, die in Armut fallen, die Heimat des Ehemannes als versorgungspflichtig gilt, besaß im ganzen deutschen Sprachraum

78 Vgl. ausführlicher mit Aktenverweisen Wendelin 2000, S. 219-221. 
Geltung. Im Fall der Habsburgermonarchie sind die Auswirkungen besonders eklatant. Mitunter konnte das nicht nur bedeuten, dass die Witwe in Regionen des Reiches abgeschoben wurde, die sie noch nie betreten hatte, sondern zusätzlich, dass die Abgeschobene, wie im geschilderten Fall, nicht einmal die Sprache ihrer zugewiesenen Heimat beherrschte. Es sind also in erster Linie die Armen und hier noch einmal in einem ganz besonderen Maß die Frauen, die unter dem Heimatrecht $\mathrm{zu}$ leiden haben. ${ }^{79}$ Eine weitere durch das Heimatrecht systematisch benachteiligte Bevölkerungsgruppe bilden die Juden. ${ }^{80}$

Ein Hemmungsfaktor für die Umsetzung des Heimatrechts waren die gegenläufigen Interessen der beteiligten Gemeinden. Denn niemand riss sich um die Ausübung seiner Versorgungspflicht, was teilweise groteske Fälle gegenseitiger Zuweisung der Verantwortung (inklusive wiederholter Schübe der Betroffenen in verschiedene Richtungen) hervorbrachte. ${ }^{81}$

Die Gemeinden schützten sich lange vor dem 19. Jahrhundert auch durch das Eherecht vor Versorgungsansprüchen. Zahlreiche Beschränkungen banden die Verehelichung an ökonomische Sicherheiten, die die Eheschließenden vorweisen mussten. Im 19. Jahrhundert führte das zu einer regen Debatte um die rechtlichen, moralischen, religiösen und politischen Implikationen des in der Anwendung für die ärmsten Bevölkerungsschichten problematischen Eherechts unter den Vorzeichen des Pauperismus. ${ }^{82}$ Zeitgenössisch wurde diskutiert, dass die Zahl der

79 Zur Situation der Frauen im Zusammenhang mit dem Schweizer Heimatrecht vgl. (anders als der Titel erwarten lässt auch informativ zum 19. Jahrhundert) Nicole Schwalbachs Arbeit zur politischen Aberkennung des Bürgerrechts in den 1940er Jahren: Schwalbach 2016.

80 Hannelore Burger zeichnet das in ihrer Studie zu Heimatrecht und Staatsbürgerschaft österreichischer Juden vom Ende des 18. Jahrhunderts bis in die Gegenwart nach, vgl. Burger 2014. 81 Harald Wendelin bringt ein Fallbeispiel, in dem die Zuständigkeit von mindestens fünf Instanzen verweigert wurde, vgl. Wendelin 2000, S. 216-219.

82 Dazu und insgesamt zum Eherecht im 19. Jahrhundert vgl. Matz 1980. Matz geht von sechs Prozent aufgrund des Eherechts abgewiesenen Ehen in den von ihm untersuchten süddeutschen Regionen Mitte des 19. Jahrhunderts aus. Diese Zahl dürfte allerdings nichts mit dem Ausmaß des Problems zu tun haben, schließlich bezieht sie sich nur auf die beantragten Ehen. Entscheidender dürfte sein, dass aufgrund des Eherechts die große Mehrheit der Heiratswilligen gar nicht den Versuch der Eheschließung unternahm. „Die Härte des Gesetzes traf vor allem die unselbständig Beschäftigten, die Fabrikarbeiter also, die Taglöhner, Handwerksgesellen, Dienstboten und unversorgten Bauernsöhne, aber auch manchen übersiedelnden Meister, den die Konkurrenz an seinem neuen Heimatort mißtrauisch beäugte und durch ein Niederlassungs- oder Heiratsverbot zu schikanieren trachtete. Besonders schwer hatten es überhaupt alle, die an einem anderen Ort als dem ihres angeborenen Bürger- oder Heimatrechts oder die in diesem eine fremde Frau zu heiraten wünschten. Schließlich waren die älteren heiratswilligen Paare in besonderer Weise betroffen, weil die Gemeindeväter bei ihnen sehr sorgsam darauf achteten, ob sie vielleicht gar zu 
unehelichen Geburten in unmittelbarem Zusammenhang mit den Eherestriktionen stehe. Da die Gemeinden in der tiefgreifenden Krise des kommunalen Armenunterstützungssystems keine Hilfe erfuhren, versuchten sie ihre Haushalte durch noch strengere Verehelichungsbeschränkungen und noch strengere Beschränkungen der Ansässigmachung zu entlasten. ${ }^{83}$ Auch staatlich gelenkte und geförderte Auswanderung war ein immer wieder vorgebrachter Vorschlag, „sich das unruhige Proletariat vom Halse zu schaffen" .84

Der Umstand, dass Gemeinden sich gern ihrer Versorgungspflicht entzogen, hatte auch zur Folge, dass sie Auswanderungswilligen teilweise die Reisekosten nach Übersee zahlten und im Gegenzug deren Heimatberechtigung einkassierten. Von den über fünf Millionen deutschen Auswanderern allein in die USA (hier fehlen die Auswanderer nach Südamerika und in andere Länder) kehrten Ungezählte wieder zurück, konnten dann allerdings ohne Heimatschein nicht mehr auf Unterstützung hoffen. Insbesondere in der Schweiz zahlten Gemeinden bis Ende des 19. Jahrhunderts anscheinend systematisch Geld an Fürsorgeabhängige für die Auswanderung nach Amerika und entzogen ihnen gleichzeitig ihre Heimatzugehörigkeit. ${ }^{85}$ In großem Umfang wurde dieser Weg auch in Südwestdeutschland im Zeitraum 1845 bis 1855 erprobt. $^{86}$

bald der öffentlichen Armenkasse zur Last fallen könnten.“ Matz 1980, S. 268. Zum Zusammenhang von Ehe- und Heimatrecht vgl. auch ausführlich Riedel 1881.

83 Vgl. Matz 1980, S. 87.

84 J.M. Maier: Die Noth der untersten Volksklassen und ihre Abhilfe. Erlangen 1849, S. 111, hier zitiert nach Matz 1980, S. 90.

85 Diese Aussage findet man in der Literatur sehr häufig, jedoch stets ohne Verweis auf belegende Quellen. Zum Schweizer Heimatrecht des 19. Jahrhunderts insgesamt vgl. Burckhardt 1931, Art. 45 BV, S. 398 - 399 und S. 402-404; Schlaepfer 1969; Schönberger 2005, S. 85 - 88. Belege zum ausschließenden Charakter des Heimatrechts in der Schweiz finden sich auch in: Argast 2003 und Argast 2007.

86 Vgl. Helbich/Kamphoefner/Sommer 1988, S. 15. Ein Fallbeispiel einer Mutter zweier unehelicher Kinder aus dem Württembergischen von 1857: „Friederike Kaiser wurde auf ihren Antrag hin von ihrer Heimatgemeinde Kleinheppach ein Reisekostenzuschuß von 45 Gulden bewilligt - wie aus dem Protokoll des Gemeinderats hervorgeht, ohne langes Zögern und mit der Begründung, daß sie und ihre Kinder ohnehin ,in kurzer Zeit der Gemeinde zur Last gefallen wären'. Dennoch reichte das Reisegeld der Familie nicht aus. Am 15. Juli sah sich der Kleinheppacher Rat mit einem Brief der Friederike Kaiser konfrontiert, in dem sie mitteilte, daß sie mit ihren Kindern mittlerweile in Le Havre angelangt sei, jedoch nicht mehr über genügend Geld verfüge, um den notwendigen Reiseproviant bezahlen zu können. Falls man ihr nicht sogleich weitere 25 Gulden übersende, gehe das Schiff ohne sie ab, und sie habe keine andere Wahl, als mittellos in ihre Heimatgemeinde zurückzukehren. Bürgerausschuß und Rat beschlossen daraufhin noch am selben Tag nach längeren Verhandlungen, ,für das liederliche Subjekt noch einmal 25 fl. nebst 15 Kreuzer Postporto aus der Gemeindekasse aufzuopfern', in der Hoffnung, durch diese weitere Zahlung das ,Subjekt‘ mitsamt seinen Kindern endgültig loszuwerden. [...] Die Finanzierung der Reise nach 


\section{Reformversuche ab den 1840er Jahren}

Die durchgreifendsten Konsequenzen aus der Misere des Heimatrechts zog Preußen; de facto bedeuteten die Maßnahmen zwar noch keine Abschaffung, aber eine entscheidende Schwächung der Prinzipien des Heimatrechts: Am 31. Dezember 1842 erließ Friedrich Wilhelm IV. für Preußen die Gesetze über Armenpflege, Freizügigkeit und Staatsangehörigkeit, die einen Fürsorgeanspruch aller preußischen Untertanen auf Grundlage der preußischen Staatsangehörigkeit festlegten. Die Verfasser des Entwurfs des Armenpflegegesetzes verfolgten das Ziel, dass diejenigen Gemeinden die Versorgungslast tragen sollten, die zuvor auch von der Arbeit des jetzt in die Versorgungsbedürftigkeit Geratenen profitiert hatten. Dort, wo die Leistung für die Gemeinde erbracht worden war, sollte der Bedürftige auch eine Leistung zurückbekommen:

Wenn nun solche Personen aus ihrer Heimath (nach jenem Begriff) viele Jahre entfernt sind, und dort auch die Erinnerung an sie nicht mehr oder kaum noch lebt, so soll die sogenannte Heimath dennoch für sie sorgen? Und die Ortschaft, der sie vielleicht jahrelang ihre Kräfte gewidmet haben, die von ihren Diensten als Gesinde, Handarbeiter etc. jahrelang Nutzen gezogen hat, und wo sie sich Beschützer, Freunde, Bekannte erworben haben, soll kein Interesse an ihnen zu nehmen verpflichtet seyn? ${ }^{87}$

Heimat „nach jenem Begriff“, also die juristisch bisher gültige Heimat, ist nach diesem Verständnis nur noch eine „sogenannte Heimath“, weil das ökonomische und soziale Verhältnis von Geben und Nehmen gar nicht mehr besteht. Eben unter dieser ökonomischen Logik soll das Verhältnis neu bestimmt werden; neben der Heimat gilt nun das ,Hilfsdomizil ‘ - der Ort des tatsächlichen Wohnsitzes - als Ort der Versorgung. Der Erwerb einer neuen rechtlichen Heimat soll erleichtert und rechtliche Heimatlosigkeit verhindert werden. ${ }^{88}$ Faktisch konnte dieses Ziel mit dem Gesetz nicht erreicht werden, da die Fürsorgepflicht der früheren Heimatgemeinde erlosch, wenn ein Abgewanderter drei Jahre lang abwesend gewesen war, er aber andererseits erst nach drei Jahren kontinuierlichen Wohnsitzes ein neues Heimatrecht erlangen konnte. Wechselte etwa eine Dienstmagd, wie es die Regel war, jährlich ihre Stelle und überschritt dabei Gemeindegrenzen, war sie nach drei Jahren zwangsläufig heimatlos. ${ }^{89}$ Viele Kommunen zwangen ihre

Amerika erwies sich [...] als die langfristig kostengünstigere Möglichkeit zur Lösung des Armutsproblems.“ Helbich/Kamphoefner/Sommer 1988, S. 503-504, hier mit näheren Nachweisen. 87 Motive zu dem Gesetz-Entwurf wegen der Verpflichtung zur Armenpflege, ALWL, Bestand 101, Nr. 373, f. 83-83v., hier zitiert nach Lerche 2009, S. 51.

88 Vgl. Motive zu dem Gesetz-Entwurf wegen der Verpflichtung zur Armenpflege, ALWL, Bestand 101, Nr. 373, f. 85, zitiert nach Lerche 2009, S. 51-52.

89 Vgl. Lerche 2009, S. 66. 
Dienstboten, den Ort vor Ablauf der drei Jahre wieder $\mathrm{zu}$ verlassen, um nicht versorgungspflichtig zu werden..$^{90}$ Die Betroffenen verloren also ihre Heimat unabhängig davon, ob sie bereits eine neue erworben hatten; Heimatlosigkeit wurde entgegen der ursprünglichen Intention des Gesetzes befördert. ${ }^{91}$ Immerhin hatten die teilweise durch die Gesetzesreform neu geschaffenen Heimatlosen erstmals einen legitimen Anspruch auf Fürsorge, die über das repressive Arbeitshaus hinausging; ${ }^{92}$ es sollte keine Personen mehr geben, für die niemand zuständig war. Für heimatlose Bedürftige hatten die provinzialen Landarmenverbände $z u$ sorgen. ${ }^{93}$

Als Landarme galten diejenigen Armen, die vom Land Preußen und nicht von der Gemeinde versorgt wurden, weil sie keiner Heimat zuzuordnen waren. Es war mitunter vorteilhaft, als Landarmer eingestuft zu werden; denn während die Gemeinden je nach eigener Einschätzung und Kassenlage den zu ihrer Gemeinde Zählenden die Unterstützung auch verwehren konnten, mussten die Landarmenverbände ihre Armen zumindest geringfügig unterstützen und taten es auch, da ihre Auslagen auf die Kommunen umgelegt wurden; verbindliche Fürsorge in Notlagen war so eher gewährleistet. ${ }^{94}$

In den nicht-preußischen Teilen Deutschlands galt dieses Prinzip, dass das Land eingreift, wo die Gemeinde versagt, noch nicht. Eine Maßnahme, die schon vor 1848 mehrfach erfolglos angeregt worden war und schließlich 1851 in Gestalt der sogenannten Gothaer Übereinkunft ${ }^{95}$ umgesetzt wurde, regelte immerhin die gegenseitige „Uebernahme der Ausgewiesenen und Heimatlosen“ zwischen den deutschen Bundesstaaten. $§ 1$ setzt fest, dass die fortdauernden, aber auch vormaligen Angehörigen einer Regierung, „auch wenn sie die Unterthanenschaft nach der inländischen Gesetzgebung bereits verloren haben, so lange, als sie nicht dem anderen Staate nach dessen eigener Gesetzgebung angehörig geworden sind - auf Verlangen des andern Staates wieder zu übernehmen“96 seien. Der Plan, daraus eine allgemeingültige Regelung für alle deutsche Staaten zu schaffen, blieb unausgeführt. ${ }^{97}$

90 Vgl. Lerche 2009, S. 67.

91 Vgl. Lerche 2009, S. 61.

92 Vgl. Lerche 2009, S. 52 und S. 62.

93 Alle Gesetze abgedruckt bei Sachße/Tennstedt/Roeder 2000, S. 916-928. Zur Vorgeschichte dieser Gesetze für Preußen und insbesondere Westfalen vgl. Lerche 2009, S. 45-72.

94 Vgl. Lerche 2009, S. 106.

95 Seydel 1890, S. 178-194.

96 Zitiert nach Riedel 1881, S. 270.

97 „Die Aufstellung gleichmässiger Grundsätze über die Heimathsverhältnisse war schon vor dem Jahre 1848 mehrfach in der Bundesversammlung angeregt, und sogar am 15. Jan. 1846 ein Commissionsentwurf in derselben zur Vorlage gekommen. Hieran im Wesentlichen anschliessend 
Bayern reformiert sein Heimatrecht 1868 grundlegend, allerdings nicht wie Preußen mit dem Ziel, den Zentralstaat auf Kosten der Gemeinden zu stärken, sondern andersherum die Armenversorgung bei den Gemeinden zu belassen. Das Bayerische Gesetz über Heimat, Verehelichung und Aufenthalt vom 16. April 1868 räumt die Hindernisse der Ansässigmachung aus (bisher war die Zustimmung der Gemeinden dafür erforderlich, erst jetzt wird es zum Recht aller, sich selbständig in jeder Gemeinde niederzulassen, Gewerbe zu betreiben und Grundbesitz zu erwerben). Fortan ist es ,jeder Person, und zwar ohne Rücksicht auf Geschlecht, Confession oder Vermögensbesitz“, möglich, nach einer bestimmten Aufenthaltszeit „die Verleihung von Heimat zu beanspruchen““.98 Gemäß Artikel 11 sind „Heimatgebühren“ zu entrichten. ${ }^{99}$

Mit der Gründung des Norddeutschen Bundes 1866 wurde das preußische Modell des Hilfsdomizils, dem zufolge schon nach kürzerer Zeit der Ort des tatsächlichen Aufenthalts den Bedürftigen zu unterstützen hatte, auf alle Bündnismitglieder ausgedehnt. Zusätzliche tiefgreifende Reformen schwächten das Heimatrecht im Gebiet nördlich der Mainlinie weiter: Mit dem Gesetz über die Freizügigkeit von 1867, dem Gesetz über die Gewerbefreiheit von 1869 und dem Gesetz über die Aufhebung der polizeilichen Beschränkung der Eheschließung von 1868 waren mehrere Faktoren beseitigt, die Ortsfremde vom Heimatrecht ausgeschlossen hatten.

wurde am 15. Juli 1851 von Preussen mit einer Anzahl anderer Bundesgenossen zu Gotha ein Vertrag (sogenannter Gothaer Vertrag) abgeschlossen, um die Schwierigkeiten zu beseitigen, welche sich bisher unter ihnen in Bezug auf die Uebernahme von Auszuweisenden oder Heimathlosen ergeben hatten, und dadurch zugleich, so viel an ihnen ist, ein allgemeines deutsches Heimathsrecht vorzubereiten. [...] Insbesondere ist jede Regierung für verpflichtet erklärt, ,Anordnung zu treffen, damit in ihrem Gebiete keine Verheirathung eines Angehörigen der anderen contrahirenden Staaten, sei es mit einer Inländerin oder Ausländerin, ohne Consens der Heimathbehörde gestattet werde‘, indem man in dem bisherigen Mangel dieser Anordnung in mehreren Staaten eine hauptsächliche Veranlassung der häufigen Heimathlosigkeit erkannte.“ Zoepfl 1863, S. 652-653, § 477b.

98 Beide Zitate Riedel 1881, S. 52. Zur bayerischen Heimatgesetzgebung vgl. neben Riedl 1881 und Seydel 1886 auch Theodor Kutzers sechshundertseitiges Kompendium zum Thema: Kutzer 1904. 99 Riedel 1881, S. 50. Schon am 23. Februar 1872 wurde dieses Gesetz einer Revision unterzogen, die aus der Reichsgründung resultierte. Der Vertrag von Versailles legte zwar fest, dass die Heimats- und Niederlassungsverhältnisse weiterhin Sache Bayerns und nicht des Reiches waren (vgl. Riedel 1881, S. 53), gleichwohl ergaben sich einige Rückwirkungen aus der veränderten Reichsgesetzgebung: Als Inländer galten fortan nicht nur die Bayern, sondern auch alle anderen Deutschen. Und umgekehrt: Angehörige des deutschen Reiches sind für Bayern fortan keine Ausländer mehr. Zudem kann die bayerische Staatsangehörigkeit nicht mehr über die Zugehörigkeit zu einer Heimatgemeinde erworben werden (vgl. Riedel 1881, S. 55). Zu den Heimatgebühren vgl. ausführlich Kutzer 1904. 
Eine von den nord- und mitteldeutschen und eine abweichende, von den süddeutschen Staaten ausgebildete Rechtsauffassung und -praxis prallen damit zum Zeitpunkt der Gründung des Deutschen Reiches aufeinander. Sinn und Umfang des Heimatrechts wurden in Reichstag und Bundesrat intensiv und kontrovers diskutiert. ${ }^{100}$ Die aus dem norddeutschen Bund übernommenen und teilweise wieder modifizierten Regelungen waren weiterhin nicht widerspruchsfrei und galten von Anfang an als überarbeitungsbedürftig. ${ }^{101}$ Die südlicheren Bundesstaaten, allen voran Bayern, wollten ihr reformiertes Heimatrecht (ihr „System der Heimat“) ${ }^{102}$ keinesfalls aufgeben. Diese Auseinandersetzungen lassen eine bundesweite Einigung auf ein einheitliches Heimatrecht scheitern. ${ }^{103}$

\section{Heimatrecht und Unterstützungswohnsitz ab 1870}

Mit der neuen Reichsverfassung von 1870 wurde Bayern, Württemberg, Baden und Elsaß-Lothringen zunächst ein Sonderstatus zuerkannt. Im restlichen Reich war das Heimatrecht zunehmend weiter von vielen anderen rechtlichen Zusammenhängen entkoppelt (das betrifft das Aufenthalts- und Niederlassungsrecht, das Recht zum Erwerb von Grundeigentum und zur Führung eines Gewerbebetriebs, zur Verehelichung und zur Gründung eines eigenen Hausstandes) ${ }^{104}$ und damit geschwächt. Das Gesetz über den Unterstützungswohnsitz ${ }^{105}$ machte einen zweijährigen Aufenthalt zur Bedingung der Unterstützung. Die Kritik am Unterstützungswohnsitz richtet sich aus süddeutscher Perspektive gegen das dadurch

100 Vgl. Seydel 1877, Sp. 545-630 und die Quellen, die Beate Althammer in ihrem Aufsatz präsentiert, vgl. Althammer 2021.

101 Vgl. Rönne 1871.

102 Seydel 1891, S. 72.

103 Zusammengefasst u.a. bei Seydel 1891, S. 72-79 und im Artikel „Heimat' in Brockhaus' Konversations-Lexikon: Anonym: Heimat, 1893, S. 970. Zu Preußen vgl. auch Walker 1971, S. 347353.

104 „Durch die Bestimmungen des Art. 3 der Reichs-Verfassung und der vorerwähnten Gesetze ist der grösste Theil der in der Mehrzahl der Bundes-Staaten bisher ausschliesslich an das Heimaths-Recht geknüpften bürgerlichen Rechte, nämlich das Recht des Aufenthalts und der Niederlassung, das Recht zur Erwerbung von Grundeigenthum und zum Gewerbebetriebe, sowie zur Verehelichung und Gründung eines eigenen Hausstandes, von diesem Zusammenhange losgelöst und zu selbstständigen, jedem Reichs-Angehörigen im ganzen Reichsgebiete zustehenden Befugnissen geworden. Aber: verschiedenartige Bestimmungen über Heimath-Recht müssen noch angeglichen werden etc.“ Rönne 1871, Sp. 2-310, hier Sp. 169-171.

105 Das „Gesetz über den Unterstützungswohnsitz vom 6.6.1870. BGBl. Norddeutscher Bund 1870" und ein Kommentar finden sich bei Stolp 1871, bei Höinghaus 1871 und bei Krech 1898. Der Begriff ,Unterstützungswohnsitz‘ etablierte sich in der preußischen Gesetzgebung schon seit 1855, vgl. Althammer 2021. 
hervorgebrachte rein administrative und kontingente Verhältnis zur Gemeinde, während das Heimatrecht in dieser Perspektive für Stetigkeit und Zugehörigkeit steht. „Der durchgreifendste Unterschied aber zwischen der gemeinrechtlichen und der preußischen Gesetzgebung“, so heißt es in der Begründung des bayerischen Gesetzentwurfs für einen Sonderstatus von 1870 (und die gemeinrechtliche Gesetzgebung meint hier die bayerische, die preußische die des norddeutschen Bundes bzw. des zukünftigen deutschen Reiches), liege darin, „daß der Verlust der einmal erworbenen Heimat grundsätzlich bis zum Erwerbe einer anderen Heimat ausgeschlossen ist, beziehungsweise nur zugleich mit dem Verluste der Staatsangehörigkeit eintritt“. Eben dies unterscheide Heimat von Unterstützungswohnsitz: „Hiedurch erst gewinnt die Heimat ihr eigenthümliches Gepräge der Stetigkeit und Unzerstörbarkeit im entschiedensten Gegensatze zu dem preußischen Grundsatze des leicht zu erwerbenden, aber auch ebenso leicht $\mathrm{zu}$ verlierenden Unterstützungswohnsitzes." ${ }^{106}$

Auch wenn alle Zahlen beweisen, dass die gepriesene Stetigkeit und Unzerstörbarkeit wenig mit den Realitäten zu tun hat, kann andererseits auch die

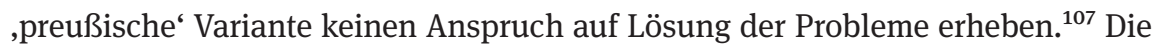
Versorgung der Armen blieb mit dem Unterstützungswohnsitz nicht mehr allein Gemeinde-, sondern wurde auch Ländersache. Dies ging mit der Errichtung von Orts- und Landarmenverbänden einher, die nun statt der Gemeinden für die Versorgung zuständig waren, und des Bundesamtes für Heimathwesen, das „die endgültig entscheidende Berufungs-Instanz in Streitigkeiten zwischen verschiedenen Bundesstaaten angehörenden Armenverbänden über die öffentliche Unterstützung Hülfsbedürftiger“"108 war. Ein Rechtsanspruch auf Armenfürsorge bestand weiterhin nicht. ${ }^{109}$ Eine Änderung setzte erst Bismarck in den 1880er Jahren

106 Beide zitiert nach Seydel 1891, S. 73 (dort ohne genaue Quellenangabe). Seydel führt aus: „Der Unterstützungswohnsitz erzeugt keine andere Beziehung zur Gemeinde als die armenrechtliche. Heimat dagegen ist Gemeindeangehörigkeit. Geburt und Aufnahme in den Gemeindeverband sind die Haupterwerbsgründe der Heimat. Die Armenfürsorgepflicht der Gemeinde ist nur eine der Wirkungen der Heimat.“ Seydel 1891, S. 73.

107 So auch die These in Beate Althammers aktuellem Beitrag zu den Kontroversen um Heimatrecht und Unterstützungswohnsitz im Norddeutschen Bund und im Deutschen Reich. Die Durchsetzung des Unterstützungswohnsitzes führte effektiv zu einer größeren Anzahl an Unterstützungsbedürftigen und konnte sich mittelfristig ebenfalls nicht als zukunftsträchtiges Instrument erweisen, vgl. Althammer 2021. Althammer argumentiert damit gegen Darstellungen, die die preußische Variante zu optimistisch als „zukunftsträchtige[n]“ Ansatz deuten, so Ziekow 1997, S. 11 .

108 Stephan 1903, S. 114.

109 In Bayern galt das bis zur Abschaffung des Heimatrechts 1916: „Der bedeutsamste Inhalt der Heimat ist, daß sie für den Fall eintretender Hilfsbedürftigkeit Anspruch gewährt auf Unterstüt- 
mit seiner umstrittenen Sozialgesetzgebung durch. Sie schloss Unfall- und Altersversicherungen für die Arbeiter ein, deren privat zu zahlenden Anteil der Staat von den Arbeitern erzwang, zugleich aber auch selbst in die Pflicht genommen wurde. ${ }^{110}$ Bismarcks Reform der Armenfürsorge brachte gegen seine liberalen Kritiker den intervenierenden ${ }^{111}$ und zugleich den zentralisierten Staat zur Geltung; sie reihte sich damit ein in die auf allen staatlichen Ebenen sich vollziehende zentralisierende Unitarisierung innerhalb eines föderalen Gefüges. ${ }^{112}$ Die ländlichen Gemeinden wurden von den Versorgungslasten befreit. Mit der Entlassung der Kommunen aus ihrer Verantwortung für das Heimatrecht wächst dem Staat eine neue Aufgabe zu. Bismarck notiert: „Die alte Kommunalarmenpflege paßt nicht zur Freizügigkeit; der Staat ist Heimat geworden und muß sie leisten“. ${ }^{113}$ Vor dem hier skizzierten Hintergrund wird verständlich, dass Bismarcks Verwendung des Begriffs Heimat auf eine präzise juristische Bedeutung zurückverweist. Und Bismarcks Notiz zeigt, dass der Staat im rechtlichen Sinn tatsächlich die Funktionen von Heimat übernehmen wollte und die ab dem letzten Drittel des 19. Jahrhunderts zunehmend zu beobachtende Deckungsgleichheit der Be-

zung durch die Gemeinde [...]. Eine Verpflichtung gegenüber den Heimatberechtigten besteht für die Gemeinde trotz des obigen Wortlautes nicht." Kutzer 1904, S. 48.

110 Vgl. Nipperdey 1990, S. 333-373.

111 Vgl. Tennstedt 1997.

112 Die Verfassung des ersten deutschen Nationalstaats ist durch „die Konstruktion des Bundesrates als Gegenpart des Reichstags“ (Nipperdey 1992, S. 92) charakterisiert. Die föderativen Elemente des Deutschen Reiches lagen vor allem im Verwaltungs-, Finanz-, Kultur- und Verfassungsföderalismus (vgl. Nipperdey 1992, S. 86); Recht, Wirtschaft, Militär und Soziales lagen in der Kompetenz des Reiches, diese Kompetenz blieb aber immer föderativ gebrochen. „Der Interventionsstaat, der damals entstand, wurde auf der Reichsebene ausgebildet, wenngleich er in weiten Bereichen dank der föderalen Grundstruktur in der Verwaltung der Bundesstaaten blieb. Diese föderative Brechung der Unitarisierung gilt selbst für den Sozialversicherungsstaat, dessen Grundlagen in den achtziger Jahren durch Reichsgesetze gelegt wurden. Der Wandel von der traditionellen Armenfürsorge zur modernen Sozialversicherung, den das Reich als Gesetzgeber vorantrieb, bedeutet einen Zentralisierungsschub, doch die Last der Durchführung oblag den Kommunen. Es war für die soziale Absicherung weiterhin wichtig, wo man wohnte, denn die kommunale Sozialpolitik entschied über die Art und Höhe der Leistungen.“ Langewiesche: Föderativer Nationalismus, 2000, S. 226; vgl. auch Ritter 1991.

113 Handschriftliche Aufzeichnung undatiert, wohl 1880; Bismarck-Archiv Friedrichsruh A 26, n.fol., zitiert nach Tennstedt 1997, S. 97, der die Notiz im Kontext der Reform des Armenwesens und des Unterstützungswohnsitzgesetzes von 1870 liest, die seit 1877 regierungsintern beraten wurde. Bismarcks Standpunkt, dass die „nähere Beteiligung des Staates an der Armenpflege [...] eine natürliche Folge der Freizügigkeit“ sei und jeder dort hilfeberechtigt sein solle, wo er hilfsbedürftig geworden sei, stand im Gegensatz zu Bayerns, aber auch Elsaß-Lothringens gegenläufiger Heimatrechtspolitik; Tennstedt 1997, S. 97. Für den Hinweis auf Bismarcks Notiz danke ich Florian Tennstedt. 
griffe von Heimat und Vaterland, verstanden als Staat aller Deutschen (vgl. I.2.1), auch eine ganz pragmatische Ursache hatte. Denn die Staatszugehörigkeit begann die sich im Heimatrecht manifestierende rechtlich relevante Lokalzugehörigkeit als Prinzip zu verdrängen.

Bis zur Jahrhundertwende führten die unterschiedlichen Heimatrechtsprechungen allerdings weiter zu Konflikten. 1890 erhielt der ,Fall Gradl‘ viel öffentliches Interesse. ${ }^{114}$ Der in München lebenden Emilie Gradl, die mit drei kleinen Kindern und von ihrem Mann verlassen Armenunterstützung beantragt hatte, wurde aufgrund des Heimat- und Eherechts keine Unterstützung gewährt. Denn die mit Anton Gradl in Suhl geschlossene Ehe sei zwar nach dortigen Vorschriften regelgerecht zustande gekommen, aber ein bestimmtes in Bayern erforderliches amtliches Dokument wurde aus Unwissen über die Regelung einzuholen versäumt. Da aus diesem Grund die Ehe seitens der bayerischen Behörden als ungültig betrachtet wurde, hatte Emilie Gradl mit ihrer Heirat nicht das bayerische Heimatrecht ihres Mannes und folglich auch nicht die bayerische Staatsangehörigkeit ${ }^{115}$ erworben; sie sei daher nicht unterstützungsberechtigt. ${ }^{116}$

Noch 1911 konstatiert eine juristische Dissertation zum bayerischen Sonderweg in Sachen Heimatrecht, „dass dieses Gesetz den in der Gegenwart herrschenden Zuständen nicht mehr genügt, und dass es für die Beteiligten ausserordentliche Härten mit sich bringt“. Wobei diese Härten in der weiteren Ausführung vor allem aus der Perspektive der Gemeinden, nicht der Hilfsbedürfigen geschildert werden:

Mit dem Wechsel des Aufenthalts ist nämlich kein Wechsel der Heimat verbunden und infolge dessen ist es im Laufe der Zeit dazu gekommen, dass in den Gemeinden mit selbst nur geringer industrieller Tätigkeit die Ortseinwohner in ganz überwiegender Mehrzahl nicht

114 Vgl. Seydel 1891, S. 72.

115 Auch noch im deutschen Kaiserreich gab es zunächst keine einheitliche deutsche Staatsangehörigkeit, sondern eine Staatsangehörigkeit zu den einzelnen Gliedstaaten wie Preußen oder Bayern. Verschiedene Gesetze, etwa das Reichs- und Staatsangehörigkeitsgesetz von 1913, stellten sicher, dass die Regelung der Staatsangehörigkeit in allen Gliedstaaten den gleichen Regeln unterstand. Erst mit der Aufhebung der Souveränität der Länder des Deutschen Reichs 1934 wurde eine einheitliche deutsche Staatsangehörigkeit eingeführt. - Die Reichsgründung konstituierte ein „gemeinsames Indigenat“ (Art. 3 der Verfassung des Deutschen Reiches vom 16.4. 1871), dieses garantierte den Angehörigen aller Bundesstaaten die prinzipielle Gleichbehandlung als Inländer; die Staatsangehörigkeit blieb aber an die souveränen Einzelstaaten gebunden. Vgl. Althammer 2014, S. 303. Ausführlicher zur Ausbildung der Staatsbürgerschaft im 19. Jahrhundert - auch für die Schweiz und Österreich und weitere europäische Staaten im Vergleich - vgl. Althammer 2014 sowie zur Entwicklung des deutschen Staatsangehörigkeitsrechts vom Deutschen Bund bis zur Bundesrepublik Deutschland Gosewinkel 2001.

116 Ausführlich dazu Anonym 1891, S. 61-71. 
mehr an ihrem Wohnsitze, sondern in einer ganz andern Gemeinde heimatberechtigt sind, in einer Gemeinde, zu welcher sie, je länger sie sich von derselben entfernt haben, in um so grösserem Masse [sic] an Kontakt verloren haben. [...] Die Heimat, welche nach der Absicht des Gesetzgebers eine lebendige Beziehung des Einzelnen zur Gemeinde bilden und aus mehrjährigem Wohnsitze sich entwickeln sollte, reduziert sich nun der Hauptsache nach auf ein Versicherungsinstitut gegen die Gefahr der Verarmung, bei welchem die Träger des Risikos in ganz ansehnlichem Prozentsatze Gemeinden wurden, für welche der Versicherte als eine ganz fremde Person erschien. Die Aufenthaltsgemeinde dagegen, welche von dem Arbeiter, solange er arbeitsfähig war, insofern wirtschaftlichen Nutzen zog, als er in ihrem Bezirke öffentliche Abgaben entrichtete und seinen Lohn verbrauchte, wird von der Pflicht zur Unterstützung des später hilfsbedürftig Gewordenen nicht getroffen. ${ }^{117}$

Erst Anfang 1916 wird auch in Bayern das Heimatrecht durch das inzwischen schon mehrfach umgearbeitete ${ }^{118}$ und immer wieder grundsätzlich diskutierte ${ }^{119}$ Gesetz zum Unterstützungswohnsitz abgelöst (das allerdings seinerseits nur kurzen Bestand hat); ${ }^{120}$ die Heimatscheine verlieren ihre Gültigkeit. In Österreich wurde die Heimatgesetzgebung 1901 reformiert, ${ }^{121}$ sie bestand bis 1939 weiter. ${ }^{122}$ Der Schweizer Kanton Bern war 1857 dieser Entwicklung schon vorangegangen, ${ }^{123}$ insgesamt bildet die Schweiz aber das Schlusslicht in der Reihe der Verabschiedungen des Heimatrechts - es gilt, wenn auch mit nur geringen faktischen Auswirkungen, bis heute. ${ }^{124}$ Als rechtlich-administrative Kategorie wird Heimat damit

117 Beide Maurer 1911, S. 67-68. Die Arbeit Alfred Maurers widmet sich dem bayerischen Heimatrecht Ende des 19. und Anfang des 20. Jahrhunderts.

118 Vgl. etwa Höinghaus 1894.

119 Vgl. Roscher 1894.

120 Das Unterstützungswohnsitzgesetz wird 1924 zugunsten der allgemeinen Fürsorgepflicht abgelöst. Vgl. Moritz 1929 und Althammer 2021.

121 Vgl. Anonym 1900. Sylvia Hahn wertet die statistisch erfassbaren Auswirkungen des Gesetzes aus, vgl. Hahn 2005.

122 Edward Timms zeigt, dass das österreichische Heimatrecht noch in den Friedensverhandlungen im Jahr 1919 bedeutsam wurde und hier die Abschiebung von Juden aus Osteuropa erleichterte, vgl. Timms 1994; vgl. auch Wendelin 2000, S. 230.

123 Als erster Kanton wandelte Bern 1857 die Fürsorgepflicht der Heimatgemeinde in die der tatsächlichen Wohnortgemeinde (entsprechend dem Unterstützungswohnsitz) um, 41 Prozent der im Kanton Wohnenden waren zu dieser Zeit nicht mehr dort geboren.

$124 \mathrm{Ab}$ der ersten Hälfte des 19. Jahrhunderts etablierte sich in der Schweiz allmählich die Niederlassungsfreiheit und damit eine Einwohnergemeinde, die nach und nach die meisten vormaligen Aufgaben der Bürger- bzw. Heimatgemeinde übernahm, ohne dass das Heimat- bzw. Bürgerrecht je ganz an Bedeutung verlor. Nach wie vor gibt es eine parallele Gemeindestruktur in der Schweiz (vgl. Historisches Lexikon der Schweiz, Artikel ,Bürgergemeinde). Jeder Schweizer Bürger besitzt weiterhin einen Bürger- oder auch Heimatort, der unabhängig vom Geburts- und Wohnort einer Person ist; er wird im Reisepass und auf der Identitätskarte aufgeführt. Die Verpflichtung des Heimatortes, einen Heimatschein auszustellen, der bei der Gemeinde des tat- 
im Laufe des 20. Jahrhunderts nach und nach obsolet, ${ }^{125}$ und heute kann man von einem fast gänzlichen Verschwinden ihrer Geltungskraft sprechen.

\section{Semantik der rechtlichen Heimat im bürgerlichen Jahrhundert}

Für die Einordnung der engeren rechtlichen Bedeutung von Heimat in die weitere Semantik des Begriffs sind für das 19. Jahrhundert vor allem zwei Beobachtungen wichtig: Erstens erscheint die rechtliche Heimat als verknüpft mit der bürgerlichen Gesellschaft. Heimat als Signatur eines Jahrhunderts, dessen bürgerlicher Wertehorizont sich von der patriarchalisch organisierten Familie bis zur Traditionstreue und Vaterlandsliebe spannt (vgl. I.2.3 und I.2.5), zeigt ihre spezifische Bürgerlichkeit auch ganz konkret als vom Bürgertum ausgeübte administrative Praxis. Denn im Zeitalter von Pauperismus und Proletariat halten sich die bürgerlichen Gemeinden, Städte und Kommunen mithilfe des Heimatrechts die Armen oft mehr vom Hals, als sie wirksam zu versorgen. Heimat ist im 19. Jahrhundert immer dann aktenkundig geworden, wenn es um Ausweisung, Abschiebung oder ,Freikauf‘ von potentiellen Versorgungsansprüchen der Armen ging. Denn nicht jedem sollte Heimat gewährt werden. Die Heimatlosen wurden zur Kehrseite der bürgerlichen Ordnung. Über diesen Aspekt wird im Folgenden insbesondere in II.2.2.3 zu lesen sein.

Zweitens entsteht ein kaum auflösbarer Widerspruch zwischen dem weit verbreiteten Verständnis von Heimat als Chiffre für Geborgenheit, Sicherheit und Vertrautheit und einem Heimatrecht, das nicht selten Zugehörigkeit und Versorgung verweigert. Wie die Literatur diese Aporien aufgreift, werden die folgenden

sächlichen Aufenthalts zu hinterlegen war, wurde erst 2003 abgeschafft. Der Kanton, in dem der Bürgerort liegt, kam noch bis 2012 in dem Fall, dass kein fester Wohnsitz nachweisbar war, für die Sozialhilfe auf. Die Vererbung des Heimatortes vom Vater auf die Kinder ist üblich. Die Ehefrau übernahm bei der Heirat den Heimatort des Mannes, dies wurde erst 2013 geändert.

125 Heimat bleibt nach dem Zweiten Weltkrieg ein mit dem Recht verbundener Begriff, steht aber unter gänzlich anderen Vorzeichen: Das ,Recht auf Heimat‘ wird nun im Kontext der Vertriebenenpolitik im deutschen öffentlichen Recht diskutiert. Prominenter Vertreter dieser Diskussion ums Recht auf Heimat war der Würzburger Öffentlichkeitsrechtler und bayerische Justizminister Winfried Bausback, vgl. auch Peeters 1961, Pernthaler 1986, Blumwitz 1987, Tomuschat 1989, Kimminich 1989. Das in der Cannstatter Charta der deutschen Vertriebenenorganisationen vom 5. August 1950 apostrophierte „Recht auf die Heimat als eines der von Gott geschenkten Grundrechte der Menschheit“ (Auszug in: Rabl 1958) wurde völkerrechtlich abgeleitet, aber auch aus nationalen Rechtsgrundsätzen europäischer Staaten historisch rekonstruiert (vgl. ebd.). Weitere Quellen sind zusammengestellt von Zimmermann 1991.Völkerrechtliche Debatten über das Recht auf Heimat werden jenseits der Vertriebenenpolitik verstärkt seit den 1970er Jahren und bis heute geführt, vgl. Haedrich 2016. 
Kapitel behandeln. Die Widersprüche zwischen Heimat als normativem Begriff und als fachsprachlichem Terminus werden auch schon innerhalb der juristischen Rede von Heimat greifbar, wie die vorangegangenen Zitate teilweise gezeigt haben. An einigen weiteren Beispielen kann deutlich werden, dass im ganzen 19. Jahrhundert auch die juristische Rede über Heimat nicht ohne ein Heimatverständnis auskommt, das wahlweise auf emphatische, anthropologisierende oder moralisierende Heimatsemantiken zurückgreift. Heimat ist demnach auch im Rechtsdiskurs nicht nur Terminus technicus, sondern zugleich Wertbegriff.

In einer ministeriellen Kommentierung des Gesetzentwurfs über das Bayerische Heimatgesetz vom 11. September 1825 wird hervorgehoben, dass Heimat nicht bloß den Ort bezeichne, an den ein Bettler oder Unterstützungsbedürftiger aus rein polizeilichen Gründen verwiesen wird, sondern zugleich als „Wiege manichfaltiger schöner Beziehungen und Gefühle“ zu gelten habe, ,aus welcher der Sinn für die Mitwirkung zu gemeinsamen Zwecken sich entwickelt, und als die Pflanzschule bürgerlicher Tugend und Ordnung, deren Gewährleistung und Pflege durch das Gesetz vermittelt werden soll“. ${ }^{126}$

Mehr als vierzig Jahre später, in der Hochphase der Auseinandersetzungen zwischen süddeutschen Heimatrechtsvertretern und norddeutschen Befürwortern des Unterstützungswohnsitzkonzepts, zitiert Emil von Riedel diese Passage zustimmend und schlussfolgert: „Die Heimat ist also einerseits der aus polizeilichen Gründen zu fixierende Aufenthalts- und Unterstützungsort, und andererseits ein besonders gewährleistetes subjectives Recht, dessen Bestand gleichzeitig einem politischen Interesse dient. “127 Dieses politische Interesse, so ist Riedel wohl zu verstehen, zielt auf einen nach Gemeinschaftlichkeit, Tugend und Ordnung strebenden Bürgersinn. Vom ministeriellen Kommentator von 1825 wird diese Idee an den Begriff der Pflanzschule (im zeitgenössischen Sprachgebrauch eine Erziehungsanstalt) gebunden, der neben dem Bild des disziplinierten Wachstums auch die topische Metaphorik der Heimat als vegetativer Heimat, d.h. als ,Wurzel enthält (vgl. I.2.1).

In der teilweise polemisch geführten Debatte um das Heimatrecht verwenden auch die Vertreter des Unterstützungswohnsitzes den Widerspruch zwischen administrativem und emphatischem Heimatbegriff für ihre Argumentation. So wird in der Begründung für den Reformbedarf des Heimatwesens in Preußen 1842 eine Heimat, wie sie das Heimatrecht vorsieht, als nur „sogenannte Heimath“ mit dem Argument angegriffen, dass es tatsächlich keine sozialen und emotionalen

126 Die ministerielle Kommentierung des Gesetzentwurfs über das Bayerische Heimatgesetz vom 11. September 1825 wird zitiert von Riedel 1881, S. 28.

127 Riedel 1881, S. 29. 
Bindungen mehr an sie gebe. ${ }^{128}$ In einer Reichstagsdebatte erklärt ein nationalliberaler, für den Unterstützungswohnsitz argumentierender Abgeordneter, dass sich mit „dem schönen deutschen Begriffe der Heimath“ des Heimatrechts keine Sicherheit verbinde, in Wahrheit werde ,dem Unterstützungsbedürftigen die letzte schöne, seinem Gemüth wohlthuende Ruhestätte seiner Heimath“ gerade nicht geboten. Denn das herrschende Recht „sichert sie ihm gar nicht, sondern führt ihn zurück an einen Ort, wo er nach der Empfindung seines Gemüths keine Heimath hat, wo er vielmehr sich fremd fühlt, wo er mißtrauisch und übelwollend empfangen wird“. Dem „deutschen gemüthlichen Heimathsgefühl“ werde mit dem Heimatrecht daher gerade nicht Rechnung getragen. ${ }^{129}$

Die sich auf eine Auseinandersetzung zwischen Nord- und Süddeutschland, Preußen und Bayern zuspitzende Debatte wird besonders ab den 1870er Jahren von den in die Defensive geratenen Bayern erbittert geführt. Was der Bezirksamtsassessor Münch 1880 in der Allgemeinen Zeitung schreibt, bildet zugleich einen Beleg für die oben vertretene These, dass Heimat auch im rechtlichen Sinn die vehement gegen die Unterschicht verteidigte Sphäre des Bürgertums ist:

Kennt der Norddeutsche [...] überhaupt den Begriff Heimat nicht und weiß er nicht, welch sittlichen Halt einem Menschen das Bewußtsein gibt, einen bestimmten Fleck Erde seine Heimat nennen zu dürfen, in einem nicht zu großen Kreise von Menschen, welchen er meist persönlich kennt und wo er gekannt ist, eine Heimat zu haben, wo er geboren wurde, wo seine Eltern und Geschwister leben, wo er selbst wieder von dem Trubel der Welt ausruhen, sich erholen, sich vielleicht dereinst ganz zur Ruhe zu setzen hofft, wo er aber auch in Zeiten der Not unter allen Umständen Hilfe und persönliche Aufnahme finden wird? Man komme mir nicht mit den Hunderten von Ausnahmen, mit den Großstädtern, Fabrikarbeitern und dergleichen, bei welchen diese Voraussetzungen nicht zutreffen und für welche daher auch das Wort Heimat nicht diesen Klang, nicht diesen inneren sittlichen Wert hat. Die Großstädter und Fabrikarbeiter bilden nicht die Mehrheit der Bevölkerung in Deutschland. ${ }^{130}$

Die Verfechter des bayerischen Sonderwegs bedienen sich auch noch in Zeiten der Weimarer Republik sentimentaler Heimatvorstellungen, um ihrem Widerstand gegen die Abschaffung des Heimatrechts eine zivilisationskritische Wendung zu

128 Motive zu dem Gesetz-Entwurf wegen der Verpflichtung zur Armenpflege, ALWL, Bestand 101, Nr. 373, f. 83-83v. Zitiert nach Lerche 2009, S. 51.

129 Rede des nationalliberalen Abgeordneten Eduard Stephani im Reichstag am 14. Mai 1870, zitiert nach Althammer 2021. Althammer kann mit weiteren Quellen die Emotionalität der Debatte um Unterstützungswohnsitz und Heimatrecht und die stark wertende Besetzung des HeimatBegriffs in beiden Lagern belegen, vgl. Althammer 2021.

130 Münch 1924, S. 86. Münch zitiert hier seinen Vater, den Bezirksamtsassessor Münch, und zwar dessen Artikel zu Unterstützungswohnsitz und Bettel, der 1880 in der Allgemeinen Zeitung erschienen ist (ein präziserer Stellennachweis für das Zitat unterbleibt allerdings). 
verleihen. Der Staatsrechtler Hans Nawiasky (seit 1914 Professor für Staatsrecht in München und später einer der Väter der Verfassung des Freistaates Bayern von 1946) wertet 1923 die juristischen Entwicklungen der zweiten Hälfte des 19. Jahrhunderts als „Vernichtung des Heimatbegriffs in Deutschland“ und meint damit mehr als die administrativen Änderungen in der Regelung der Armenfürsorge. ${ }^{131}$ Amtsrichter Münch publiziert 1924 einen Artikel in der Zeitschrift für Rechtspflege in Bayern, der angesichts des bevorstehenden unwiderruflichen Endes des Heimatrechts auch in Bayern, das durch die im selben Jahr verabschiedete Verordnung über die Fürsorgepflicht deutlich geworden ist, ein kulturpessimistisches Resümee zieht: Gepocht wird zunächst darauf, dass „der Gesetzgebung eines Volkes [...] symbolische Bedeutung für seinen inneren Werdegang“ zukomme, insofern sie „mit den tieferen Werten des menschlichen Lebens“ in Verbindung stehe. ${ }^{132}$ Diese „ethische“ Auffassung, die „Recht und Sittlichkeit eines Volkes in einem engen Zusammenhang miteinander“ sehe, wird mit dem ehemaligen Heimatrecht assoziiert und gegen die „moderne Anschauung“ verteidigt, „daß der Staat als bloßer ,Verwaltungsstaat' sich nur um die Zweckmäßigkeit und augenblickliche Nützlichkeit seiner Maßnahmen zu bekümmern“ habe. Die juristische Heimat wird explizit mit einem ethischen Verständnis von Heimat verschmolzen; Münch zufolge gibt sie ,sittlichen Halt' und ,inneren sittlichen Wert‘, der allerdings nicht allen begreiflich sei: nicht dem Norddeutschen, nicht dem Großstädter, nicht dem Fabrikarbeiter. ${ }^{133}$ Mit dem alten bayerischen Heimatrecht habe jeder gewusst, „wo er hingehörte“, es habe „die denkbar innigste Verbindung zwischen dem Unterstützungsbedürftigen und dem Träger der Unterstützungspflicht“ bestanden. Die Schwächung dieses Prinzips sei eine „verhängnisvolle[ ] Entwicklung, die man als die Loslösung des Rechts von den sittlichen Idealen eines Volkes“ bezeichnen könne. Der „an seelischen Werten reiche[ ] Begriff der Heimat“ sei „dem farblosen Begriff des Unterstützungswohnsitzes“ - und in der Folge dem der Fürsorgepflicht - geopfert worden. ${ }^{134}$ Die rechtliche Heimat wird mit der Seele, die bürokratischen Termini von Unterstützungswohnsitz und Fürsorgepflicht werden dagegen mit den zentrifugalen Kräften assoziiert, die zur „Atomisierung“ der Gesellschaft und zum „Zerfall des Staates“ führten. Der „Zusammenhang des Volkes mit dem Grund und Boden der Heimat, mit der heimatlichen Scholle“ sei zerrissen. ${ }^{135}$

131 Rehm/Nawiasky 1923, S. 215.

132 Beide Zitate Münch 1924, S. 85.

133 Alle Zitate Münch 1924, S. 86.

134 Alle Zitate Münch 1924, S. 86.

135 Alle Zitate Münch 1924, S. 87. 
Die juristische Rede über Heimat ist im 19. Jahrhundert nicht von der emphatischen, teils moralisierenden, teils sentimentalisierenden, teils anthropologisierenden Rede über Heimat zu trennen, denn sie bedient sich ihrer Argumente, Begriffe und Metaphern. Während das bisher behandelte Textkorpus zum allergrößten Teil juristischen Fachzeitschriften und Abhandlungen fürs Fachpublikum, Handbüchern für die Rechtspraxis der Verwaltung sowie ministeriellen Gesetzentwürfen und deren juristischen Kommentierungen entnommen ist, wird im Folgenden die Perspektive geändert und gezeigt, welche Rolle das Heimatrecht in der Belletristik des 19. Jahrhunderts spielt.

\subsection{Heimatrecht und Literatur}

Sucht man das Heimatrecht in der schönen Literatur vor 1800, wird man höchstens in Texten fündig, die auf der Schwelle zwischen Juristischem, Alltagssprachlichem und Literarischem angesiedelt sind, etwa in den pragmatischen Schriften Justus Mösers. Der Jurist, der praktischen Rat zur Verbesserung des Allgemeinwesens für die breitere Öffentlichkeit publizierte und dabei zugleich Literatur schuf, steht in der Tradition des frühaufklärerischen Patriotismus (vgl. I.2.1), in dem der Einsatz fürs Allgemeinwohl sich auf die konkrete eigene Umgebung (in diesem Fall Osnabrück) bezog, idealerweise aber auch darüber hinaus fruchtbar werden sollte. ${ }^{136}$ Der so verstandene Patriotismus ist streng pragmatisch und basiert nicht auf der Annahme besonderer Vorzüge der eigenen Zugehörigkeit (im Gegensatz zum Nationalismus des 19. Jahrhunderts, vgl. I.2.1). ${ }^{137}$ In Mösers Patriotischen Phantasien (ab 1766;1774) fallen die Begriffe Patriotismus, Vaterland, Provinz, Nation sehr häufig, der Begriff der Heimat wird bis auf wenige Ausnahmen gar nicht verwendet. Ist dies doch der Fall, hat der Begriff einen neutral beschreibenden Charakter: Wenn es um Vorschläge zur Regelung des Hausierens geht und die damit verbundene Unterscheidung von Waren, die aus der Heimat kommen, und solchen, die aufgekauft sind, ${ }^{138}$ oder wenn es in ähnlichen ökonomischen Kontexten um den Handel mit England ${ }^{139}$ oder die Vor- und Nachteile der Neuansiedlung von Bauern in Westfalen geht, ${ }^{140}$ dann bezeichnet Heimat eine

136 Vgl. das Vorwort zu den Patriotischen Phantasien: Möser 1780.

137 Vgl. Stauf 1991.

138 Vgl. Möser 1780, S. 230 -231. Im regionalen Wortschatz Mösers ist hier nicht vom Hausierer, sondern vom Packenträger die Rede.

139 Vgl. Möser 1780, S. 270-274.

140 Bei Möser werden die aus dem Rheinland stammenden neuen Siedler als Kolonisten, Emigranten und Fremdlinge bezeichnet. 
verwaltungstechnische Größe. In seiner Osnabrückischen Geschichte beschreibt Möser als Folge des regionalen Rechts („Märkerrecht“), dass es unmöglich gewesen sei, „einen Mann außerhalb seiner Heimat zu Recht zu stellen“, sofern er auf freies Geleit reiste. ${ }^{141}$ Nur ein Knecht habe unter diesen Bedingungen verurteilt werden können. Entsprechend heißt es über die Ursachen des Leibeigentums: „Die Furcht, ein Wildfang ${ }^{142}$ zu werden, zwang den Knecht zu bleiben und machte jede Heimat angenehm, eher und bevor Städte eine Zuflucht der Flüchtlinge wurden und Menschen ohne Acker und Pflug ernährten. “ ${ }^{143}$ Das ,Angenehme“ der Heimat resultiert also aus der gesicherten Rechtsgrundlage des Verhältnisses zwischen Leibeigenem und Herrn. Aus dieser (für einen Leibeigenen allerdings minimalen) Sicherheit, die an ein bestimmtes Territorium gebunden war (das nicht notwendig der Geburtsort, sondern der Ort der Leibeigenschaft war), erwächst also ein positives Verhältnis zur Heimat. ${ }^{144}$ Diese nüchterne Diagnose, die die Liebe zur Heimat aus einem bestehenden Rechtsverhältnis zwischen Leibeigenem und Herrn und einer daraus entspringenden Sicherheit ableitet, ist umso bemerkenswerter, als sie sich ja bereits innerhalb eines patriotischen Diskurses bewegt. Besondere Emphase hingegen, etwa emphatischer Patriotismus, verbindet sich bei Möser an keiner Stelle mit ,Heimat‘.

Die Bedeutung von Heimat, die sich noch in der Zeitgenossenschaft Mösers zu etablieren beginnt, schlägt dann ein grundsätzlich neues Kapitel in der Semantik von Heimat auf. Es liegt nahe, dass dieser neue, auf der religiösen Semantik aufsattelnde Heimatbegriff das Wissen um dessen rechtliche Dimension zunächst so gut wie gar nicht aktiviert, da sich die zunehmend mit dem Begriff konnotierten Heilungs- und Ganzheitsvorstellungen schwerlich mit der administrativen Bedeutung in Einklang bringen lassen. Und die gezielte Suche bestätigt: Die rechtliche Dimension von Heimat ist im Zusammenhang mit Heimat um 1800 nicht relevant. Erstmals in den 1840er Jahren verschränken sich literarische und rechtliche Bedeutungen von Heimat in nennenswertem Umfang.

Diese Verschränkung speist sich aus einer Vielzahl von Faktoren und erfüllt eine ganze Reihe von Funktionen. Der Beginn der literarischen Aufmerksamkeit

141 Beide Zitate Möser 1964, S. 78-79. Weitere Beispiele für die Verwendung des Terminus ,Heimat‘ im Kontext der Rechtsprechung vgl. Möser 1964, S. 227.

142 In der mittelalterlichen und frühneuzeitlichen Rechtssprache ist der Wildfang eine Person ohne eigenen Leibherrn, die aus einer anderen Gegend zugezogen ist und deshalb Leibeigener des Ortsherrn wird.

143 Möser 1964, S. 110.

144 Dies legt auch die zugehörige Anmerkung nahe: „Die Liebe zum Vaterlande ist in einem Zeitpunkt berühmt geworden, wo man in der Fremde ohne Geleit nichts als Wildfang oder Knecht sein konnte.“ Möser 1964, S. 111. Vaterland und Heimat sind hier synonym verwendet, vgl. I.2.1. 
auf das Heimatrecht ab den 1840er Jahren korrespondiert zunächst mit einer zunehmenden lebensweltlichen Relevanz des Themas, die sich aus wachsenden Bevölkerungszahlen, steigender Mobilität und der dadurch zugespitzten Anwendungsproblematik des Heimatrechts ergab. Die großen Auswanderungswellen und Binnenmigrationen begannen in den 1830er Jahren. Parallel dazu stieg auch die Publikationsdichte juristischer Schriften zum Heimatrecht und die Frequenz, in der das Heimatrecht regional modifiziert, angepasst und reformiert wird.

Im selben Zeitraum lässt sich erstmals eine Metaphorisierung der Rede vom Heimatrecht in der Alltagssprache belegen. Ein Heimatrecht zu haben, meint dann auch in einem übertragenen Sinne, heimisch zu werden: So heißt es in Karl Gutzkows Zeitschrift Unterhaltungen am häuslichen Herd 1853 in einem Artikel über den kaiserlichen Tiergarten in Schönbrunn, es seien dort gegenwärtig „viele Raub-, Sumpf- und Wasservögel, verschiedene Hühner- und Taubenvölker aus allen Ländern der Erde“ zu bewundern, „die aber bei uns Bürger- und Heimatsrechte erlangt haben“. ${ }^{145}$ Diese Aspekte können aber noch nicht hinreichend erklären, warum das, wie gezeigt, schon lange vorher virulente Heimatrecht plötzlich in relevantem Umfang in der Literatur auftaucht.

Wichtiger sind die Neuerungen im literarischen Feld selbst: Die Aufnahme des rechtlichen in den literarischen Heimatbegriff fällt zusammen mit dem Beginn von ,realistischen ${ }^{6}$ Weltentwürfen in der Literatur. ${ }^{146}$ Die Autoren von Romanen, Erzählungen, Gedichten, Theaterstücken greifen nun einen lebensweltlichen, pragmatischen Bedeutungsaspekt von Heimat auf, der in der literarischen Semantik von Heimat vor 1840 keine Rolle gespielt hat. Dies ist auch als direkter Reflex auf die beginnende Emphatisierung von Heimat ab $1800 \mathrm{zu}$ interpretieren.

$\mathrm{Zu}$ einem Element der Handlung wird das Heimatrecht in den 1840er und 1850er Jahren zunächst in Prosatexten bei Berthold Auerbach und Gottfried Kinkel, in den 1850er Jahren bei Fritz Reuter, Adalbert Stifter, Hermann Kurz und Gottfried Keller; in den 1860er bei Robert Schweichel und Friedrich Gerstäcker, in den 1880er bei Ludwig Ganghofer, in den 1890er Jahren bei Wilhelm Raabe und noch Anfang des 20. Jahrhunderts bei Clara Viebig. Die Texte dieser Autoren eint, dass sie sich im Zusammenhang mit dem Heimatrecht vornehmlich den armen

145 Beide Zitate Wegener 1853, S. 294.

146 Der literarische Realismus zeichnet sich insgesamt durch seine Affinität zu Fragen des Rechts aus, und es ist kein Zufall, dass dem frühen Realisten Jeremias Gotthelf eine ganze Abhandlung zu seiner Kritik ,am zeitgenössischen bernischen Recht“ gewidmet ist, vgl. Dürrenmatt 1947. Mit den hier interessierenden Fragen beschäftigen sich in Bezug auf Gotthelf besonders die Kapitel zur „Gemeindegesetzgebung“ und zum „Armenwesen“, allerdings ohne direkte Bezugnahme auf das Heimatrecht, vgl. Dürrenmatt 1947, S. 100-108 und 108-120. 
Bevölkerungsschichten widmen. Bei Auerbach oder Keller, Kinkel, Reuter, Kurz, Schweichel, Gerstäcker oder Viebig sind es die armen Landbewohner, bei Stifter ist es der wohlhabende bürgerliche Großstädter, der sozial abstürzt, bei Raabe der kleinstädtische Kleinbürger, dessen Existenzbedingungen prekär sind. Dieses sozial-ökonomische Setting liegt angesichts des realistischen Anspruchs der Texte nahe, denn das Heimatrecht kam, wie gesehen, gerade im Zusammenhang mit dem Armenrecht in Anwendung.

Die realistische Darstellung der Welt geht oft mit der Kritik an den sozialen Verhältnissen einher, wie etwa bei Fritz Reuter, Gottfried Kinkel, Robert Schweichel und Hermann Kurz, allesamt Autoren, die sich ans Heimatrecht knüpfende soziale Missstände aufdecken wollen; anders allerdings bei Friedrich Gerstäcker, wo die Auswirkungen des Heimatrechts eher als burleskes Element verwendet werden, ohne dass hier eine sozialkritische Intention naheliegen würde.

Der kritische Impuls muss sich nicht unbedingt (nur) gegen die sozialen Konsequenzen einer konkreten Rechtspraxis richten, sondern kann (zugleich) auch das emphatische Verständnis von Heimat hinterfragen. Denn in welchem Verhältnis soll ein nüchterner rechtlicher Heimatbegriff zum emphatischen stehen? Solche Fragen werfen die Texte Berthold Auerbachs auf. Hier wird durch eine Kontrastierung des emotionalen Gehalts von Heimat mit ihrer rechtlichen Bedeutung ein Widerspruch offengelegt. Gerade angesichts der literarischen Programmatik Auerbachs, die sich dezidiert gegen ein romantisches Literaturverständnis wendet, wird deutlich, dass es ihm um eine Neuvermessung des literarischen Feldes und eine Abgrenzung gegenüber ästhetischen Entwürfen der Romantik geht, zu denen auch Heimat zählt. Damit eröffnet er eine neue literarische Behandlungsweise von Heimat, unter deren Vorzeichen auch die Texte von Gottfried Keller, Adalbert Stifter, Wilhelm Heinrich Riehl und Clara Viebig stehen.

Die literarischen Auseinandersetzungen mit dem Heimatrecht stellen vor allem drei Personengruppen in den Mittelpunkt: die Gruppe der Bettler, versorgungsbedürftigen Alten und mittellosen Tagelöhner, die mit dem Heimatrecht in Berührung kommen, wenn sie abgeschoben werden (II.2.2.1); die Gruppe der Auswanderer, die durch ihre Auswanderung mit dem Heimatrecht konfrontiert werden (II.2.2.2); die Gruppe der Heimatlosen, denen das Heimatrecht grundsätzlich verweigert wird (II.2.2.3).

\subsubsection{Abschiebung und Heimatrecht: Tagelöhner, Bettler, Arme (Reuter, Riehl, Stifter, Viebig)}

Das Schubwesen des 19. Jahrhunderts stellt die praktische Durchsetzung des Heimatrechts sicher, da die Gemeinden sich mit diesem Mittel aller unliebsamen 
Personen entledigen konnten, die sie nicht rechtmäßig aufzunehmen hatten. Ein Eintrag in der Allgemeinen deutschen Real-Encyklopädie von 1845 zeigt, dass der Zusammenhang von Schubwesen und Heimatrecht zum Allgemeinwissen des 19. Jahrhunderts gehört:

\begin{abstract}
Am schwierigsten gehen einzelne Orte daran, Fremden das Heimatrecht durch Aufnahme zu bewilligen, weil sie immer an die Möglichkeit denken, daß die Versorgung Derer, welche etwa verarmen, der Ortsgemeinde zur Last falle. Da nun nach einem beinahe allgemeinen Prinzip der selbständige Aufenthalt an einem Orte, mit eigener Wohnung und Haushaltung, wenn er eine gewisse Reihe von Jahren gedauert hat, das Heimatsrecht gibt, so sind die Gemeinden sehr wachsam, Auswärtige, welche auf irgend eine Weise einen vorübergehenden Aufenthalt im Orte haben, vor Ablauf dieser Zeit zu entfernen, wodurch nicht selten die ganze bürgerliche Existenz einer redlichen und arbeitsamen Familie ohne alle Nothwendigkeit vernichtet wird. Gleichwol ist die unbedingte Annahme, daß jederzeit der Geburtsort die Versorgungspflicht haben solle, auch mit Härten und Unzuträglichkeiten verknüpft, indem hier der Verarmte oft aus seinen Verhältnissen gerissen und einem Orte, wo er vielleicht ganz unbekannt geworden, als eine hülflose unwillkommene Last zugeschoben wird. ${ }^{147}$
\end{abstract}

Die heimatrechtlich begründete Abschiebung, der Schub, konnte also, wie der Artikel klarmacht, denjenigen treffen, der keinen Anspruch auf Heimatrecht durch bloße Aufenthaltsdauer erwerben sollte und deshalb der Gemeinde verwiesen wurde, oder denjenigen, der fürsorgebedürftig wurde und dann zwangsweise in seine Heimatgemeinde abgeschoben wurde. Dass der Schub schon seit dem 18. Jahrhundert im offiziellen Verständnis immer weniger als Strafe, dagegen immer mehr als Fürsorgemaßnahme definiert wurde (so gibt es Aktennotizen, die vermerken, dass der Schub im Gegensatz zu einer selbst initiierten Reise in die Heimat kostenfrei sei), verhinderte nicht, dass er in der Praxis die Existenznöte verschlimmerte und zudem eine soziale Stigmatisierung der Schüblinge bedeutete. ${ }^{148}$

Die in diesem Kapitel versammelten Texte von Adalbert Stifter (Turmalin 1852), Fritz Reuter (Ein Heimathloser in Mecklenburg 1856/57), Wilhelm Heinrich Riehl (Vergelt's Gott 1862) und Clara Viebig (Die Heimat 1914) machen den Zusammenhang von Heimatrecht und Abschiebung zum literarischen Sujet.

\title{
Fritz Reuter: Ein Heimathloser in Mecklenburg
}

Fritz Reuter (1810 - 1874) zählt zu den Autoren, die als Heimatschriftsteller gelten, weil ihre Gegenstände lokal gebunden sind. Es zeigt sich an Reuter, dass die in der

147 Anonym 1845, S. 2.

148 Zum Schubwesen vgl. ausführlich Wendelin 2000, S. 231-339. 
Regel mit verharmlosenden und harmonisierenden Vorstellungen einhergehende Bezeichnung eines Autors als Heimatschriftsteller nicht immer überzeugend ist. Denn Reuter erweist sich mit den hier vorgestellten Texten als politisch engagierter Autor, der nicht an der Klischierung von Heimat, sondern an ihrer Kritik arbeitet. Angesichts des extremen Armutsmilieus, aus dem seine Figuren stammen, und angesichts des Anspruchs, dem ,Volk aufs Maul zu schauen', ließe sich stattdessen sogar begründet von einer Vorläuferschaft zum Naturalismus sprechen.

In Reuters tragisch endender Verserzählung Kein Hüsung (1857) wird die Willkür der Gutsbesitzer und die Unfreiheit der Tagelöhner thematisiert. Schrecklicher als eine Feuersnot sei die Gewalt, die der Gutsbesitzer über den Armen habe, denn er kann ihm nicht nur sein materielles Gut nehmen wie das Feuer, das ihn aufs ,freie Feld' wirft, wenn das Haus abbrennt, sondern ihm darüber hinaus die Heimat - eben im Sinn der Aufenthaltsberechtigung - verwehren und ihn ,elend in die Welt jagen':

\footnotetext{
Denn de em röppt, dat is sin Herr,

Vel schrecklicher, as Füersnoth.

Dat Füer, dat kann sin All'ns vertehren

Un smitt em up dat frie Feld;

Sin Herr kann't ok, doch sin Gebot,

Dat kann de Heimath em verwehren

Un jagt em elend in de Welt. - - ${ }^{149}$
}

Tatsächlich waren die heimatrechtlichen Verhältnisse in den beiden Großherzogtümern Mecklenburgs im 19. Jahrhundert besonders drückend, da es hier nach Abschaffung der Leibeigenschaft 1822 nicht zu einer Anpassung des Niederlassungsrechts kam, so dass die ehemaligen Leibeigenen nicht mehr durch ihre ehemaligen Herrschaften versorgt wurden, sich aber auch nicht frei ansiedeln und Gemeinde- und Heimatrechte erwerben konnten (vgl. II.2.1). ${ }^{150}$ Mecklenburg blieb bis 1918 von feudalen Strukturen geprägt und bestand aus drei verschiedenen Verwaltungstypen, dem Domanium (dem herzoglichen Besitz), der Ritterschaft (dem ritterschaftlichen Besitz) und der Landschaft (den Städten und ihrem städtischen Landbesitz), deren verwaltungsrechtliche Aufgaben allerdings nie befriedigend geklärt wurden. Der Pastor von Badendiek, einem domanialen Bauerndorf bei Güstrow, schreibt in seinem jährlichen Informationsbericht an die Superintendantur Güstrow im Juni 1861: „Die himmelschreienden Mißbräuche der

149 Reuter: Kein Hüsung, 1904, S. 29.

150 Vgl. Koch 1997; Pade 2004, mit Verweis aufs Heimatrecht S. 62. 
Heimats- und Niederlassungsverhältnisse in den Domanialbauerndörfern wirken entvölkernd und demoralisierend und zerrüttend auf Sittlichkeit, Familienleben, Vertrauen nach Oben, Liebe zum Lande." ${ }^{151}$ Die Heimatrechtspraxis ist nach Ansicht des Pastors also eben gerade nicht die ,Pflanzschule' des Bürgersinns, als die sie ein Ministerialbeamter 1825 gesehen haben wollte. ${ }^{152}$

Reuters Text Ein Heimathloser in Mecklenburg (1862) ${ }^{153}$ stellt eine literarische Kritik solcher aus dem Heimatrecht erwachsenden sozialen Missstände dar. Die „Tatsache“, von der im Stil des kommentierten Berichts in diesem Text die Rede ist, dient dem Autor als Beispiel für „die Misere unserer deutschen Heimatsverhältnisse“, auch wenn infolge der 1851 geschlossenen Gothaer Konvention immerhin Aussicht auf Besserung bestehe. ${ }^{154}$ Schon der einleitende Vorbericht gibt einen Eindruck vom Stil des weiteren Textes:

Es ist genug, daß dergleichen Fälle - und gewiß nicht vereinzelt - dem Begriff vom einigen deutschen Vaterlande arge Stöße versetzt haben, und daß das komische Element, welches wir darin finden müssen, wenn mächtige Regierungen sich mit erhitzten Noten und drohenden Demonstrationen abquälen, um Bagatellsachen zu beseitigen, bei weitem durch die Tragik überboten wird, die das Haupt des unbeschützten einzelnen trifft. - Kurz! Die Sache wäre lächerlich, wenn sie nicht so traurig wäre. ${ }^{155}$

Zwischen Tragik und Komik bewegt sich dieses Stück literarisch verarbeiteter Realität. Die Signale der Unzuverlässigkeit, die der Text enthält, verweisen weniger auf seine Fiktivität als auf den exemplarischen Status des Falls, bei dem es deshalb nicht auf die Exaktheit der Details ankommt: Ein Tagelöhner mit dem Namen „Krischan Schult, Meier oder Müller“ erhält „1850 oder 1851“ die Kündigung vom Gut Käseke, Demminer Kreis in Vorpommern (Preußen) und wird,

151 Zitiert nach Koch 1997, S. 79.

152 Vgl. II.2.1. Die ministerielle Kommentierung des Gesetzentwurfs über das Bayerische Heimatgesetz vom 11. September 1825 wird zitiert von Riedel 1881, S. 28.

153 Fritz Reuters Text wurde in der hier angegebenen Schreibweise des Titels in Gustav Freytags und Julian Schmidts Die Grenzboten (21. Jg., 1862) veröffentlicht - in dieser Zeitschrift werden zugleich in Sachbeiträgen auch mehrfach Fragen des Heimatrechts berührt (vgl. I.1.3). Ich zitiere nach den Sämtlichen Werken von 1904, die die Schreibweise zu Ein Heimatloser in Mecklenburg angleichen.

154 „Ob die nachstehende Tatsache der alleinige zwingende Grund oder nur eine Veranlassung mehr war, daß Mecklenburg sich der am 15. Juli 1851 geschlossenen, sogenannten Gothaer Konvention ,über die gegenseitige Übernahme Ausgewiesener` anschließen mußte, wollen wir unentschieden lassen, da es im ganzen gleichgültig ist, an welchem Beispiele die Misere unserer deutschen Heimatsverhältnisse zuerst so recht deutlich ans Tageslicht getreten.“ Reuter: Ein Heimatloser, 1904, S. 25.

155 Reuter: Ein Heimatloser, 1904, S. 25. 
nachdem er neun Jahre dort gewohnt hat, mit Frau und sieben Kindern auf die Straße gesetzt. ${ }^{156}$ Da er vorher auf dem ritterschaftlichen Gut des Grafen Blessen auf Ivenack in Basepohl (Mecklenburg) gelebt hat, wird er dorthin abgeschoben, dort aber nicht aufgenommen und innerhalb Mecklenburgs von der Ritterschaft zum Domanium abgeschoben - ohne Erfolg: „Er mag tausendmal ein Mecklenburger sein, wenn er nicht aus dem Domanium gebürtig ist, können wir uns mit der Sache gar nicht befassen; der Kerl gehört der Ritterschaft an; fort mit ihm dahin, woher er gekommen ist!“157 „Die Herren hatten recht“, erläutert nun der Erzähler im sarkastischen Ton, „denn Mecklenburg scheidet sich in drei Landesteile, großherzogliches Domanium, Ritterschaft und Städte, die unter sich vice versa die Heimatsgesetzgebung energischer aufrecht erhalten, als dies sogar einem fremde Staate gegenüber geschieht [...].“"158 Fünf Mal wird Krischan Schult mit seiner Familie wieder nach Demmin/Preußen abgeschoben, fünf Mal zurück nach Mecklenburg verfrachtet. Dann nimmt sich die preußische Regierung der Sache an und fragt bei der mecklenburgischen Regierung an, welche gesetzlichen Bestimmungen

\begin{abstract}
in bezug auf die nach Preußen ausgewanderten und dort nicht naturalisierten Landeskinder in den mecklenburgischen Landen geltend wären. - Die Antwort war, daß alle, die zwei Jahre oder länger abwesend wären, oder im Auslande einen eigenen Hausstand gegründet hätten, als aus dem Untertanenverbande ausgeschieden betrachtet würden. Und - fragte Preußen weiter - unter welchen Bedingungen erwerben die diesseitigen Landeskinder das Heimatsrecht in Mecklenburg? - Wenn sie fünfzehn Jahre ununterbrochen an einem und demselben Orte sich aufgehalten hätten, hieß es. / Dies war denn doch ein zu großes Mißverhältnis; die preußische Regierung drang auf gegenseitige Gleichheit in diesen Verhältnissen, und um ihrer Forderung mehr Nachdruck zu geben, drohte sie widrigenfalls alle über die Grenze gegangenen und nicht naturalisierten Mecklenburger, eventualiter mit Frau und Kind, auszuweisen und in ihr Geburtsland zurücksenden zu wollen. ${ }^{159}$
\end{abstract}

Dies hätte dreißig- bis vierzigtausend Personen betroffen, fügt der Erzähler an. So viele Personen hatten „nach mecklenburgischen Gesetzen in ihrem früheren Wohnort das Heimatsrecht verloren und in Preußen kein neues erworben" und wären, „falls man sie über die Grenze geschickt hätte, als Heimatlose dem Mecklenburgischen Landarbeitshause verfallen gewesen“. ${ }^{160}$ Denn das Landarbeitshaus, in diesem Fall das alte Wallenstein-Schloss zu Güstrow, war zuständig für alle Heimatlosen. Eben dieses Schicksal erleidet Krischan Schult schließlich:

156 Reuter: Ein Heimatloser, 1904, S. 25.

157 Reuter: Ein Heimatloser, 1904, S. 28.

158 Reuter: Ein Heimatloser, 1904, S. 28.

159 Reuter: Ein Heimatloser, 1904, S. 29.

160 Reuter: Ein Heimatloser, 1904, S. 29. 
Krischan Schult und seiner Familie wird die Aufnahme überall verweigert, „und so war er denn vor dem Gesetz ein heimatloser Vagabund, der ins Landarbeitshaus gehörte, dessen friedliche Räume ihn denn auch aufnahmen“. ${ }^{161}$ Wie das weitere Schicksal Krischan Schults verlaufen ist, weiß der Erzähler nicht. Es gehe um das „allgemeine Interesse“ ${ }^{162}$ das hinter diesem Fall stehe. Der distanziertberichtende Ton, durch sarkastische Untertöne grundiert - „Ganz in der Ordnung!“ heißt es beispielsweise immer, bevor eine neue ungeheuerliche Konsequenz der bürokratischen Verordnungen vom „Notenhimmel der Grenzbehörden“ und der „deutschen Polizei-Idylle“163 eintritt - lässt die Unerträglichkeit des Falls stärker hervortreten, als es eine mitfühlende Erzählung vermocht hätte. Mit der Aussparung jeder Innensicht der betroffenen Figur holt die Erzählung kalkuliert den Gegenstand ihrer Kritik ein: Die Figur wird zum rein administrativ kategorisierten Fall; ihre Ansprüche auf Individualität oder Emotionalität werden nicht anerkannt. Umso stärker wird ihre Ohnmacht betont. Aus ähnlichen Gründen wird wohl auch ein emphatisches Heimatverständnis im ganzen Text nicht aufgerufen.

\section{Wilhelm Heinrich Riehl: Vergelt's Gott}

Wilhelm Heinrich Riehl bietet zeitgleich das spät-biedermeierliche Gegenprogramm zum sozialkritischen Reuter (zu Riehl vgl. II.3.2). In seiner Novelle Vergelt's Gott (1863), die zwei Bettler zu ihren Hauptgestalten macht, ist selbst der Schub nur Kulisse einer beschaulichen Welt. ${ }^{164}$

Die Regelung für fremde - d.h. nicht ortsansässige - Bettler, die regelmäßig auf den Schub kommen, und die dadurch bedingte Konkurrenz der beiden Bettler Veit und Hans wird in der Novelle zum Ausgangspunkt der Handlung. Denn Veit hat gegenüber Hans einen ,beneidenswerten Vorzug: er war ein Augsburger Stadtkind; die eingeborenen Bettler aber duldete man dauernd, während die

161 Reuter: Ein Heimatloser, 1904, S. 29-30.

162 „Ob er später ein anderweitiges Unterkommen gefunden hat, ob er wieder mit seiner Familie vereinigt worden ist, wissen wir nicht. Wir haben diese Geschichte nur so erzählt, wie das allgemeine Interesse, welches begreiflicherweise dieser eklatante Fall, namentlich bei den Ausgewanderten, hervorrufen mußte, sie zu jener Zeit täglich besprach. / Man hat nachträglich behauptet, Krischan Schult sei ein Taugenichts gewesen, aber ändert das etwas an der Sache selbst? Und - wäre er ein dreimal geschliffener und facettierter Tugendspiegel gewesen, eingefaßt in den vergüldeten Rahmen frommer Denkungsart, wäre er nicht in dieselbe Lage gekommen?“ Reuter: Ein Heimatloser, 1904, S. 30.

163 Alle Zitate Reuter: Ein Heimatloser, 1904, S. 27.

164 Zum Schubwesen vgl. II.2.1; insgesamt zu Armut und Bettel im 19. Jahrhundert vgl. Althammer 2007. 
fremden so eins ums andere Jahr aus der Stadt geschafft wurden“. ${ }^{165}$ Dieses Los droht wiederum Hans, der „selbst nicht wußte, wo er zur Welt gekommen“ und deswegen vom Schub bedroht ist. Er findet allerdings Mittel, sich dem Schub regelmäßig zu entziehen: „Hans behauptet zuletzt, er sei zwar kein Eingeborener, aber auch kein Fremder, sondern ein Adoptivkind der Reichsstadt Augsburg.“ Wenn Hans beim Ort seines Bettelns und damit bei seinem Heimatrecht nachhilft, tut Veit es beim Grund seines Bettelns, denn er spielt seine Verkrüppelung nur. Veit und Hans sind Spiegelgestalten: „Hans war ein natürlicher und Veit ein künstlicher Krüppel, Veit dagegen ein natürlicher und Hans ein künstlicher Augsburger." 166 Der Schub, dem sich der heimatlose Hans entzieht, erweist sich nicht als existenzgefährdend, wie er es realweltlich war, sondern dient dazu, auch das beschaulich geschilderte Bettlerleben in einen bürgerlichen Werthorizont einzupassen: Dass Hans nicht „fahrender Bettler“ werden und damit „gemeine Landstreicherart“ annehmen solle, begründet er gut bürgerlich: „In jedem Beruf ist der sesshafteste Mann der ehrenfesteste“. ${ }^{167}$

Veit gelingt im Verlauf der Novelle die Befreiung aus seinem Bettlerdasein, während Hans Bettler bleibt und als solcher stirbt. Aber erst der Tod von Hans bringt Veit die endgültige Aussöhnung mit der Bürgerlichkeit: Veit kann sich ein neues Dasein als Hausmeister aufbauen, fängt aber plötzlich an, sich nach seiner Existenz als Bettler zu sehnen und geht aus einer Mischung aus alter Gewohnheit und unklarer Sehnsucht wieder betteln. Der Pfarrer will ihn durch ein Gleichnis wieder von dieser „Krankheit“ befreien und auf den rechten Weg führen:

Wenn wir aus unserer Jugendheimat in ein viel schöneres Land gezogen sind, dann freuen
wir uns anfangs der Veränderung, finden alles gut und besser und denken kaum zurück an
die verlassene Gegend. Doch nach kurzer Zeit steigt die alte Heimat schön und immer
schöner, wie verklärt wiederum vor unserem Geiste auf, es friert uns in dem neuen Lande,
und drüben auf der verlorenen Ferne ruht warmer Sonnenschein; wir möchten davonlaufen,
so zieht es uns hinüber, wir möchten vergehen vor Heimweh. Das aber währt nur eine ge-
messene Frist, die wir mannhaft überwinden müssen. Allmählich verblasst das ferne, ge-
träumte Bild wieder von Selbst, wir freuen uns doppelt des Guten, welches uns umgibt, und

165 Riehl: Vergelt’s Gott (1863), in: Riehl 1937, S. 361-383, hier S. 364.

166 Alle Zitate Riehl 1937, S. 364-365.

167 Riehl 1937, S. 365. Heimatlosigkeit und Schubwesen werden anhand zweier Nebengestalten angedeutet, auch hier bleiben die sozialkritischen Implikationen aber dezent: „Zur selbigen Zeit lag ein heimatloses Mädchen im Spital, welches man fieberkrank aus einer Herberge gebracht hatte“; „das Mädchen [war] eine Betteldirne, und da vor etlichen Wochen ein starker Schub fremder Bettler aus der Stadt geschafft und die Mutter vermutlich mit ausgewiesen worden war, so konnte sie freilich ihr krankes Kind im Spitale nicht aufsuchen“. Riehl 1937, S. 376-377. 
zuletzt ist doch der Mann nur da ganz zu Hause, wo ihm Gott eine gesegnete Arbeit zugewiesen hat und gute Menschen ihn ehren in seinem Tagewerk. ${ }^{168}$

Die Notwendigkeit, sich in ein bürgerliches Leben zu fügen, wird hier als Verabschiedung der ,Jugendheimat‘ zugunsten einer ,mannhaften` Zuwendung zu einer von Gott gesegneten und soziale Anerkennung bringenden Arbeit gefasst. Die,wie verklärte',alte Heimat' sei nur ein ,fernes, geträumtes Bild'; dagegen gelte es, sich den realen Ansprüchen der eigenen Gegenwart zu stellen. Auch der Pfarrer selbst hat eine Jugendleidenschaft, die Dichtkunst, der er wider besseres Wissen nicht ganz entsagen kann und auf die das Gleichnis ebenfalls bezogen wird.

Die Sicht, dass die alte Heimat (also das vormalige, gleichsam kindlich-verantwortungslose Betteln bzw. das ebenfalls außerhalb der bürgerlich-ökonomischen Logik liegende Dichten) verabschiedet werden muss, wenn man sich den bürgerlichen Werten von Haus und Arbeit zuwendet (schon vorher prominent in Gustav Freytags Soll und Haben entfaltet, vgl. II.3.2.2, dort auch zu den Bezügen zwischen Riehl und Freytag), bestätigt sich erst über einen Umweg. Veit wird noch einmal betteln, der Pfarrer noch einmal reimen, diesmal aber auf geläuterte Art: Beide verrichten ihre Jugendsünde ein letztes Mal für einen anderen, den sterbenden Hans, und der Rückfall in die „Jugendheimat“ ist zugleich ihre Läuterung. Fortan kommen beide ohne Betteln und Dichten aus.

Die Aufstiegsgeschichte des Bettlers Veit ins bürgerliche Leben, sein Rückfall und seine erneute Eingliederung in die bürgerliche Ordnung werden seitens der Figur des Pfarrers in die Metapher der ,Jugendheimat' gefasst, die durch ein ,Zuhause' ersetzt werden muss, das in der Einbindung in eine bürgerliche (Arbeits-)Ordnung und dadurch bedingte soziale Anerkennung besteht. Das so verstandene Zuhause steht nicht im Widerspruch zur juristischen Heimat - im Gegenteil harmonieren beide miteinander. Das ,Heimweh` nach der ,alten Heimat‘ muss überwunden werden, das ,ferne, geträumte Bild‘ erweist sich als Chimäre: Hier findet eine gänzliche Absage an die romantische Heimat statt, die ganz durch eine des bürgerlichen Realismus ersetzt worden ist.

\section{Adalbert Stifter: Turmalin}

In Adalbert Stifters Turmalin (1852), der dritten Erzählung der Bunten Steine, sind Heimatrecht und Schub nicht nur harmlose Kulisse einer bürgerlichen Welt wie bei Riehl, sondern werden zur Chiffre bürgerlicher Ordnung. Nur in einem einzigen Satz ist von den Behörden, die für die Heimatlosen zuständig sind, die

168 Riehl 1937, S. 376. 
Rede - er ist gleichwohl entscheidend, weil er die Berührung des gutbürgerlichen Subjekts mit den Rändern der bürgerlichen Ordnung markiert, aus der es selbst im Folgenden herausfallen wird. Das ,Lapidarium des Wissens ${ }^{6}{ }^{169}$ das die Forschung in Stifters Bunten Steinen erblickt, ist demnach um einen rechtsgeschichtlichen Aspekt zu ergänzen.

Die Erzählung spielt um 1850 und beginnt in Wien, wo die Ehefrau des wohlhabenden, gutbürgerlichen Rentherrn spurlos verschwindet. Daraufhin zeigt er die Sache bei den Behörden an: „Aber auch die Ämter fanden nichts, und unter den Verunglükten, die sich vorfanden, war sie nicht, und unter den Aufgefundenen, die sich als heimathlos auswiesen, war sie nicht. " 170 Bei seinem Gang auf die Wiener Behörden kommt der Rentherr also mit der administrativen Kategorie der Heimatlosigkeit in Berührung. Der Kommentar zur historisch-kritischen Ausgabe schweigt zu dieser Stelle. Folgendes wäre dazu zu sagen: In Wien hatte die Heimat- und die damit verbundene Abschiebepolitik schon um die Jahrhundertmitte drastische Ausmaße angenommen. Die Zahlen für 1851 zeigen die Dringlichkeit des Problems: In Niederösterreich, inklusive Wien, sind in diesem Jahr 20 Prozent der in der Stadt lebenden Personen fremd, haben ihre Heimat also anderswo (im Jahr 1900 sind es dann 60 Prozent). ${ }^{171}$ Diejenigen aus dieser Gruppe, die als Bettler, Landstreicher oder anders auffällig geworden sind, werden mittels des Schubwesens aus Wien entfernt. 1846 sind es 3.392 Personen, die mit dem sogenannten Hauptschub aus Wien abtransportiert werden, weitere Personen kommen in den sogenannten Partikularschüben hinzu, 1867 sind es dann schon 10.118 Personen. ${ }^{172}$

Der Rentherr fällt durch den nicht aufklärbaren Verlust seiner Frau in eine tiefe Krise. Er verlässt zusammen mit seinem kleinen Kind die großbürgerliche Wohnung und lässt mit seinem sämtlichen Besitz auch die eigene bürgerliche Identität zurück. Er wird einer der Heimatlosen, unter denen er seine Frau nicht finden konnte.

Das zentrale Thema der Erzählung ist die Bedrohung von Ordnung, wie schon einleitend herausgestellt wird. Der Erzählung sei zu entnehmen, „wie weit der Mensch kömmt, [...] wenn er von dem innern Geseze [sic], das ihn unabwendbar

169 So der Untertitel des Buchs von Benjamin Bühler und Stefan Rieger zu Stifters Bunten Steinen, Bühler/Rieger 2014. Albrecht betont die „Vielzahl von ästhetischen, politischen, pädagogischen und naturwissenschaftlichen Diskursen“, die in Turmalin überblendet werden (Albrecht 2017, S. 87).

170 Adalbert Stifter: Turmalin, in: Stifter 1982, S. 133-179, hier S. 144.

171 Vgl. Hahn 2005, S. 30.

172 Vgl. Wendelin 2000, S. 286. Bis 1850 war das Kreisamt, nach 1850 die sogenannte Stadthauptmannschaft die für die Schüblinge zuständige Stelle, vgl. Wendelin 2000, S. 242. 
zu dem Rechten führt, läßt, sich unbedingt der Innigkeit seiner Freuden und Schmerzen hingibt, den Halt verliert, und in Zustände geräth, die wir uns kaum zu enträthseln wissen.“ Hier geht es um die innere Ordnung, die inneren Gesetze eines Menschen, die gefährdet sind und deren Verlust zu Haltlosigkeit führt diese Haltlosigkeit ergebe sich für denjenigen, dem das „Licht seiner Vernunft“ getrübt sei und der „die Dinge nicht mehr versteht“. ${ }^{173}$ Und es geht um die Rätselhaftigkeit dieses Zustandes für diejenigen, die innerhalb der Ordnung verbleiben.

Tatsächlich sind die späteren Eindrücke von jenem heruntergekommenen Mann ungeklärter Identität, die aus der Perspektive einer Großbürgerin wiedergegeben werden, für diese hochgradig unangenehm und verwirrend, auch und gerade, weil sie teilweise Anziehendes enthalten, so wie dessen „seltsames Flötenspiel“, das sie und ihr Mann eines Nachts hören. Dieses Spiel weiche von allem ab, „was man gewöhnlich Musik nennt, und wie man sie lernt“. Dies hat etwas Anziehendes und Abstoßendes zugleich: „Was am meisten reizte, war, daß, wenn er einen Gang angenommen, und das Ohr verleitet hatte, mit zu gehen, immer etwas anderes kam, als was man erwartete, und das Recht hatte, zu erwarten [...]. “174 Erst später wird geklärt, dass es sich bei dem Flötenspieler um den ehemaligen Rentherrn gehandelt hat. So wie die Erzählerin „etwas Fremdartiges“ in dem Flötenspiel entdeckt und durch dieses in „eine Verwirrung gerieth, die man beinahe irrsinnig hätte nennen können“, ${ }^{175}$ wirkt auch die Bekanntschaft mit dem Mädchen, das sich später als die herangewachsene Tochter des Rentherrn erweist, verstörend in ihrer Gemengelage von Abstoßung und Anziehung. Die Gedanken des Mädchens seien ,von Allem, was sich immer und täglich in unserem Umgange ausspricht“, derartig verschieden, „daß man das Ganze für blödsinnig hätte halten können, wenn es nicht zum Theile wieder sehr verständig gewesen wäre“. ${ }^{176}$ Sowohl das Flötenspiel des vormaligen Rentherrn als auch die Redeweise seiner Tochter lösen bei der Erzählerin ein diffus empfundenes Unbehagen aus, denn sie bieten etwas anderes, „als was man erwartete, und das Recht hatte, zu erwarten“. Das Gehörte wirkt „,beinahe irrsinnig“ und „blödsinnig“, aber scheint doch unbekannten und deshalb suspekten Regeln zu unterliegen.

In der weiteren, durchgängig aus der Perspektive der homodiegetischen Erzählerin wiedergegebenen Schilderung, wird diese Störung eliminiert und Ordnung wiederhergestellt. Dies kommt für die Erzählerin selbst einer existentiellen

173 Alle Adalbert Stifter: Turmalin, in: Stifter 1982, S. 133-179, hier S. 135.

174 Stifter 1982, S. 152-153.

175 Beide Stifter 1982, S. 153.

176 Stifter 1982, S. 164. 
Notwendigkeit gleich. Hatte das Flötenspiel des zum Heimatlosen gewordenen Rentherrn diese nur „beinahe gerührt“, vor allem aber verstört, ${ }^{177}$ gibt ihr sein Tod wieder die Möglichkeit der Rücküberführung der Geschehnisse in eine überschaubare Ordnung. Der detaillierten Schilderung aller ärztlichen und behördlichen Schritte zur Dokumentation seines Todes eignet eine gewisse Beruhigung, ja Befriedigung.

Mit großer erzählerischer Detailtreue rückt die Resozialisierung jener Tochter ins Zentrum des Textes, die ohne jede andere soziale Bindung mit ihrem Vater in einem feuchten Kellerzimmer hauste, bis er starb. ${ }^{178}$ Breitesten Raum gibt die Erzählerin den Nachforschungen zur bürgerlichen Identität des Mädchens, der medizinischen und psychologischen Betreuung, die den langsamen Aufbau von Vertrauen, ihre Überführung aus dem Kellerloch zurück in die bürgerliche Welt mit weiblichen Nadelarbeiten und Übungen im Katechismus umfasst. Mit der Erfüllung dieses pädagogischen Auftrags, das heißt mit der aus Sicht der Erzählerin zutiefst befriedigenden Wiedereingliederung des Mädchens in die bürgerliche Ordnung endet der Bericht. - Eingliederung in eine (heimatliche) Gemeinschaft ist immer wieder das Telos von Stifters Erzählungen. ${ }^{179}$ Die aus der bürgerlichen Ordnung Ausgebrochenen bleiben in Turmalin verschollen (die Ehefrau des Rentherrn), sind gestorben (der Rentherr) oder werden in die alte Ordnung überführt (die Tochter). Die Ordnungsverweigerung bleibt rätselhaft, erhält aber keinen romantischen Glanz. Das Flötenspiel des vagabundierenden Rentherrn ist - wie das Geigenspiel des ,schwarzen Geigers' bei Gottfried Keller (II.2.2.3) - nicht das des romantischen Vagabunden, sondern belästigend und verstörend. Und so wie der Tod des Rentherrn von der Erzählerin beinahe als befreiend dargestellt wird, sind es auch die Wiedereingliederungsbemühungen an dessen Tochter. Denn die Infragestellung der bürgerlichen Ordnung, die in der Existenz der Heimatlosen liegt, kann so abgewendet werden.

Stifters heimatlose Gestalten sind solche, die nicht Mitleid, sondern Irritation auslösen und verstören. Dies verbindet seinen Text mit denen von Hermann Kurz

177 Stifter 1982, S. 153.

178 Die Nähe zum Kaspar-Hauser-Stoff arbeitet Eva Geulen heraus, vgl. Geulen 1993, S. 651. Das Kind als „Objekt eines umfassenden Resozialisierungsprogramms“, das sich zuletzt wieder „auch ökonomisch in eine bescheidene bürgerlich-biedermeierliche Existenz" fügt, bildet auch einen Fokus der Interpretation von Tim Albrecht. Albrecht 2017, S. 89.

179 In der Erzählung Bergkristall werden die beiden Kinder Konrad und Susanna, deren Mutter aus dem Nachbartal kommt und deswegen in ihrem Dorf als Fremde gilt, erst nach einer lebensgefährlichen Katastrophe in den Bergen in die Dorfgemeinschaft aufgenommen: „Die Kinder waren von dem Tage an erst recht das Eigenthum des Dorfes geworden, sie wurden von nun an nicht mehr als Auswärtige sondern als Eingeborne betrachtet, die man sich von dem Berge herab geholt hatte.“ Adalbert Stifter: Bergkristall, in: Stifter 1982, S. 181-240, hier S. 239. 
und Gottfried Keller (vgl. II.2.2.3). In allen Texten wird die durch die Heimatlosen repräsentierte Infragestellung bürgerlicher Ordnung nur um den Preis des Todes überwunden: durch den Sturz des ehemaligen Rentherrn von einer Leiter, bei dem es wahrscheinlich ist, dass es sich um Selbstmord handelte (Stifter), durch den Freitod des Liebespaares in Romeo und Julia auf dem Dorfe (Keller), durch das Todesurteil, das über den Protagonisten im Sonnenwirth gefällt wird (Kurz).

\section{Clara Viebig: Die Heimat}

Auch in Clara Viebigs Novelle Die Heimat (1914) ist das Wissen um den rechtlichen Aspekt von Heimat zentral. ${ }^{180}$ Sie unterscheidet sich von den Texten Reuters, Riehls und Stifters, indem sie als einzige zugleich einen emphatischen Begriff von Heimatliebe entwickelt (und mit dieser Verknüpfung von Heimatrecht und Heimatliebe in die Nähe von Auerbachs Texten rückt, vgl. II.2.2.2; vgl. zu Viebig auch II.3.3.2).

Der schon im Titel aufgerufene Begriff wird in der Novelle in seiner rechtlichen Dimension, aber auch unspezifischer als Bezeichnung für den emotional positiv besetzten Herkunftsort verwandt. Die emphatischsten Darstellungen der Verbundenheit mit dem Ort der eigenen Herkunft kommen dabei allerdings ohne die Begrifflichkeit der Heimat aus.

Ein alter Armer, „der Bräuersch Lippi“, ${ }^{181}$ der nie vom rheinland-pfälzischen Dorf fortgekommen ist, liebt die Landschaft seiner Herkunft mehr als alles andere. Der Blick auf Felder, Berge und Flüsse erfüllt ihn mit „einer wahrhaft verklärenden Heiterkeit“ und einer „Liebe, wie er sie zu nichts anderem je empfunden hatte“, auch zu seiner Ehefrau nicht. Während diese tot ist, lebt die Landschaft um ihn herum: „Diese hier aber war ganz und gar lebendig, sah ihn an mit lebendigen Augen, sprach $\mathrm{zu}$ ihm mit lebendiger Stimme, nickte ihm $\mathrm{zu}$ mit lebendigem Lächeln, so lieb, so vertraut, daß sein altes, langsames Herz schneller zu schlagen begann, daß es klopfte wie das eines glücklichen Kindes, das in die Arme der Mutter eilt. “182 Die fraglose Liebe zur Landschaft wird mit der glückspendenden Liebe eines Kindes zur Mutter verglichen. Durch die ,verklärende‘ Wirkung, die

180 Clara Viebigs Novelle erschien erstmals 1914, ein Jahr später schon in der siebten Auflage. Nach dieser wird hier zitiert. Auch in anderen Texten Viebigs taucht die rechtliche Dimension von Heimat auf, beispielsweise in der Novelle Mutter Clara (1911), ebenfalls in der Novellensammlung Heimat enthalten. Hier findet eine Abschiebung einer unverheirateten Mutter in deren Heimat statt: „Dann wurde sie abgeschoben [...] sie mußte wieder in die Heimat zurück.“ Viebig: Mutter Clara, 1915, S. 97.

181 Viebig: Die Heimat, 1915, S. 219.

182 Alle Viebig: Die Heimat, 1915, S. 223-224. 
dieser Liebe zugesprochen wird, und durch die Personifizierung der Landschaft erhält diese Liebe Anklänge an eine überirdische, ja an eine Muttergottesliebe.

Die Gemeinde will den mittellosen Alten im Landarmenhaus bei Trier unterbringen. Eigennutz und Humanität sind dabei nicht klar zu trennen: Man will den Einsamen nicht sich selbst überlassen; auch falle er „der Gemeinde zur Last, und die hatte schon Lasten genug“. Alle haben den Alten gern, ,aber sie hatten selbst nicht viel zu beißn““. ${ }^{183}$ So sind sie beruhigt, als sie den Alten im Landarmenhaus versorgt wissen, auch wenn er nur gegen seinen Willen dort untergebracht werden kann. Nach überstandenem Winter bricht er ungefragt aus dem Landarmenhaus auf und läuft zu Fuß in sein Geburtsdorf zurück. Die Wiederbegegnung mit der Ley, dem Fluss des Geburtsdorfes, wird ins Bild ,überquellender Glückseligkeit" ${ }^{\text {"184 }}$ gefasst. Seine Freude über die Rückkehr wird von der Gemeinde nicht geteilt, sie wollen ihn zurückschaffen. Lippis Weigerung, ins Landarmenhaus zurückzukehren, begründet er juristisch korrekt:

„Landarmenhaus?!“ Der Lippi grinste ganz verächtlich. „Lao gehören ech doch net hin!“ Landarm waren nur die, die keine Heimat hatten. „Ech sein doch net landarm?!“ Und dabei blieb er. Es war ihm nicht begreiflich zu machen, daß das Landarmenhaus eine Wohlfahrtseinrichtung sei, eigentlich eine Art Versorgungsanstalt für Bedürftige, Einsame und Alte. Er schüttelte immerfort den Kopf: „Ech sei net landarm - hei, hei is mein Land. Hei bleiwen ech!“ ${ }^{185}$

Tatsächlich sind die Landarmenhäuser eine preußische, später auch im Deutschen Reich weiterbestehende Einrichtung (Trier gehörte seit 1815 zu Preußen), die für solche Arme zuständig ist, denen keine Gemeinde zugeordnet werden kann, weil sie kein Heimatrecht besitzen. Teilweise war es von Vorteil, als Landarmer eingestuft zu werden, da die Gemeinden je nach eigener Einschätzung und Kassenlage die Unterstützung der zu ihrer Gemeinde Zählenden auch verwehren konnten. Die Landarmenverbände mussten ihre Landarmen zumindest geringfügig unterstützen (vgl. II.2.1). ${ }^{186}$ Lippis Argument ist demnach richtig - er besitzt ein Heimatrecht und ist damit kein Fall fürs Landarmenhaus -, allerdings handelt er nicht rational, da seine Versorgung im Landarmenhaus besser gewährleistet wäre. Um die Macht der Liebe zum Ort der eigenen Herkunft gegen jede Rationalität geht es der Novelle. Bemerkenswert ist, dass sich das Beharren Lippis auf

183 Beide Zitate Viebig: Die Heimat, 1915, S. 226-227.

184 Viebig: Die Heimat, 1915, S. 229-230.

185 Viebig: Die Heimat, 1915, S. 233.

186 Vgl. Lerche 2009, S. 106. 
dem Heimatrecht hier mit einem emphatischen Heimatverständnis deckt, denn es ist die Gemeinde, die gegen das Heimatrecht handelt, nicht er.

Bei seinem zweiten unfreiwilligen Abtransport ins Landarmenhaus ist es wieder die personifizierte Landschaft, die ihm zuruft, zu bleiben. Während des folgenden Aufenthalts im Landarmenhaus überblenden sich Erinnerungen an die Wallfahrten, die Lippi früher mit Frau und Kindern unternommen hat, das „Muttergottesgesicht“187 seiner Krankenpflegerin, die Sehnsucht nach dem Geburtsdorf und die Wallfahrten des Marienmonats mit einer Vision der Muttergottes: „Groß stand sie vor ihm, ganz nahe, nur ein paar Schritte weit weg, gewaltig und doch so liebevoll: sein Heil, seine Trösterin, seine Zuflucht, seine Mutter." ${ }^{188}$ Heimat- und Muttergottesliebe fallen in eins, so dass in der Erzählung einmal mehr eine Effemination von Heimat vorgenommen wird (vgl. I.2.3). ${ }^{189}$ Durch die ausschließliche Innensicht, in der Heimat- und Muttergottesliebe präsentiert werden, enthebt sich die Erzählung einer Stellungnahme: Es bleibt der Leserin überlassen, ob er die intern fokalisierte Erscheinung als Vision ernst nehmen oder als dem wirren Geist eines sterbenden Mannes entsprungen verstehen will.

Der Alte entweicht ein zweites Mal aus dem Landarmenhaus, aber diesmal erreicht er sein weltliches Ziel nicht mehr - „bis in seine Heimat war er nicht gelangt“. Lippi wird zurück ins Landarmenhaus gebracht, „kümmerte wie eine Pflanze, die ihren rechten Boden nicht hat"190 und stirbt. Die emphatische Heimat, das zeigt auch dieser Text von 1914, bleibt durchs ganze 19. Jahrhundert eng mit der himmlischen Heimat verknüpft (vgl. II.1). Ob Lippi in ein Himmelreich eingeht, lässt die Erzählerinstanz in einer vieldeutigen Wendung offen: „Bald ging der Lippi ein“, ${ }^{191}$ lautet der letzte Satz. Neben der offensichtlichen religiösen Bedeutung eröffnet sich damit auch eine materialistische in dem Sinne, dass das kreatürliche Eingehen einer sterbenden Pflanze mit dem Tod Lippis assoziiert werden könnte.

\section{Zwischen Heimatliebe und Verwaltungslogik}

Die unterschiedliche Behandlung des Themas durch die Texte von Reuter, Riehl, Stifter und Viebig lässt sich resümierend in zwei Fragen bündeln: Wie werden

187 Viebig: Die Heimat, 1915, S. 238.

188 Viebig: Die Heimat, 1915, S. 242.

189 Vgl. auch Bland 2019, S. 33.

190 Beide Zitate Viebig: Die Heimat, 1915, S. 243.

191 Viebig: Die Heimat, 1915, S. 243. 
rechtliche und emphatische Heimatbedeutung jeweils miteinander verknüpft? Und welche Perspektive auf die Figuren wird jeweils gewählt?

Reuters Text kritisiert die Auswüchse einer inhumanen Verwaltungslogik. Heimatrecht und Schubwesen stehen für eine auf Kosten der Ärmsten operationalisierte Rechtssituation, die in ihrer Unhaltbarkeit bloßgestellt wird. Dafür bedarf es gar nicht einer Konfrontation der rechtlichen mit einer emphatischen Heimat - es reicht aus, einen realen Rechtsfall zu schildern. Die kalkulierte Zurücknahme jedes emotionalisierten Heimatbegriffs entspringt einer heterodiegetischen Erzählstimme, die ausschließlich extern fokalisiert. Das so erzeugte Fehlen einer Innensicht des Betroffenen hat - parallel zur Aussparung eines emphatischen Heimatbegriffs - zum Effekt, dass die Reduzierung des Menschen auf den administrativen Fall, die Ohnmacht der Armut und zugleich die überindividuelle Aussagekraft des Falls besonders hervortreten. Der sozialkritische Anspruch des Textes wird durch den sarkastischen Ton deutlich, der dem neutralberichtenden Stil unterlegt ist.

Riehls nur wenige Jahre später entstandener Text könnte unterschiedlicher nicht sein. Kritik an Heimatrecht und Schubwesen gibt es nicht, beide bilden vielmehr eine unproblematische Kulisse für die beschauliche Geschichte zweier Bettler, die ein einträgliches Auskommen durch ihre Bettelei erzielen und ein im Ganzen sorgenfreies Leben führen. Armut zeigt sich als kindlich-naiver, vorbewusster Zustand, aus welchem den Armen herausgeholfen werden muss und kann. Dieser Zustand wird mit einem mit der Romantik assoziierten Heimatverständnis korreliert, das es zugunsten eines bürgerlichen Heimatbegriffs zu überwinden gilt. Dieser , mannhafte ${ }^{\mathbf{1 9 2}}$ Schritt in ein gleichsam erwachsen gewordenes Heimatverständnis zieht die bürgerliche Existenz einer mit Müßiggang, Dichtung und Sentimentalität verbundenen Existenz vor. Diesem Anliegen entspricht es, dass Riehl einen heterodiegetischen, nullfokalisierenden Erzähler wählt, der dergestalt über die Moral des Textes herrscht.

Bei Stifter zeigt die Konfrontation des bürgerlichen Rentherrn mit dem ,Schub، seine Konfrontation mit dem Abgrund einer bürgerlichen Ordnung, in den er selbst kurz darauf fallen wird. Heimatrecht und Schub sind hier nicht einmal mehr Kulisse, sondern nur noch Chiffre für die bürgerliche Ordnung. Die Bedrohung dieser Ordnung ist das zentrale Thema der Erzählung. Wie bei Riehl ist auch bei Stifter das Telos der Erzählung die Wiedereingliederung einzelner aus der Ordnung der bürgerlichen Gesellschaft Herausgefallener. Bei Riehl ist dies ein gemütlicher, fast widerstandsloser Vorgang und Armut eine als kindlich-naiv stilisierte Existenzform. Bei Stifter ist der Abgrund, in den der Bürgerliche fallen

192 Vgl. Riehl: Vergelt's Gott (1863), in: Riehl 1937, S. 361-383, hier S. 376. 
kann, bedrohlich und verstörend. Die Komplexität von Stifters Text, in der Zusammenstellung dieses Kapitels nur noch von Keller überboten, zeigt sich schon in seinem Spiel mit der Erzählstimme, die zunächst heterodiegetisch ist und dann auf einer intradiegetischen Ebene von einer homodiegetischen Erzählerin abgelöst wird. Beide Erzählinstanzen schauen mit maximaler Außensicht auf die Figuren, die außerhalb der bürgerlichen Ordnung stehen, und zum Thema wird in variierter Form gerade die Unmöglichkeit des Verstehens. Anders als bei Riehl zerfällt die Moral des Textes damit in verschiedene Perspektiven, die mehrere Deutungen zulassen.

Viebigs Text bildet in einiger Hinsicht das Komplement zu Reuters Text: Anders als bei Riehl und Stifter wird bei Viebig wie bei Reuter das Heimatrecht problematisch; auch hier geraten Individuum und Verwaltungslogik bzw. Gemeindeinteresse in Konflikt. Aber während Reuters Text ganz auf den Effekt der objektiven Schilderung eines entindividualisierten Falls setzt, wählt Viebig die Strategie der größtmöglichen Identifizierung mit der Figur und der größtmöglichen Emphase im Heimatbegriff. Viebigs Erzählstimme wechselt kontinuierlich zwischen auktorialer und intern fokalisierender Sicht. Mit dieser Innensicht, die sie als einzige wählt, verbinden sich auch die emphatischsten Heimatvorstellungen. Heimatliebe und Heimatrecht stellen in der Logik der Novelle deswegen keinen Widerspruch dar. Denn es geht um eine Gemeinde, die das Heimatrecht, das sie einem versorgungsbedürftigen Alten schuldet, nicht einlöst. Das Heimatrecht gerät hier also nicht strukturell, sondern nur als Fall einzelnen Versagens in die Kritik.

\subsubsection{Migration und Heimatrecht: Auswanderer und Heimkehrer (Gerstäcker, Auerbach)}

Die Widersprüche zwischen einer veralteten Rechtsprechungs- und Fürsorgepraxis und den durch Mobilität geprägten Lebensrealitäten zeigen sich eklatant auch beim neuen Massenphänomen Auswanderung. Den Zusammenhang von Migration und Heimatrecht und die politisch-administrative Lösung der sich in diesem Zusammenhang ergebenden Probleme beschreiben Zeitgenossen als eine der drängendsten Fragen der Zeit: Dass in Zeiten der Auswanderung „die Conflicte der Interessen und Ansichten in Beziehung auf das Heimathswesen immer schneidender hervortreten, ist Thatsache, und es gibt daher für den Staatsmann, den Gelehrten und jeden gebildeten Staatsbürger keine Materie, die für ihn 
practischere Wichtigkeit haben könnte, als das Auswanderungs- und Heimathswesen“. 193

Jeder Auswanderer war mit dem Heimatrecht konfrontiert, denn Auswanderung begann mit Verwaltungsgängen, Besorgen von Papieren, Ausstellen von Dokumenten. Bescheinigt werden musste auch die Heimatberechtigung des Auswanderungswilligen auf deutschem Boden, wie es etwa am 11. Juli 1863 durch die großherzogliche Bürgermeisterei Lanzenhain geschah:

Der Maria Bönsel, ledig, von Lanzenhain, im Kreise Lauterbach, welche sich in der Wetterau zu Schneider begeben will, wird auf Verlangen bescheinigt, daß dieselbe in hiesiger Gemeinde geboren und heimathsberechtigt ist und jeder Zeit hierher zurück kehren kann. Das Betragen derselben ist gut und steht kein weiteres Hinterniß dem Vorhaben entgegen. Sollte ein Heimathschein verlangt werden, so kann derselbe baldigst nachgeschickt werden. ${ }^{194}$

Die Heimatberechtigung wurde je nach Person und Heimatgemeinde auch für den Fall einer Rückkehr gewährleistet, so bei Maria Bönsel - oder aber sie wurde mit erfolgter Auswanderung entzogen. Das war beispielsweise dann der Fall, wenn die Gemeinden dem mittellosen oder straffällig gewordenen Ausreisenden seine Reisekosten oder einen Teil davon zahlten, sich dafür aber jeder weiteren Fürsorgepflicht entledigten, indem die Heimatberechtigung aufgekündigt wurde (vgl. II.2.1). Für viele Auswanderungswillige nach Übersee begann das Leiden an der rechtlichen Seite der Heimatlosigkeit schon, bevor sie amerikanischen Boden betraten - für alle diejenigen nämlich, deren Reisegeld an den großen Häfen Europas aufgebraucht war und die sich die Überfahrt nicht mehr leisten konnten, wie der Reisebericht Ludwig Galls es für das Amsterdam des Jahres 1819 beschreibt:

Das Wenige, was sie mitgebracht hatten, war verzehrt; [...] der ihnen in dem fremden Lande bewilligte Aufenthalt ging zu Ende, und die Heimath war den meisten von ihnen, den Würtembergern, welche nach ihren Pässen auf das Bürgerrecht ausdrücklich hatten verzichten müssen, verschlossen. In dieser Lage heimath- und mittellos denke man sich den verzweifelnden Vater halbnackter, ausgehungerter Kinder [...]. Tausende von Unglücklichen dieser Art, den Stachel der bittersten Reue in der wunden Brust, kehrten endlich, unter nie

193 So der Großherzogliche Regierungsrat Alexander Müller in seiner Schrift Die deutschen Auswanderungs-, Freizügigkeits- und Heimaths-Verhältnisse, Müller 1841, S. IV.

194 Abschrift eines Gutachtens innerhalb des Briefkonvoluts Tavenrath/Boensel in der Auswandererbriefsammlung der Forschungsbibliothek Gotha. Das Briefkonvolut erstreckt sich über den Zeitraum von 1859 bis ca. 1901, der Auswanderer ist Christian Boensel (1838-1901). Dokumente zu Vergabe und Entzug von sogenannten ,Heimatberechtigungen' durch die Gemeinden sind auch publiziert in Helbich 1988, S. 84. 
beschriebenen Mühseligkeiten, zurück in die verlassene Heimath, ihren Gemeinden und sich selbst zur Last und den meisten der Zurückgebliebenen ein Gegenstand des Spottes. ${ }^{195}$

Der traurige Stoff, den all diejenigen boten, die schon in Amsterdam oder in anderen Hafenstädten zu Bettlern wurden und die nur im besseren Fall die Mittel aufbrachten, zurückzukehren, für die sich aber in der ehemaligen Heimat keiner mehr zuständig fühlte, wurde schon lange vor B. Travens literarischer Bearbeitung des Themas im Totenschiff (1926) in der Literatur des 19. Jahrhunderts aufgegriffen. Travens Protagonist Gales gilt als staatenlos, weil ihm sein Identitätsdokument abhandenkommt - „keine Papiere, kein Heimatland“196 -, was ihn zum aus jeder menschlichen Gesellschaft Verbannten, zum lebendigen Toten macht. Die Heimatlosigkeit des 19. ist wie die Staatenlosigkeit des 20. Jahrhunderts ein Begriff, der zunächst auf einen administrativen Sachverhalt verweist (vgl. II.2.1) der Unterschied ist, dass dies für die Heimatlosigkeit und mit ihr für alle anderen Facetten des Heimatrechts in Vergessenheit geraten ist.

Das auf den Zusammenhang von Auswanderung und Heimatrecht bezogene Alltagswissen findet sich allerorten in der Literatur des 19. Jahrhunderts, beispielsweise in Gottfried Kellers Grünem Heinrich ${ }^{197}$ oder in Wilhelm Raabes Die Akten des Vogelsangs (1896), wo es über die aus Amerika in die ländliche Residenz-Vorstadt ,Am Vogelsang“ zurückgekehrten Mrs. und Miss Trotzendorff heißt: „Von Heimatberechtigung kann ja wohl nicht die Rede sein“ - aber, so weiter, „wohin sollte die Kommune sie abschieben“, ${ }^{198}$ wenn Mr. Trotzendorff die Versorgung seiner Familie nicht übernehme. Mr. Trotzdendorff war Auswanderungshelfer und übersiedelt schließlich selbst mit Frau und Tochter nach Amerika; sie kommen ohne ihn zurück und die Nachbarschaft füttert sie durch, obwohl sie nicht dazu verpflichtet ist - da eben keine ,Heimatberechtigung vorliegt. Was Raabe an dieser Stelle des Romans zeigt, ist die versöhnliche Seite der Heimat, die Geborgenheit und Schutz durch die Nachbarschaft bietet. Die funktionierende Vorstadt-Gemeinschaft hilft aus, wo die Verwaltung nicht in der Pflicht ist - jedenfalls aus der Perspektive des Erzählers, des Verwaltungsbeamten

195 Gall 1822, S. 18. Zum ,Brennpunkt Amsterdam', wo allein im Mai 1817 um die 30.000 Amerikaauswanderer wegen Mittellosigkeit, teils auch wegen Betrugs durch Auswanderungsagenten, ihren Auswanderungsversuch abbrechen und sich vom Betteln ernähren mussten, vgl. Behringer 2015, S. 185-187. Dort auch zu Heimatscheinen, die vom Schweizerischen Konsul an die rückkehrwilligen Schweizer ausgeteilt wurden.

196 Traven 1978, S. 262.

197 Der Graf berichtet von einem von Auswanderern zurückgelassenen Kind, dem er den Namen Dortchen Schönfund gibt, als er ihm „später sein Heimatsrecht [...] sicherte“. Keller 1985, S. 829. 198 Raabe 1970, S. 234. 
Krumhardt. Der Roman zeigt, wie so oft bei Raabe, diese geborgen-gemütliche Seite des Lebens aus der Erzählperspektive des beschränkten Philisters; und er zeigt durch andere Figuren zugleich ein dem entgegenstehendes, kompromissloses Verhältnis zur Welt - in den Akten des Vogelsangs repräsentiert von dem Auswanderer Andreas Velten, der am Ende des Romans, heimgekehrt, sein Haus mit sämtlichem Inventar, alles, was an Materiellem zu seinem Leben gehörte, und am Ende sich selbst vernichtet. Die Existenz einer geborgenen Welt, in der der Heimkehrer selbst ohne Heimatberechtigung sein Unterkommen findet, wird hier radikal in Frage gestellt.

Das kurze Beispiel aus Raabes Romans zeigt, dass die großen Migrationsbewegungen das Heimatrecht noch einmal aus einer anderen Perspektive zu einem Problem und einem Thema werden lassen. ${ }^{199}$ Interessant für die literarische Gestaltung ist diese Perspektive, insofern das dialektische Verhältnis von Heimat und Fremde durch das Heimatrecht unterlaufen werden kann: Heimat ist dann nämlich unter Umständen nicht mehr der sichere Hort, sondern der Ort, der dem Auswanderer das Recht auf Bleiben verwehrt oder der ihn bei der Rückkehr nicht mehr mit offenen Armen empfängt. Oder aber, wie bei Raabe: Das Heimatrecht versagt dem Heimgekommenen Hilfe, aber die Nachbarschaft folgt einem ,natürlichen' Verständnis von Heimat. Für den rätselhaften Rückkehrer Velten gibt es trotz alledem keine Heimat mehr. Damit verrätselt sich auch das vermeintlich natürliche Heimatgefühl, das Velten von sich weist.

\section{Friedrich Gerstäcker: Der Heimathschein}

1864 werden in der Gartenlaube zahlreiche Artikel gedruckt, die das Thema Auswanderung und Heimat berühren: ein Bericht über Charles Sealsfield und dessen „geliebtes Adoptivvaterland“200 Amerika, das er aber in Zeiten des Bürgerkrieges verlässt und heimkehrt in die Alte Welt; die kritische Besprechung eines Auswanderungsratgebers, der unpatriotisch sei, so der Rezensent, weil für eine schnelle Akkulturation in die brasilianische Kultur geworben werde, statt die deutsche Sprache und Kultur auch unter den Ausgewanderten hochzuhalten; ${ }^{201}$ die bebilderte Geschichte „Sie gehen nach Amerika“ eines Autors mit den Initialien F.H. (Abb. 36). Wichtig für das Bild „Auswanderer auf dem Rhein. Nach der

199 Im Einleitungskapitel ist ausführlicher auf den Bezug von Auswanderung und Heimat in der Literatur des 19. Jahrhunderts und insbesondere bei Raabe eingegangen worden (vgl. I.2.4).

200 Hartmann 1864, S. 55. W.G. Sebald widmet Charles Sealsfields ambivalentem Verhältnis zur Heimat 1988 den Aufsatz Ansichten aus der Neuen Welt - Über Charles Sealsfield, neu publiziert in Sebald 2004, S. 17-39.

201 Vgl. Anonym: Theodor Oelckers, 1864. 
Natur aufgenommen von H. Leutemann“ und die ihm angefügte Erzählung zur (angeblichen) Bildentstehung ist, wo die Auswanderer dargestellt werden - noch auf deutschem Boden bzw. Gewässer, und zwar auf dem deutschesten, dem Rhein. Richtig äußert auch einer der Auswanderer: „Wir hätten's wohlfeiler haben können auf der Eisenbahn und auf dem geraden Wege zum ersten besten Hafen. Aber wir wollten unsern lieben Rhein noch einmal recht anschauen und ein Stück von Deutschland dazu, ehe wir ihm vielleicht auf ewig Ade sagen." Rheinromantik und Vaterlandsliebe werden zeittypisch verknüpft, aber auch Amerika kann zur neuen Heimat werden. Die Erzählerstimme ruft ihnen nach: „Den Rhein hinab - aus dem Vaterland! Ja, es ist ein Entschluß! Der Himmel gebe, daß Ihr glücklich drüben gelandet und fröhlich angewurzelt seid auf dem Boden Eurer neuen Heimath! Gott sei mit Euch!“202

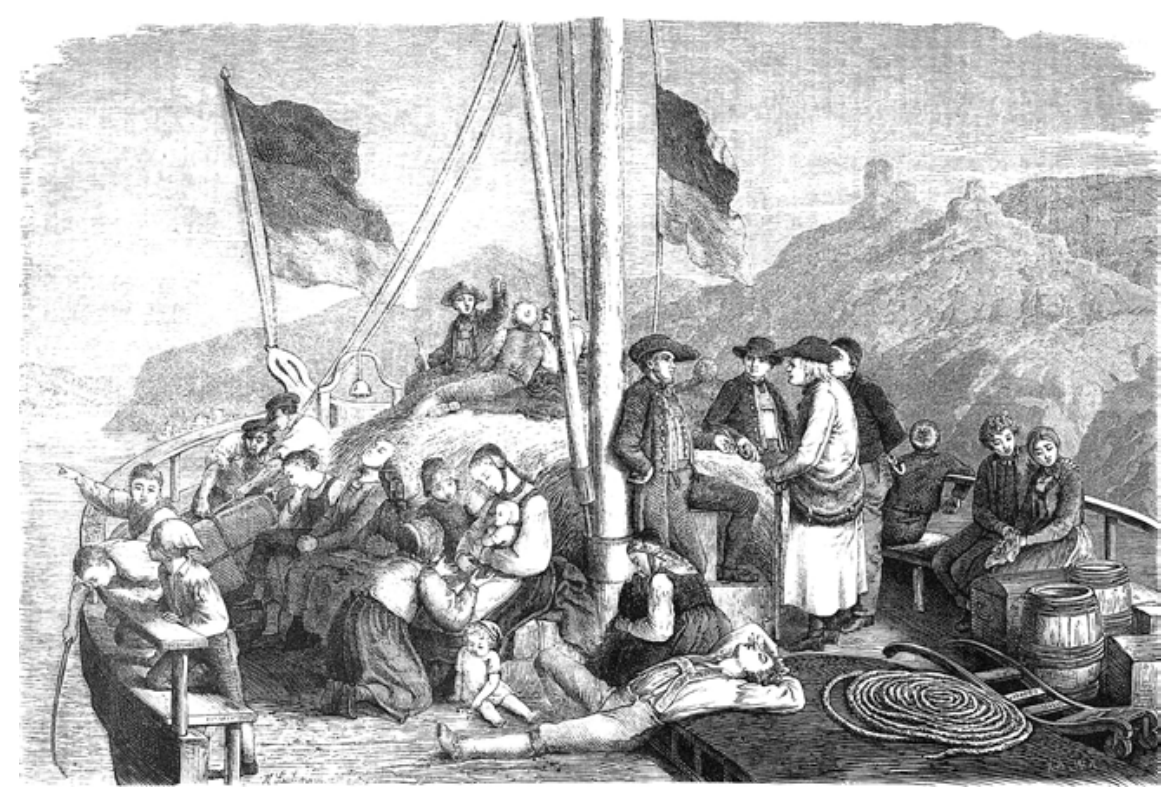

Abb. 36: Auswanderer auf dem Rhein. Nach der Natur aufgenommen von H. Leutemann. In: Die Gartenlaube Heft 6 (1864), S. 84 (gemeinfrei über Wikimedia commons)

Die in der Gartenlaube viel thematisierte Auswanderung bildet auch den Hintergrund von Friedrich Gerstäckers (1816 - 1872) Erzählung Der Heimathschein, einer 1864 in Fortsetzung gedruckten Posse über das deutsche Verwaltungssys-

202 Beide Zitate Anonym: Sie gehen nach Amerika, 1864, S. 87. 
tem - das im Gegensatz zu Fritz Reuters Heimathlosem (vgl. II.2.2.1) dem Protagonisten allerdings nicht das Genick bricht, sondern ihn zu seinem Glück vor einem folgenreichen Fehltritt bewahrt. Die Erzählung beginnt mit dem Segen des Traubenwirts zum Heiratswunsch seiner Tochter Lieschen und Hans, dem Sohn des Bauern Barthold, und endet mit einer Heirat, allerdings nicht zwischen Hans und Lieschen, sondern zwischen Hans und Katharina. Das untreue Lieschen wandert mit ihrem Schatz nach Amerika aus. Der Grund für die immer wieder aufgeschobene Heirat ist ein fehlender Heimatschein. Am Ende werden die bürokratischen Hindernisse zum Segen, weil sie Hans vor der schönen, aber falschen Braut bewahren. Die bürokratischen Hürden auf dem Weg zum Heimatschein bilden neben den Liebesverwirrungen der Beteiligten den komischen Gehalt des Textes: „eine Eingabe an ein Consistorium und ein Heimathschein, selbst für den urgeduldigen Deutschen ist es ein Meisterstück, die beiden Dinge ruhig abzuwarten“. 203

Grund für die Schwierigkeiten, eine Heimatberechtigung für den Sohn zu halten, ist eine Auswanderungsgeschichte in der Elterngeneration: Der alte Barthold war in seinen Jugendjahren aus Thüringen erst nach Schlesien, dann nach Ungarn ausgewandert. ${ }^{204}$ Der Deutschenhass der Ungarn bringt Barthold dazu, sein Gut in Ungarn zu verkaufen und wieder nach Thüringen zu ziehen. Der Sohn will heiraten, alle beteiligten Familien sind einverstanden und für das Aufgebot benötigt der Pfarrer nun „Geburtsschein, Impfschein, Heimathschein, die Erlaubniß der Eltern kann mündlich erfolgen, dann ein Schein von da, wo Sie sich früher aufgehalten, daß Sie sich dort nicht schon verehelicht haben“. ${ }^{205}$ Die reine „Formsache“ ${ }^{206}$ entpuppt sich als schier unüberwindliches Hindernis. Einem natürlichen Rechtsempfinden widerspricht der ganze Vorgang. ${ }^{207}$ Ohne

203 Gerstäcker 1864, S. 307.

204 Es geht also um die zweite Generation der Rückkehrer einer Auswanderungsbewegung nach Osten, die für das 18. Jahrhundert bestimmend war. Dazu zählten die von Maria Theresia abgeworbenen Deutschen, die die Habsburger Gebiete im Osten besiedeln sollten, die sogenannten Banater Schwaben und Donauschwaben. Ein Großteil der deutschen Auswanderer des 18. Jahrhunderts ließ sich in Nordwest-Ungarn, im Banat und in der Batschka nieder. Von hier ausgehend fand teilweise eine Binnenwanderung nach Slawonien in Ostkroatien, Siebenbürgen und andere osteuropäische Regionen statt. Aber auch nach Russland emigrierten unter Katharina der Großen viele Menschen.

205 Gerstäcker 1864, S. 290.

206 Gerstäcker 1864, S. 290.

207 „,Was muß er denn nur für Papiere haben?` frug die Mutter. ,Sie kennen uns doch hier und wissen, daß wir ordentliche und rechtschaffene Leute sind, und unser Auskommen haben wir doch auch.' ,Ja, ja, Mutterchen,' lachte der Vater, ,das hilft Nichts bei den Gerichten, die wollen Alles Schwarz auf Weiß haben, und womöglich auch auf einem Stempelbogen, mit einem großen 
Heimatschein kann Hans nicht heiraten, wie der Vater dem Gerichtsschreiben entnimmt: „Du wärst in Preußen gar nicht heimathberechtigt, wenn auch da geboren, denn ich wäre mit Dir, als Du noch minderjährig gewesen, in das Ausland ausgewandert, und ich und meine Kinder hätten dadurch unser Heimathsrecht in Preußen aufgegeben. “208 Auch das ungeliebte Preußen gegen die eigene Gemeinde auszuspielen, bringt indes nichts. ${ }^{209}$ Fast scheint es, die Behörden hätten Spaß daran, die Sache in die Länge zu ziehen:

Und der Heimathschein erst - was für eine Masse Papier die Leute in der Stadt schon in der Angelegenheit verschrieben hatten, nur um herauszubekommen, welcher Fleck in Deutschland ihm nachher auf einem Viertelbogen bescheinigte, daß er überhaupt da sei und das Recht habe, hier oder dort einmal Ansprüche an das Gemeindearmenhaus zu machen. Es war ganz erstaunlich, und man hätte nun glauben sollen, sie wären auf dem Gericht selber bös geworden über die entsetzliche Mühe und Arbeit, die es ihnen machte, aber Gott bewahre.

An dieser Stelle mischt sich der Erzähler ein: Nur „das eine Wort „Heimathschein““ begreife so viele „Laufereien, Schreibereien, Scheerereien und Quälereien“ in sich, dass jeder, der es „,selber schon einmal durchgemacht“, nur traurig mit dem Kopf nicken könne. ${ }^{210}$ Und so muss Hans weiter mit einer dem menschlichen Verstand zuwiderlaufenden Situation leben. Drei lange Monate bekommt Hans keinen Heimatschein und zunehmend erweist sich, dass es den Behörden nicht um eine Lösung des Problems, sondern um reine Institutionenlogik zu tun ist.

Inzwischen ist so viel Zeit verstrichen, dass die überstürzten Ehepläne von Hans und Lieschen zerstört worden sind: Lieschen entpuppt sich als unbeständige Braut, die den Zukünftigen betrügt, und Hans erkennt endlich Katharina als die ihm gemäße Frau. In der Erzähllogik können nun auch die bürokratischen Hürden fallen. Der alte Barthold hatte sein Gut dem Sohn übergeben: „Dadurch wurde Hans ansässig, und sie konnten ihm dann das Heimathrecht nicht länger verweigern.“211

Siegel drunter, und daß Einer ein ehrlicher und rechtschaffener Mensch ist, glauben sie ihm erst recht nicht, wenn er nicht im Stande ist, es ihnen schriftlich zu beweisen. Komm Du denen!““ Gerstäcker 1864, S. 291.

208 Gerstäcker 1864, S. 306.

209 „,Und was liegt d’ran?‘ rief Hans, den Brief trotzig auf den Tisch zurückwerfend, ,irgendwo muß ich zu Haus gehören, das sieht ein Kind ein, und wenn Preußen nichts von mir wissen will was ich ihm nicht verdenken kann, denn mir geht's in manchen Stücken gerade so - ei, dann müssen sie mir hier einen solchen Wisch geben. [...] Hier haben wir unseren Grund und Boden, und hier gehören wir also auch her. Was kümmert uns Preußen!““ Gerstäcker 1864, S. 306.

210 Alle Zitate Gerstäcker 1864, S. 322.

211 Gerstäcker 1864, S. 339. 
Am Ende der Odyssee durch die Bürokratie steht kein Michael Kohlhaas und nicht einmal ein Krischan Schult (eine Figur Fritz Reuters, vgl. Kap II.2.1.1), sondern nur ein verblendeter Heiratswilliger, der auf den rechten Weg gebracht werden und dafür einige Ärgernisse in Kauf nehmen muss, die auch ihr Gutes haben. Heimatliebe und Heimatgefühl werden durch die juristisch-bürokratische Seite von Heimat nicht tangiert: „,Was brauch' ich überhaupt einen Heimathschein?' sagte Hans, ,wenn ich nur eine Heimath habe, denn so ein Wisch giebt mir doch keine. ““212

\section{Berthold Auerbach: Schwarzwälder Dorfgeschichten}

Berthold Auerbach (1812-1882) wurde zwischen 1843 und 1882 „ein Lieblingsautor der deutschen Nation“213 und war neben Ferdinand Freiligrath und Ludwig Uhland zeitweise der populärste Autor Deutschlands. ${ }^{214}$ Sein Gesamtwerk ist auf vielschichtige Weise mit dem Heimat-Thema verknüpft. ${ }^{215}$ Besonders seine unter Zeitgenossen äußerst populären und literaturgeschichtlich einflussreichen Schwarzwälder Dorfgeschichten (1843-1854) thematisieren immer wieder Fragen der Heimat. Dies hängt mit der frührealistischen ${ }^{216}$ Neuausrichtung auf das ,Volkstümliche` zusammen, die sich vom romantischen Verständnis ausdrücklich

212 Gerstäcker 1864, S. 306.

213 Geiger 1910, S. 231.

214 Vgl. Bettelheim 1907, S. 288. Die Breitenwirkung der Schwarzwälder Dorfgeschichten zeigt sich auch in den zahlreichen Übersetzungen in fast alle europäischen Sprachen; sie gehörten über mehrere Jahrzehnte zum Lektürekanon der Schulen; 1880 war eine Auflagenhöhe von 84.000 deutschsprachigen Exemplaren erreicht; George Sand und Lew Tolstoi gehörten zu der großen Zahl an Bewunderern von Auerbachs Werk über die deutschen Grenzen hinaus; mit weiteren Nachweisen vgl. Mettenleiter 1974, S. 350 - 355. Auch Karl Mays Erzgebirgische Dorfgeschichten sind nachweislich durch Auerbach geprägt und auf den noch näher zu beschreibenden Zusammenhang zwischen der Gattung der Dorfgeschichte und dem mayschen Abenteuerroman wurde hingewiesen, vgl. Ueding 2001, S. 374. Zur Gattung der Dorfgeschichte allgemein vgl. Hein 1976. 215 Die Literaturwissenschaft bemüht sich in den letzten Jahren wieder verstärkt um Auerbach, vgl. vor allem die Arbeiten von Hans Otto Horch, exemplarisch: Horch 1996. Vgl. weiterhin Schlüter 2010; Wild 2011; Reiling 2012; Hamann/Scheffel 2013. Zur Thematik der Heimat bei Auerbach vgl. Horch 2004, Rohde 2014 und Scharnowski: Heimat, 2019, S. 41-55.

216 Zur tragenden Rolle von Auerbachs Dorfgeschichten für den deutschsprachigen Realismus vgl. Schönert 2002; Lehmann 2011, S. 121. Mit dem Argument, dass sich Auerbachs zwischen 1843 und 1882 entstandenes Gesamtwerk nicht sinnvoll mit der historischen Einordnung des Frührealismus erschließen lässt, schlägt Mettenleitner die „strukturbezogene Terminologie des Detailrealismus“ zur Klassifizierung von Auerbachs Werk vor; Mettenleiter 1974, S. 321. Ich verwende den Begriff des Frührealismus hier bezogen auf die frühen programmatischen Schriften Auerbachs. 
absetzt. Volksschriftsteller zu sein, bedeutet für Auerbach und seine Zeit, ${ }^{217}$ dass die großen Themen von Moral und Menschlichkeit genauso anhand des ,einfachen Volkes'entwickelt werden sollten wie anhand von Figuren, die aus der kleinen gebildeten Oberschicht stammen. Volksliteratur in diesem Verständnis bedeutet, den Abstand von Masse und Elite zu überbrücken und Gemeinschaft zu stiften. Jenseits von Auerbachs Programmatik ist aber nicht allein die Genese von Gemeinschaft, sondern auch ihre Kritik ein wichtiges Thema der Schwarzwälder Dorfgeschichten. Die gemeinschaftsstiftende Funktion von Heimat wird bestätigt und zugleich hinterfragt.

Auerbachs deutsch-jüdische Perspektive ist Teil seiner spezifischen Bearbeitung von Heimat. Biographisch ist der Autor mit dem bürgerlichen Namen Moses Baruch Auerbacher, der so viel über Heimatverbundenheit schreibt und dem ,einfachen Volk‘ mit seinen Schriften eine Stimme geben möchte, immer wieder mit seiner ihm aufgezwungenen Außenseiterrolle konfrontiert worden. Am eindringlichsten vermittelt sich das in einem vier Monate vor seinem Tod notierten Kindheitserlebnis. Es beginnt so: „Ich bin gekreuzigt worden, das ist das bitterste, was ich zu sagen habe. “218 Andere Dorfjungen haben mit Gewalt versucht, Moses zu zwingen, sich zum Christentum zu bekennen. Als er ablehnt, fesselten und banden sie ihn in der Position des Gekreuzigten, erst nach Stunden wurde er durch einen Zufall von seinem Onkel entdeckt und befreit. Der Neunundsechzigjährige hält fest, dass er dieses Erlebnis in seinem ganzen Leben nur einmal und nur einer einzigen Person erzählt habe. Diese nicht genannte geliebte Frau (wohl seine erste Frau Auguste Schreiber) riet ihm, das Erlebnis erst nach seinem Tod preiszugeben, dann aber würden manche wohl sagen, „es muß ein starkes gutes Herz in dem Menschen gepocht haben, der doch selten nach solcher Erfahrung gerade den Christen und den Kindern seiner Heimath so viel Gemüthsinnigkeit zudichtet“. ${ }^{219}$

Die Sympathie der auktorialen Erzählerinstanz in Auerbachs Texten gilt allen Figuren des christlichen Dorfkosmos, Ressentiment ist ihr fremd. Blitzen hin und wieder jüdische Schicksale in den Erzählungen auf, dann am Rande: In Die Kriegspfeife heißt es über die Kriegsplünderungen in einem Satz, dass es den

$217 \mathrm{Zu}$ den auch Mitte des 19. Jahrhunderts kontroversen Auffassungen des Volksschriftstellers vgl. Reiling 2016. Reiling nennt Otto Ludwig als weiteren Repräsentanten einer utopischen Idee der Volksliteratur, vgl. Reiling 2016, S. 217. Zu Auerbachs zwischen sozialem und ethischem Verständnis changierendem Begriff des ,Volks‘ und seinen Bezügen zu den organischen Staatsund Volkslehren der Zeit, u. a. auch im Kontext der Auswanderung, vgl. Hamann 2014, S. 189 - 195. 218 Berthold Auerbach: [Aufzeichnung eines Kindheitserlebnisses], Cannstatt, 20. Oktober 1881, in: Auerbach 2014, S. 259-264, hier S. 259.

219 Auerbach 2014, S. 259. 
Juden am übelsten dabei ergehe, weil Juden nur bewegliches Habe, aber keine Äcker besitzen könnten und man ihnen deswegen alles nehmen könne. ${ }^{220}$ In Tonerle mit der gebissenen Wange wird im Vorübergehen erwähnt, dass auf „dem jüdischen Gottesacker“ vier Trauerweiden an „die Großmutter, die Mutter und ihre fünf Kinder“ erinnerten, „die alle in Einem Hause verbrannt sind“. ${ }^{221} \mathrm{Ob}$ es sich um ein antisemitisches Pogrom gehandelt hat, erfährt der Leser nicht. ${ }^{222}$ Immer sind es nur Nebensätze und Nebenschauplätze der Handlung, die der Leser verfolgen mag oder auch nicht. Die für Auerbachs Texte zentralen Themen der Identität und Dazugehörigkeit, der Ausgrenzung und des Fremdwerdens behandelt Auerbach in seinen Dorfgeschichten nicht primär an jüdischen Figuren seine den Dorfgeschichten vorangehenden Versuche, sich als dezidiert jüdischer Autor zu etablieren, wurden von ihm fallengelassen. ${ }^{223}$ Aber die Texte zeigen, dass auch die deutsch-jüdische Problematik zumindest eine Facette dieser Themen bildet, ${ }^{224}$ und die biographische Notiz lässt erahnen, dass die Dringlichkeit dieser Themen auch hier einen Ursprung haben mag.

Auerbachs Bemühungen um eine sozial befriedete deutsche Nation, die mit den Vokabeln von Volk, Volksgeist und Volkstum beschworen wird, stehen in einer aufklärerischen Tradition, die auch das Fremde nicht als feindlich, sondern als Bereicherung zu sehen bereit ist. Der moderne Volksgeist, so Auerbach optimistisch in seiner dem Vorbild Johann Peter Hebel gewidmeten Programmatik Schrift und Volk von 1846, will sich nicht abschließen, sondern Fremdes ,heimisch“ machen. So wie die Völker „fremde Pflanzen [...] in ihre Heimaterde übergesiedelt“ haben, sei auch „auf dem Boden des Geistes vieles Fremde ganz heimisch geworden““.225 Auerbach kleidet seine Poetologie in die dialektische Figur von Fremde und Heimat (vgl. I.2.3). Hebel als Autor der Allemannischen Gedichte wird mit einem aus der Fremde Heimkehrenden verglichen, der es fortan auch den

220 Vgl. Berthold Auerbach: Die Kriegspfeife, in: Auerbach 1857, S. 45-66, hier S. 58.

221 Berthold Auerbach: Tonerle mit der gebissenen Wange, in: Auerbach 1857, S. 121-150, hier S. 121 .

222 Andere Beispiele (Die Sträflinge, Die feindlichen Brüder, Ivo der Hajrle, Florian und Kreszenz, Der Lauterbacher, Luzifer) wählt der bezogen auf die Heimat-Thematik insgesamt instruktive Aufsatz von Hans Otto Horch, vgl. Horch 2004.

223 Mit dem literaturästhetischen Essay Das Judenthum und die neueste Literatur (1836), den Romanen Spinoza (1837) und Dichter und Kaufmann (1840) hatte Auerbach kaum Erfolg.

224 Vgl. Horch 2004. Stark gemacht wird der Bezug auch von Carsten Rohde; vgl. Rohde 2014. Rohde versteht „Heimat und Fremdheit“ bei Auerbach auch „als biographisches Narrativ“ (Rohde 2014, S. 82) und diskutiert, inwiefern dieses auch in Anton Bettelheims Monographie zu Auerbach eine zentrale Rolle spielt, vgl. Bettelheim 1907.

225 Berthold Auerbach: Schrift und Volk. Grundzüge der volksthümlichen Literatur, angeschlossen an eine Charakteristik J.P. Hebel's (1846), in: Auerbach 2014, S. 7-173, hier S. 31. 
Daheimgebliebenen ermöglicht, das Eigene mit neuem Blick zu betrachten. Heimat gelangt so über ihre Entgegensetzung wieder zu sich selbst, ohne noch die gleiche zu sein. Die in der Fremde gemachte Erfahrung von „Gegensatz“ und „Entzweiung“ wird zurück in der Heimat in eine „Vermittlung“ überführt. Altes und Neues feiert „Auferstehung“ und kann als ein neues Drittes ,verkündet“ werden. ${ }^{226}$ Die eingesetzte religiöse Sprache unterstreicht, dass die neue Heimat nicht als schlechtes Surrogat für die alte, nicht mehr wiederzugewinnende zu verstehen ist, sondern als deren Steigerung. Direkt im Anschluss wird das dialektische Bild auf Hebel übertragen. Das räumlich verstandene In-die-FremdeFahren wird hier auf die Bildungsgeschichte Hebels, dessen „Gedankenfahrten“ in die historische Vergangenheit und verschiedenste Wissensgebiete, übertragen. Auch hier wird das dialektische Verständnis vom Durchgang durch Heimat und Fremde als Bedingung für den Gewinn einer neuen Heimat ins religiös konnotierte Bild einer auf diesem Weg gewonnenen ,neuen Glorie‘ gefasst. ${ }^{227}$

Der Vorstellung von Heimat wird damit ein integratives Potential zugesprochen. Sie ist in der Lage, das Fremde in sich aufzunehmen, und die dadurch initiierte Transformation führt sie zu ,neuer Glorie‘. Das Aufklärungsprogramm, das dieser Lesart von Heimat inhärent ist, gibt der Hebel-Verehrer Auerbach nie auf. Aber er wird zunehmend enttäuscht vom anwachsenden, antisemitisch grundierten Nationalismus: „Rätselhaft ist mir der neuerwachte furor teutonicus gegen die Juden. Ich möchte die Grundzelle finden. Besteht sie vielleicht darin, daß das Selbstgefühl der Deutschen jetzt erwacht ist?“, fragt er seinen Freund Jakob Auerbach 1876. „Aber der Judenhaß war ja auch in Zeiten der Unterdrückung und besonders stark in den 18 Jahren der Reaction von 1812-30. Wo steckt es also?“228

Zur aufklärerischen - oder zumindest anti-romantischen - Lesart von Heimat gehört bei Auerbach, dass Heimat nicht primär transzendent aufgefasst wird, sondern auch in ihren ganz konkreten und alltäglichen Erscheinungsformen wie dem Heimatrecht thematisiert wird. So sind Auerbachs Schwarzwälder Dorfgeschichten im Zusammenhang mit Heimat nicht zuletzt deshalb bemerkenswert, weil sie zu den frühesten Zeugnissen einer literarischen Verarbeitung des Hei-

226 Alle Zitate Auerbach 2014, S. 29; die Passage zum Heimkehrer wird in I.2.4 ausführlicher wiedergegeben und unter dem Aspekt ihrer Dialektik besprochen.

227 Alle Zitate Auerbach 2014, S. 29-30; auch die Passage zu Hebel wird in I.2.4 im Zusammenhang zitiert.

228 Beide Zitate: Berthold Auerbach an Jakob Auerbach am 1. Januar 1876, in: Auerbach 2015, Bd. 2, S. 269-270, hier S. 269. 
matrechts überhaupt gehören. Diese Thematisierung des Heimatrechts wird bei Auerbach immer wieder mit dem Thema der Auswanderung verbunden. ${ }^{229}$

Auerbachs Erzählung Des Schloßbauers Vefele wird zuerst 1842 in der Zeitung für die elegante Welt (Nr. 73-78) gedruckt. Es ist seine erste Dorfgeschichte, die dann 1843 in den ersten Band der Schwarzwälder Dorfgeschichten aufgenommen wird. Am Ende der Erzählung wird die von dem Heiratsschwindler und vorgeblichen Amerika-Auswanderer ${ }^{230}$ Brönner schwangere und verlassene Vefele aus dem Dorf ihres Bruders vertrieben. Hier hatte sie nach dem Tod ihres Vaters ein Unterkommen gefunden. Aber der Schultheiß des Ortes, selbst einmal Bewerber um Vefeles Gunst, toleriert den Aufenthalt nicht, als er von ihrer unehelichen Schwangerschaft erfährt. Er ,ließ Vefele durch den Dorfschützen sagen, es müsse das Dorf verlassen und nach seinem Geburtsort zurückkehren, da sonst das Kind, wenn es hier geboren würde, Heimathsrechte ansprechen könnte“ . ${ }^{231}$ Die Folgen sind tragisch, Vefele schlägt ein letztes Hilfsangebot aus, verlässt den Ort und ertränkt sich im Fluss. Kurz vor ihrem Selbstmord sieht sie in einer Vision den untreuen Brönner, der ihr alles Geld entwendet hat, auf der Überfahrt nach Amerika bei einem Schiffbruch sterben.

Der Begriff der Heimat kommt in dieser Dorfgeschichte nur in Form der Heimatrechte vor, die gegen die ins Elend gefallene Vefele angewendet werden. Damit wird auf eigenwillige Art das Hauptthema der Erzählung - der Ausschluss aus der Gesellschaft - variiert. Zu diesem Thema gehören der aus einem anderen Dorf stammende und auch nach dreißig Jahren Ansässigkeit nicht als zur Dorfgemeinschaft gehörig akzeptierte Schloßbauer, der Vater Vefeles, dessen Rechtsstreitigkeiten mit dem ganzen Dorf dazu führen, dass auch seine Kinder als Ausgestoßene behandelt werden und seine darüber in Depressionen fallende Frau stirbt. Es geht um die psychologischen Folgen des Ausschlusses und des Stolzes der Ausgeschlossenen, wie am Schloßbauern und schließlich auch an Vefele vorgeführt wird, die keinen Bauern mehr heiraten und doch auch die Stadtkleider nicht tragen will. Zum Thema gehört auch der Dorfjude, der sich mit seinen Schachereien nicht beliebt macht, aber am Ende zum „theilnehmenden

229 Zur Auswanderungsthematik bei Auerbach (allerdings nicht mit Blick auf das Heimatrecht) vgl. auch Wild 2011, S. 188 - 198, Susteck 2008; Belgum 2009; Hamann 2013, Hamann 2014, S. 177 202.

230 Die weit entfernte Neue Welt wird zur auch literarisch genutzten Möglichkeit, Identitäten zu verschleiern, wie hier mit der Figur Brönner. Und sie wird in unzähligen anderen Auswanderergeschichten literarisch gestaltet, wie etwa mit der Figur des Joseph Henkel in Friedrich Gerstäckers Nach Amerika!

231 Berthold Auerbach: Des Schloßbauers Vefele, in: Auerbach 1857, S. 69-117, hier S. 113. 
Bruder“232 der Selbstmörderin wird. ${ }^{233}$ Eine weitere Variation des Themas ist das Heimweh der im Feldzug nach Russland gefallenen ältesten Söhne des Schloßbauern, Philipp und Caspar. Die kurze Episode sei in Gänze als charakteristisch für die lapidare, skizzenhaft-szenische Erzählkunst Auerbachs wiedergegeben:

Der Philipp und der Caspar sind wahrscheinlich im russischen Schnee begraben, man hat nie mehr etwas von ihnen gehört; nur das Eine hat der General Hügel oft erzählt: Auf dem Rückzuge von Moskau aus sah er einen Soldaten, der etwas abseits ging und dem die Kälte oder die Noth und das Heimweh, oder vielleicht Alles zusammen, die Thränen stromweise über die Backen herunterrinnen machte. Der General ritt auf ihn zu und fragte ihn freundlich: „Woher?“ / „I bin des Schloßbauern Bua vom Schwarzwald do obe ra!“ erwiederte der Soldat, nach der Seite zudeutend, als ob seines Vaters Haus nur einen Büchsenschuß weit dort um die Ecke läge. Der General mußte über die Antwort des Soldaten, der in Gedanken so nahe zu Hause war, so herzlich lachen, daß auch ihm Thränen über die Backen liefen, die aber in seinem langen Schnurrbarte als Eistropfen hängen blieben. / Das ist Alles, was die Geschichte über das Leben und Ende der beiden Söhne des Schloßbauern berichtet. ${ }^{234}$

Das Heimweh, das im 19. Jahrhundert im Kräftefeld zwischen Literatur, Religion und Medizin ganz unterschiedlichen Auslegungen unterliegt, wird hier entsprechend den zeitgenössischen medizinischen Fallbeschreibungen dem ,einfachen Volk‘ zugeschrieben. Der Abwertung, die das in der Medizin der Zeit mit sich bringt, wird in der Literatur und auch hier bei Auerbach nicht gefolgt. ${ }^{235}$ Anrührend ist die Textstelle gerade deswegen, weil ihren Protagonisten Sentimentalität fremd ist: Es bleibt offen, was die Ursache der Tränen des Soldaten ist und auch seine Antwort auf die Frage des Generals ist denkbar lapidar. Die Tränen des

232 Auerbach 1857, S. 116.

233 Zur Thematik von Heimat und Fremde unter dem Aspekt des Deutsch-Jüdischen in Des Schloßbaueren Vefele vgl. ausführlich Horch 2004, S. 155-157.

234 Berthold Auerbach: Des Schloßbauers Vefele, in: Auerbach 1857, S. 69-117, hier S. 82-83. 235 Der Mediziner Ludwig Meyer schreibt 1855 in Der Wahnsinn aus Heimweh explizit gegen literarische Darstellungen des Phänomens ,Heimwehs‘ an; tatsächlich sei Heimweh eine Geisteskrankheit, die sich nur bei schwachen Intelligenzen auspräge: Es sei eine „Lächerlichkeit [...], das Heimweh als die Sehnsucht eines zarten Gemüts nach der erhabenen Szenerie und dem idyllischen Leben einer heimatlichen Landschaft aufzufassen. Der beschränkte Bildungsgrad und die meist träge Natur der an Nostalgie Leidenden eignet sich am wenigsten für eine derartige ästhetische Auffassung. Nimmt die Poesie demnach das Heimweh in diesem Sinne zum Vorwurf ihrer Darstellungen, so entsprechen die Empfindungen, welche jene Vorstellungen erwecken, am allerwenigsten den Empfindungen des Heimwehs. [...] Das Heimweh ist eine passive asthenische Geisteskrankheit von vorne herein, ihre Symptome sind Symptome eines individuellen Mangels, sind Schwächesymptome [...]. Es scheint in seiner ersten Entfaltung mehr die Reaktion des Gemütes gegen die Hilflosigkeit einer schwachen und seiner gewöhnlichen Stütze beraubten Intelligenz zu sein.“ Meyer 1855, S. 8. Karl Jaspers zitiert und kommentiert Meyer ausführlich in Heimweh und Verbrechen (1909), vgl. Jaspers 2019, S. 26-28. 
Generals sind Lachtränen, die nur verschlüsselt in Form ihres unmittelbaren Wechsels in einen anderen Aggregatzustand als Vorahnung des Todes lesbar sind.

In Des Schloßbauers Vefele sind Heimat bzw. das Heimatrecht und die Auswanderung thematisch eher lose miteinander verbunden und beide variieren nur leicht das Thema scheiternder Dazugehörigkeit. In Der Viereckig oder die amerikanische Kiste rücken Heimat und Auswanderung ins Zentrum. Die Dorfgeschichte erscheint zuerst 1852 in den Unterhaltungen am häuslichen Herd. Auswanderung ist auch in dieser Zeitschrift ein kontinuierliches Thema. Im Jahrgang 1852 ist beispielsweise in der Rubrik Anregungen unter dem Titel Auch ein Auswandererbild eine zynische Abrechnung mit dem Phänomen der Auswanderung zu lesen. Die Motivation der Auswanderer sei nur eine „gedankenlose, leere und nichtige Sucht der Neuerung“, und ihr Ursprung sei ein Mangel an ,Heimatsinn“. Dieser Mangel an Heimatsinn, der Hang „zum nichtsnutzigen Weltwandern“, wird als spezifisch deutsch charakterisiert - eine Aussage, die man Ende des 18. Jahrhunderts vermuten würde. Im 19. Jahrhundert (und darüber hinaus) wird gewöhnlich das Gegenteil behauptet.

Es sind zwei Dinge, die an den Auswanderern geradezu abstoßend und peinlich sind. Einmal der Mangel jenes allen Nationen tief einwohnenden Heimatsinns, dieser Mangel, den fast alle Deutsche theilen. Die Auswanderer treibt nicht die Noth, nicht eine Betrachtung über das deutsche Vaterland hinweg: nur die deutsche Abenteuerlust und der uralte Hang unsers Volks zum nichtsnutzigen Weltwandern. Ganze Länderstrecken bei uns leben jetzt in diesem amerikanischen Sehnsuchtstaumel, der sich auf nichts begründet als auf einen, nur den Deutschen eigenen Köhlerglauben an alles Fremde und Entfernte ... ${ }^{236}$

Auch Auerbachs Der Viereckig oder die amerikanische Kiste interessiert sich für den ,amerikanischen Sehnsuchtstaumel' und seine Beziehung zum ,Heimatsinn“, aber auf komplexere Weise. Zentrales Thema dieser erzählerisch zu den besten Leistungen Auerbachs zählenden Dorfgeschichte ist, wie die Auswanderung unabhängig vom tatsächlichen Vollzug - Imaginationskräfte weckt, die Heimat überhaupt erst als Kategorie entstehen lassen und sie zugleich zerstören. Mit dem fulminanten Beginn der Erzählung wird in die Thematik von Glauben, Unglauben und Einbildungskraft eingeführt:

„Ich glaub’ nicht an Amerika“, sagte einst die alte Lachenbäuerin in der Hohlgasse, als man ihr Vielerlei und darunter auch Fabelhaftes von dem fernen großmächtigen Land erzählte. Die Leute erlustigten sich über diese einfältige Rede, denn die Lachenbäuerin hatte keineswegs damit nur sagen wollen, daß sie nicht an die Verheißungen und Hoffnungen

236 Anonym: Auch ein Auswandererbild, 1852, alle Zitate S. 64 (die Auslassungspunkte gehören zum Zitat). 
Amerika's glaube, sie erklärte sich einfach dahin, sie glaube überhaupt nicht an das Dasein von Amerika, das sei alles lauter Lug und Trug. Sie bemühte sich dazu nicht zu mehr Beweisen, als die Großen am spanischen Hofe gegen Columbus vorbrachten, sie glaubte eben nicht an Amerika, und fester Unglaube lässt sich ebenso wenig überführen als fester Glaube. / Wenn heutigen Tages Jemand im Dorf durch irgend welche Hindernisse nicht nach Amerika auswandern kann, hilft er sich mit der Scherzrede: „Ich glaub’ nicht an Amerika, wie die alte Lachenbäuerin.“ / Es gibt aber auch landauf und landab kein Haus mehr, in dem man nicht den lebendigen Beweis vom Gegentheil hätte. Da ist ein Geschwister, dort ein Verwandter oder auch nur ein Bekannter in Amerika, man weiß den einzelnen Staat zu nennen, in dem sie sich angesiedelt haben, man hat Briefe von ihnen gelesen und gehört. ${ }^{237}$

Der eröffnende und im weiteren Erzählverlauf leitmotivisch eingesetzte Satz „Ich glaub' nicht an Amerika“, der Unglaube also der alten Lachenbäuerin, dass es Amerika überhaupt gebe, schlägt das Thema des Umgangs mit den Verheißungen der Fremde an, für die Amerika steht. ${ }^{238}$ Diese Verheißungen werden durch die Briefe der ausgewanderten Verwandten und Bekannten, aber auch durch die Werbebroschüren und -plakate der Auswanderungsagenturen verbreitet, die an den Wirtshauswänden hängen.

Realweltlich ist die Rolle der Auswanderungsagenturen für die Migrationsbereitschaft belegt: Sie halfen bei der Beschaffung der für die Auswanderung notwendigen Papiere, insbesondere bei der Organisation der Überfahrt; ab 1840 hatten sie fast vollständig den direkten Vertragsabschluss zwischen Passagieren und Reedereien verdrängt. Die insbesondere in den 1850er und 60er Jahren möglich gewordene enorme Gewinnspanne für die Makler steigerte deren Interesse, die Bedingungen für die Auswanderer in Amerika schönzumalen. Dies ging bis zur Verbreitung gefälschter Briefe und Berichte, die das angebliche Glück der Emigranten schilderten. Aber auch schon die Werbung in Wirtshäusern wurde von staatlicher Seite immer wieder moniert, wenn auch ohne Möglichkeit, juristisch einzuschreiten. 1881 kritisiert die Königliche Polizei-Direktion in Wiesbaden, dass „fast in sämmtlichen Wirtshäusern“ die Fahrpläne der großen Beförderungsfirmen mit zusätzlicher Eigenwerbung der Auswanderungsagenten plakatiert seien. Besorgnis errege dies, „da durch diese Plakate der ohnehin schon starke Auswanderungstrieb nur noch mehr gefördert wird. Ein solches Plakat dürfte wohl schon oft indirekte Veranlassung zur Auswanderung gegeben haben.

237 Auerbach: Viereckig, 1858, S. 183-184.

238 Nach Amerika führt der Großteil der Auswanderungen des 19. Jahrhunderts. Der allergrößte Anteil der Auswanderer wählte Nordamerika; Südamerika wurde nur für zehn Prozent der Auswanderer zum Ziel. Hier war wiederum Brasilien das wichtigste Einwanderungsland für die Deutschen, dorthin wanderten in der zweiten Hälfte des 19. Jahrhunderts ca. fünf- bis zehntausend Deutsche pro Jahr aus. 
Es lenkt die Aufmerksamkeit auf sich und giebt Stoff zur Unterhaltung in den Wirtshäusern.“'239

Die Plakate der Auswanderungsagenturen, „Meisterstück[e] der Buchdruckerkunst“, 240 gedruckte Bilder, gedruckte Worte, wecken auch aus der Perspektive von Auerbachs auktorialer Erzählerinstanz gerade im Umfeld des Wirtshauses bei den Bauern Wünsche und Hoffnungen und befördern das unablässige Gespräch über das Auswandern, „und kehren sie dann heim in ihre Behausungen, so kommen sie aus dem fernen Land zurück, und spät in der Nacht wird noch mit der Frau überlegt, ob man nicht auch auswandern wolle, dahin, wo man nicht mehr zinse und steuere““. ${ }^{241}$ Es geht der Erzählinstanz nicht darum, die Auswanderung zu verurteilen, sondern eher um eine psychologische Studie, was die Verlockungen der Fremde für die Daheimbleibenden bedeuten. Denn Heimat verändert sich unter den Bedingungen der Auswanderung auch für diejenigen, die sie nie verlassen:

Es wäre thöricht, die unabsehbare Befruchtung und den großen Alles bewältigenden Zug der Menschheitsgeschichte in dem Auswanderungstriebe verkennen zu wollen. Das hindert aber nicht, ja fordert eher dazu auf, die Herzen derer zu erforschen, die, vom Einzelschicksale gedrängt in die Reihen der Völkerwanderung eintreten, deren weltgeschichtliche Sendung unermeßbar und den Einzelnen, die mitten im Zuge gehen, unerkennbar ist. Daneben ist es von besonderem Belang zu beobachten, welche Wandlung solch ein Trieb, der die ganze Zeit ergriffen, im beschränkten Lebenskreise der Scheidenden und Verbleibenden hervorbringt. ${ }^{242}$

Den Folgen, die jene „Hoffnungen für Amerika“, die „zu hoch gespannt, zu träumerisch unklar waren, weil man ein Fabelreich daraus machte“, ${ }^{243}$ auch für diejenigen haben, die nie auswandern, gilt nach der einleitenden auktorialen Reflexion das Interesse der Erzählung. In ihrem Zentrum steht Xaveri, der Enkel der alten Lachenbäuerin. Xaveri behauptet schon als Kind, nach Amerika auswandern zu wollen. Was als halbes Spiel, als Druckmittel gegen den Bruder, als Reaktion auf bloßes Gerede beginnt, wird ernst für den Erwachsenen: Er ist nun

239 Zitiert nach der Studie von Agnes Bretting und Hartmut Bickelmann zu Auswanderungsagenturen und Auswanderungsvereinen im 19. und 20. Jahrhundert, vgl. Bickelmann/Bretting 1991, S. 57. Im ersten Teil wird quellengesättigt über die Ausbildung des Gewerbes der Auswanderungsagentur, ihre Formen der Werbung und die gesetzlichen Maßnahmen zur Kontrolle des Agentenwesens, im zweiten Teil über die Programmatik und Praxis der Auswanderervereine informiert.

240 Auerbach: Viereckig, 1858, S. 184.

241 Auerbach: Viereckig, 1858, S. 184-185.

242 Auerbach: Viereckig, 1858, S. 185-186.

243 Auerbach: Viereckig, 1858, S. 188-189. 
selbst davon überzeugt, demnächst sein Leben in Amerika fortzuführen. Dadurch ändert sich der Bezug zu seiner Lebenswelt grundsätzlich. Er fühlt sich zum Müßiggang berechtigt, denn „er zog ja von dannen und durfte sich's wohl noch in der Zeit seines Verweilens in der Heimath bequem machen“, ${ }^{244}$ so Xaveri. Weil alles zu einer zukünftigen radikalen Veränderung des eigenen Lebens in Bezug gesetzt wird, erscheint die eigene Gegenwart wertlos. Die Vorstellung ,Amerika‘ führt zu einem falschen Leben im richtigen. ${ }^{245}$

In Anbetracht der baldigen Auswanderung kümmert sich Xaveri um die Auswanderungspapiere, kauft sich Kleidung für die Neue Welt und eine große Transportkiste für die Überfahrt. Er gibt auch offiziell sein Heimatrecht auf:

Xaveri war indes an diesem Tage vor dem versammelten Gemeinderathe erschienen und hatte seinen Austritt aus der Gemeinde gemeldet. Der Schultheiß rieth ihm, daß er gar nicht nöthig habe, sein Heimathsrecht aufzugeben, er könne sich einfach einen Paß nehmen, und wenn es ihm in Amerika nicht gefalle, wieder zurückkehren oder auch unterwegs andern Sinnes werden. Xaveri lachte höhnisch über diese Zumuthung und drang jetzt gerade um so mehr auf Entlassung aus dem Orts- und Heimathsverbande. ${ }^{246}$

Der Schultheiß überbringt Xaveri die Entlassungspapiere und sagt „spöttisch, daß er ihn nun als Fremden im Dorfe begrüße; er sei hier nicht mehr daheim“. ${ }^{247}$ Heimat als gelebtes Sozialgefüge und das Heimatrecht geraten hier (anders als in Des Schloßbauern Vefele und in Barfüßele) nicht in Konflikt miteinander. Der Entzug der Heimatrechte vollzieht sich innerhalb eines funktionierenden sozialen Netzwerks. Der Schultheiß als Vertreter der Administration rät Xaveri, sein Heimatrecht zu behalten. Nicht die Unmenschlichkeit eines Systems, sondern die Starrköpfigkeit eines Einzelnen soll an dieser Stelle dargestellt werden. ${ }^{248}$ Mit der rechtlichen Heimat weist Xaveri zugleich Heimat als soziale und emotionale Zugehörigkeit zurück.

244 Auerbach: Viereckig, 1858, S. 219.

245 Theodor W. Adornos Satz - „Es gibt kein richtiges Leben im falschen“ - ist der letzte Satz des Aphorismus Nr. 18 „Asyl für Obdachlose“, in dem es um die Problematik der Heimatlosigkeit in der Moderne geht. Vgl. Adorno 1997, S. 43.

246 Auerbach: Viereckig, 1858, S. 226-227.

247 Auerbach: Viereckig, 1858, S. 228.

248 Es ist charakteristisch für Auerbachs Texte, dass Konfliktsituationen aus der Gemengelage von Charakterdisposition der beteiligten Figuren, aus der psychologischen Dynamik von Personenkonstellationen und aus den sie grundierenden sozio-ökonomischen Verhältnissen entwickelt werden. Bei seiner Figur Xaveri handelt es sich um die Mischung aus Starrköpfigkeit und Überlegenheitsgefühl, aber auch überzogenen Erwartungshaltungen seines Umfelds - aus denen andererseits wieder Missgunst Einzelner entsteht, die zum Konflikt beiträgt. 
Xaveris Auswanderungsvorbereitungen führen zu Verzweiflung in der Familie. Seine Mutter verschwört sich mit einer eigentlich von ihr abgelehnten jungen Witwe, die Xaveri heiraten möchte, um ihren Sohn auf diesem Weg zu halten. Als dieser sich schließlich tatsächlich überreden lässt zu bleiben, muss er sich unter Spott wieder in die Gemeinde aufnehmen lassen: „Die Leute waren ihm fast gram, daß er sie um ihre Theilnahme an seinem Weggehen betrogen hatte; sie hatten ihm diese gewidmet und er war ihnen nun auch schuldig, wegzugehen." Immer wieder richtete man die Frage an ihn, ,wie es in Amerika aussehe, und wie er die Seekrankheit überstanden habe“. ${ }^{249}$ Die halbherzig eingegangene Ehe ist von Anfang an unglücklich und der Glaube, nur in Amerika sein Glück finden zu können, wird Xaveri zur festen Gewissheit:

Der Gedanke der Auswanderung hatte ihn erlahmt, er hatte sich gewöhnt, das Dorf gar nicht mehr als den Kreis seiner Thätigkeit anzusehen, er hatte, so zu sagen, auf einen neuen Lebensmontag gehofft, an dem er sich scharf in's Geschirr legen wollte; jetzt sollte er mitten in der alten Woche im alten Gleise doppelt frisch zugreifen. Und wie das Dorf und Alles, was darin vorging, ihm keine Freude mehr machte - weil er sich daran gewöhnt hatte, sich nur von einem ganz andern Leben, von ganz andern Verhältnissen Erfrischung zu versprechen und Alles, was um ihn her vorging, gleichgültig zu betrachten - so war ihm auch gleicherweise das erheirathete Anwesen alt und morsch, es bot keine Gelegenheit, mit starker Kraft etwas ganz Neues zu schaffen, wie er sich's so glänzend ausgedacht hatte..$^{250}$

Die Situation wird immer unerträglicher und führt zum neu gefassten Entschluss, tatsächlich und endgültig alles hinter sich zu lassen. Erst zu diesem Zeitpunkt wird der Ort der eigenen Gegenwart zur emphatisch empfundenen Heimat: „Dann warf er sich wieder auf das Antlitz nieder, als wolle er sich in die Heimatherde einbohren und eingraben. Jetzt liegst du noch auf der Heimatherde, und bald mußt du sie verlassen!“251

Es gibt zwei Enden der Erzählung. In der überarbeiteten, in alle späteren Fassungen übernommenen Variante kehrt Xaveri nach Ablauf von drei Jahren geläutert zurück und beginnt ein gelingendes Leben: Die Misserfolge in der Fremde haben ihn gelehrt, was er an der Heimat hat, und geben ihm die Kraft, von vorn anzufangen. In dieser verklärten Variante wird die Möglichkeit gelingender Heimat in Aussicht gestellt, auch wenn dies innerhalb der Erzählung nicht mehr ausgeführt wird.

In der ersten Fassung von 1852, die in Karl Gutzkows Zeitschrift Unterhaltungen am häuslichen Herd erschien, gibt es diese Aussicht nicht. Hier kommt

249 Alle Auerbach: Viereckig, 1858, S. 235.

250 Auerbach: Viereckig, 1858, S. 237-238.

251 Auerbach: Viereckig, 1858, S. 255. 
wenige Wochen nach Xaveris Aufbruch die Reisekiste, die schon Jahre früher zum Symbol seines im Vorsatz erstarrten Aufbruchs geworden war, ohne ihren Besitzer zurück: Xaveri ist beim Einladen der Kiste im Hafen von Le Havre von ihr erschlagen worden, wie es lapidar heißt. ${ }^{252}$ Der die Erzählung eröffnende Satz der alten Lachenbäuerin, dass sie nicht an Amerika glaube, bestätigt sich hier in seiner ganzen latenten Komik: So wie die Lachenbäuerin nicht sagen will, dass sie nicht an die Verheißungen Amerikas glaube, sondern an seiner puren Existenz zweifelt, so scheitert Xaveri nicht an der Fremde, sondern erreicht sie schlicht nicht. $^{253}$

Auerbachs Barfüßle (1856), paratextuell teilweise als Roman, teilweise als Erzählung eingeordnet, zeitgenössisch zum internationalen Erfolg geworden und in fast alle europäischen Sprachen übersetzt, von der zeitgenössischen Literaturkritik gleichwohl als manieriert abgelehnt und von Literaturhistorikern zu den schwächeren Texten Auerbachs gezählt, wird neuerdings im Hinblick auf seine artifizielle Selbstreflexivität ästhetisch wieder ernster genommen. ${ }^{254}$ Die Erzählung des märchenhaften Aufstiegs der Protagonistin Amrei vom bitterarmen Waisenkind zur wohlhabenden Bauersfrau tauscht den charakteristischen, zwischen Nüchternheit und Emphase changierenden auerbachschen Erzählerton der 1840er und früheren 50er Jahre jedenfalls oft gegen einen sentimentalen ein. Die sozialen Härten unter den Bedingungen ärmster dörflicher Verhältnisse werden aber gleichwohl Thema, unter anderem auch die des Heimatrechts. ${ }^{255}$

Erzählt wird, wie die verwaisten Geschwister Amrei und Dami, schon als Kleinkinder im Dorf hin- und hergestoßen, kaum Barmherzigkeit Einzelner oder Fürsorge der Gemeinde erfahren. Damis schließliche Auswanderung nach Amerika als Halbwüchsiger zeigt dann die zweifelhafte Fürsorge der Gemeinde, die sich mit der Übernahme der Reisekosten von weiterer finanzieller Unterstützung freikauft: „es sei beim Gemeinderath Alles bewilligt, aber nur auf die Bedingung hin, daß Dami jedes Heimathsrecht im Dorf aufgebe“, ${ }^{256}$ heißt es, und weiter: „Er mußte vom Schiff aus, bevor dasselbe in's weite Meer segelte, eine Bescheinigung

252 Vgl. Auerbach 1853, hier Nr. 31, S. 484 und S. 485.

253 Zum doppelten Ende von Der Viereckig und der Erzählung insgesamt vgl. auch die Interpretation von Christof Hamann, Hamann 2014, S. 185-187, im Kontext seiner Darstellung der Bilder und Funktionen von Amerika und der ,Semantik der Fremde، in Auerbachs Schwarzwälder Dorfgeschichten, Hamann 2014, S. 177-202.

254 Vgl. Born 2016.

255 Auf den rechtlichen Aspekt von Heimat im Barfüßele geht Carsten Rohde innerhalb einer konstellativen Lektüre mit Gottfried Kellers Romeo und Julia auf dem Dorfe ein; vgl. Rohde 2014, S. 61-90.

256 Auerbach: Barfüssele, 1858, S. 111. 
seiner Abfahrt unterzeichnen und erst dann wurde das Geld ausgezahlt.“ Die Schwester empfindet bei dieser Nachricht „ein tiefes Wehe, daß doch ihr Bruder eigentlich wie auf dem Schub fortgeschafft würde“. ${ }^{257}$ Der Gemeinderat dagegen „pries seine Weisheit, daß er sich von einem Menschen befreit habe, der gewiß einmal der Gemeinde zur Last gefallen wäre““. ${ }^{258}$ Dami kehrt erfolglos aus Amerika zurück; er hat dort sein Glück nicht machen können. Es kommt nicht so, wie er vor der Abfahrt getröstet worden ist (,Wirst sehen, wie gern du dann hier wieder die Bürgerannahme bekommst“259 - dann nämlich, wenn er mit Geld heimgekommen wäre). Der Gemeinderat verkündet Dami, „daß er aus dem Ort ausgewiesen sei; er habe kein Recht hier zu bleiben, um vielleicht der Gemeinde wieder zur Last zu fallen“. ${ }^{260}$ Als „Fremder“ habe er die Erlaubnis, „drei Tage im Dorfe zu bleiben; habe er bis dahin kein Unterkommen gefunden, werde er ausgewiesen und nöthigenfalls mit Zwangsmitteln über die Grenze gebracht“. ${ }^{261}$ Zwar gibt es Zweifler an dieser Rechtsauslegung - „Zuträger sagten dem Dami, er solle nur einen Proceß anfangen, man könne ihn nicht ausweisen, weil er noch an keinem andern Orte angenommen sei, das sei stillschweigende Voraussetzung beim Aufgeben des Heimathsrechtes“262 - aber Damis weiterer Lebensweg bringt keine Befreiung aus seiner armseligen Lage. Das liegt an den sozio-ökonomischen Verhältnissen, aber auch an den charakterlichen Dispositionen Damis, wie sie der Text differenziert entwickelt.

An einer früheren Stelle der Erzählung geht es um die Entscheidung seiner Schwester Amrei gegen eine Auswanderung. Auch diese ist in einem rechtlichen Kontext situiert: Der Onkel der elternlosen Kinder wandert nach Amerika aus und will Amrei und Dami mitnehmen. Dies könne er aber nicht so ohne weiteres, wird ihm mitgeteilt: „[M]an kann das nicht ohne den Gemeinderath, und der kann's nicht einmal allein. Die Kinder haben hier ein Heimathsrecht.“263 Die Kinder selbst sollen deshalb zwischen Dableiben und Fortgehen wählen. Die Selbstvergewisserungsszene, die das Fortmüssen aus der Heimat thematisiert, zeigt die einsame und über ihrer Entscheidung verzweifelnde Dreizehnjährige inmitten der Natur. Amrei beneidet die Pflanzen und die Tiere um den Platz, den ihnen niemand streitig macht: „Amrei stand an dem Vogelbeerbaum und legte die Hand an seinen Stamm und sagte: ,Du, warum gehst du denn nicht fort? warum heißen

257 Beide Zitate Auerbach: Barfüssele, 1858, S. 112.

258 Auerbach: Barfüssele, 1858, S. 115.

259 Auerbach: Barfüssele, 1858, S. 113.

260 Auerbach: Barfüssele, 1858, S. 168.

261 Auerbach: Barfüssele, 1858, S. 170.

262 Auerbach: Barfüssele, 1858, S. 172.

263 Auerbach: Barfüssele, 1858, S. 34. 
dich die Menschen nicht auch auswandern?““264 Sie nimmt sich den Star zum Vorbild, der auch „nicht in ein Haus von neuen Brettern zieht“. ${ }^{265}$ Amreis Heimatverständnis bindet sie - trotz Armut und Elternlosigkeit und obwohl sie kaum menschliche Zuwendung erfährt - emotional an den Ort ihrer Herkunft. Die Szene schließt mit einem Erzählerkommentar: Amrei sei eingeschlafen ,auf der Heimatherde, von der sie sich nicht trennen konnte“. ${ }^{266}$ Mit der zeittypischen Kombination der Lexeme Heimat und Erde wird eine naturhafte Verwurzelung der Protagonistin mit dem Ort ihrer Herkunft evoziert. Heimat ist hier keine juristische, sondern eine vermeintlich natürliche Kategorie.

Beide Erzählstränge, der von Damis Verstoßung durch die Gemeinde aufgrund des Heimatrechts und der von Amreis Entscheidung für die Heimat, kreuzen sich in der Reaktion Amreis auf das Bestreben der Gemeinde, den Bruder auszuweisen. Sie setzt Moral gegen Gesetz und plädiert für eine Heimat, die jenseits aller Verordnungen dem Menschen zustehe: „Man kann Niemand ausweisen aus dem Ort, wo seine Eltern begraben sind, da ist er mehr als daheim; und wenn's tausend und tausendmal da in den Büchern steht.“267 Hier ist es eine naturrechtliche Heimat, die moralisch eingefordert wird und sich im Widerspruch $\mathrm{zu}$ einer rechtspositivistischen Heimat befindet.

Diese in den natürlichen Ansprüchen des Menschen fundierte Heimat erlangt in einem betont märchenhaften Ende ihr moralisches Recht. Denn die bescheidene, arbeitsame und moralisch feste Amrei macht wie Aschenputtel am Ende ihr Glück - nicht als Braut des Prinzen, aber als die des Allgäuer Landfriedbauern Johannes. Dieser war von den Eltern in die mütterliche „Heimath geschickt“ worden, um sich von dort „eine Frau zu holen“. ${ }^{268}$ Im Schwarzwald, der Heimat seiner Mutter, findet er Amrei und führt sie ins Allgäu heim. Matriarchale und patriarchale Semantiken gehen in dieser Konstruktion eine harmonische Einheit ein: So wie Amrei klaglos die eigene Heimat für die des Mannes aufgibt (wie es das Heimatrecht realweltlich auch vorsieht), ist es eben die Heimat der Mutter, in der der Mann seine Zukünftige sucht und findet.

Offensichtlich prallen im Roman verschiedene Heimatbegriffe aufeinander. Mit Fokus auf den rechtlichen Heimatbegriff können drei literarische Funktionen für den Text benannt werden: Erstens übt der sich in die humanistisch-volksaufklärerische Tradition Johann Peter Hebels stellende Auerbach direkte Kritik an den sozialen Realitäten seiner Zeit. Dass sich die Gemeinde von den Lasten, die

264 Auerbach: Barfüssele, 1858, S. 41.

265 Auerbach: Barfüssele, 1858, S. 44.

266 Auerbach: Barfüssele, 1858, S. 44.

267 Auerbach: Barfüssele, 1858, S. 168-169.

268 Auerbach: Barfüssele, 1858, S. 176. 
Damis Versorgung bedeutet, freikaufen kann, indem sie ihn auf ihre Kosten nach Amerika verschickt, wird von Amrei nicht von ungefähr mit einer Abschiebung verglichen. Auch der Leser soll dies empörend finden. Dazu passt, dass Auerbach in seiner zentralen poetologischen Schrift unter dem Stichwort „Pauperismus“ nicht mit sozialkritischer Gegenwartsanalyse spart. Hier ist etwa zu lesen, dass sich der „Polizeistaat“ auf „seine Verordnungen gegen das Betteln“ und „seine Gefängnisse“ zurückziehe und die „Erschwerung der Ansässigmachung“ „einen sittlichen und ökonomischen Zerfall“ anzeige, „den auch der Polizeistaat sich nicht länger wird verhehlen können“. ${ }^{269}$ Volksdichtung ist bei Auerbach immer auch Volksaufklärung. Diese Volksaufklärung - und damit ist Auerbach Teil einer breiten, wenngleich literaturgeschichtlich noch nicht genügend gewürdigten literarischen Bewegung ${ }^{270}$ - ist Mitte des 19. Jahrhunderts ein hochgradig politisch gemeintes Unterfangen. Aufklärung ist hier nicht ein einseitiger Vorgang der Belehrung der Ungebildeten durch die Gebildeten, sondern richtet sich auch an die Gebildeten mit der Aufforderung, die Lebensbedingungen der Armen zur Kenntnis zu nehmen und sie zu verändern.

Die Bezugnahme auf das Heimatrecht deckt im Text zweitens ein Missverhältnis zwischen einer verwaltungstechnischen Auffassung und einem emotionalen Bedürfnis nach Heimat auf. Die Diskrepanzen, die sich in der Auffassung von Heimat als juristischer Kategorie hier, als Gemütswert dort ergeben, werden sichtbar, als Dami an dem Stock vorbeikommt, auf dem Name und Amtsbezirk des Ortes markiert sind, den er nun als Heimatloser verlässt. Dami spricht den Stock folgendermaßen an: „Du da! Behüt dich Gott! Ich bin nicht mehr bei dir daheim, und alle Menschen da drin die sind mir jetzt grad so viel wie du. ${ }^{\text {“271 }}$ Menschen werden wie Stöcke, Stöcke werden wie Menschen angeredet. Auerbach legt durch diese Kontrastierung einen radikalen Widerspruch offen, der die emphatische Heimat in ihrer Daseinsberechtigung zugleich bestätigt und in Frage stellt.

Gerade angesichts der literarischen Programmatik Auerbachs, die sich dezidiert gegen ein romantisches Literaturverständnis richtet, wird deutlich, dass es damit drittens um eine grundsätzliche Neuvermessung des literarischen Feldes geht. In seiner knapp zweihundertseitigen Poetik Schrift und Volk von 1846 entwirft Auerbach seine Vorstellung von Volksdichtung wesentlich vor der Kon-

269 Berthold Auerbach: Schrift und Volk. Grundzüge der volksthümlichen Literatur, angeschlossen an eine Charakteristik J.P. Hebel's (1846), in: Auerbach 2014, S. 7-173, hier alle Zitate S. 169.

270 Vgl. aber Böning/Siegert 1990, 2001 und 2015, insbesondere die Bände 3.1-3.4 von Reinhart Siegert zur Aufklärung im 19. Jahrhundert: Siegert 2015; vgl. weiterhin die Beiträge von Holger Böning und Reinhart Siegert in: Mellmann/Reiling 2016.

271 Auerbach: Barfüssele, 1858, S. 112. 
trastfolie der Romantik, der Eskapismus und Selbstbezüglichkeit vorgeworfen werden. Das Volksleben werde von den Romantikern mit Vorliebe in der Vergangenheit gesucht, weil sie hier überschwänglichen Phantasien am widerstandslosesten Raum geben könnten. Nirgends sei dagegen „der Pulsschlag der Gegenwart“272 zu fühlen. Der literarische Ästhetizismus der Romantiker korrespondiert Auerbach zufolge mit einem Mangel an politischer wie humanitärer Perspektive: „Menschen, die kein Herz für das Volk hatten, für seine niedergetretenen Rechte, seine verlorene Größe, seine Jahrhunderte lange Knechtung, sein Leiden und Hoffen - sie trieben ein ergötzliches Spiel mit willkürlichen Gebilden, die sie in die Kreise des Volkslebens versetzten." ${ }^{273}$ Wo sich in der Romantik überhaupt politische Grundsätze herausgebildet hätten, seien diese autoritär: Während „die ästhetischen Genußmenschen in der Romantik für sich die ungebundenste Subjectivität beanspruchen“, verlangten sie „vom Volke aber eine völlige Unterordnung und Hingebung an Autoritäten“. ${ }^{274}$ Dementsprechend seien sie auch nicht an einer Aufklärung des Volkes interessiert. ${ }^{275}$ Aus dieser Kritik ergibt sich ein Neuentwurf des Verhältnisses von Literatur und Volksdichtung, ${ }^{276}$ das man zugleich als eine der frühesten dezidiert realistischen Programmatiken im deutschen Sprachraum gelten lassen kann: Eingefordert wird ein Realitätsbezug, der Konkretion anstrebt und „klare[] Erkenntniß“277 der eigenen Gegenwart zum Ziel hat. Dabei hat das Poetische immer sein Eigenrecht, aber eben nach realistischer Lesart: „Wir bedürfen aber nicht des Dämmerlichtes durch gemalte Scheiben, um ein poetisches Farbenspiel zu gewinnen, die Klarheit der Erkenntniß muß zur Poesie werden.“278

Auerbach konkretisiert den Unterschied zwischen einem romantischen und einem in der Nachfolge Hebels zeitgemäßeren Umgang mit dem Volkstümlichen etwa in der Darstellungsweise von Natur. Die aus der Stadt kommenden Ro-

272 Berthold Auerbach: Schrift und Volk. Grundzüge der volksthümlichen Literatur, angeschlossen an eine Charakteristik J.P. Hebel's (1846), in: Auerbach 2014, S. 7-173, hier S. 42.

273 Auerbach 2014, S. 42.

274 Beide Zitate Auerbach 2014, S. 44.

275 „Der Romantiker findet es schön, wenn das Volk allerlei alten Aberglauben nachschleppt, er selber kümmert sich um alles das nicht und buhlt mit allen Göttern, findet aber an den poetischen Vorurtheilen des Volkes einen ästhetischen Genuß.“ Auerbach 2014, S. 44.

276 Vgl. auch Reiling 2016.

277 Berthold Auerbach: Schrift und Volk. Grundzüge der volksthümlichen Literatur, angeschlossen an eine Charakteristik J.P. Hebel's (1846), in: Auerbach 2014, S. 7-173, hier S. 41.

278 Auerbach 2014, S. 45. Mit der Anspielung auf Goethes Gedichte sind gemalte Fensterscheiben wird gesagt, dass das literarische Kunstwerk nicht mehr wie in Goethes Gedicht in einen sakralen Innenraum versetzt wird. Das realistische Gegenprogramm setzt bildlich gesprochen auf den profanen Außenraum, von dem es sich Klarheit der Erkenntnis verspricht. 
mantiker hätten die Natur zur schönen Natureinsamkeit verklärt. Dagegen entspreche es dem Volkstümlichen sehr viel mehr, Natur als selbstverständlichen Teil des Alltags darzustellen, um den kein Aufhebens gemacht werde. ${ }^{279}$ Auch im Umgang mit Sprache zeige sich die Differenz: Die romantische Schule sei vielfach vom Mittelhochdeutschen ausgegangen. Die neuere Richtung gehe „vom gegenwärtig Lebendigen, vom Dialekte“ ${ }^{280}$ aus.

Auerbachs Hauptanliegen ist die Versöhnung des Politisch-Humanitären, Belehrenden mit dem Anspruch der Kunstautonomie, ${ }^{281}$ die Versöhnung von Idealismus und Realismus, ${ }^{282}$ von Aufklärung und Romantik ${ }^{283}$ und schließlich ein ausgewogenes Verhältnis von Schönem und Hässlichem. So soll nach Auerbach das Volkstümliche weder in Form von „süßlichen Tändeleien“ einer „heimatlosen, geschniegelten Schäfer- und Idyllenpoesie“ des 18. Jahrhunderts dargestellt werden, noch solle man es als „das Vierschrötige, oder gar das Crasse“ auffassen, wie es gegenwärtig geschehe, ${ }^{284}$ sondern ein dritter, vermittelnder Weg eingeschlagen werden. So wie aus den späteren realistischen Programmatiken von Freytag bis Fontane bekannt, basiert das Kunstwerk nach Auerbach auf einer Aneignung von Alltagswelt, aber nur unter der Bedingung des verklärenden Eingriffs des Künstlers: „Ein Kunstwerk dagegen muß zu einem in sich versöhnten Abschlusse gelangen. $\mathrm{Zu}$ diesem Behufe müssen die Lichtseiten in all dem grausen Wirrwarr bestimmt hervorgehoben werden, weil in ihnen die Strahlen der endlichen Versöhnung ausströmen.“ Der Dichter solle „die aus der Wirklichkeit von ihm auferbaute Welt nach höheren Gesichtspunkten“ ordnen, „er kann und soll abschließen, wo die Wirklichkeit noch bei der Halbheit und Zerrissenheit verharrt“. 285

Für die Neujustierung von Heimat im Barfüßele hat dieser doppelte Anspruch auf Darstellung und Erhöhung von Wirklichkeit verschiedene Konsequenzen: Zur Wirklichkeit von Heimat gehört auch ihre unemphatische, ja in drastischem Widerspruch zu solch emphatischer Heimat stehende Seite. Heimat wird zunächst von ihrer den Alltag der Zeitgenossen prägenden, nüchtern-administrativen Seite gezeigt. Damit wird einer zeitlich, räumlich und lebensweltlich unbestimmt bleibenden romantischen Heimat eine Absage erteilt. Mithilfe dieses realitätsge-

279 Vgl. Berthold Auerbach: Schrift und Volk. Grundzüge der volksthümlichen Literatur, angeschlossen an eine Charakteristik J.P. Hebel's (1846), in: Auerbach 2014, S. 7-173, hier S. 49.

280 Auerbach 2014, S. 69.

281 Vgl. Auerbach 2014, S. 77-78.

282 Vgl. Auerbach 2014, S. 57-59.

283 Vgl. Auerbach 2014, S. 51-52.

284 Alle Zitate Auerbach 2014, S. 59.

285 Auerbach 2014, S. 57-58. 
sättigten Heimatbegriffs wird es zudem erst möglich, soziale Realitäten kritisch zu beschreiben. Die Wirklichkeit von Heimat wird aber zugleich überboten durch ein emphatisches Heimatverständnis, das doch wieder an die romantische Semantik anknüpft und die „Strahlen der endlichen Versöhnung“ einfängt. Allerdings wird die für die Romantik typische metaphysische Dimension von Heimat stark zurückgenommen. Sie erscheint höchstens noch in bürgerlich-säkularisierter Form, wenn der häusliche Herd am Ende von Barfüßele zum „heiligen Altar“286 wird, und erhält an solchen Stellen einen sentimentalen Stempel, den Heinrich Heine Auerbachs Dorfnovellen insgesamt aufdrückte, wenn er gegen sie polemisierte als „katzenjämmerlich sentimental und religiös-sittlich-flau““.287

\subsubsection{Heimatlosigkeit und Heimatrecht: Vaganten, Zigeuner, Juden (Kinkel, Schweichel, Kurz, Keller)}

Heimatlosigkeit bildet im 19. Jahrhundert das Antonym von Heimat, und das in einem rechtlichen und einem kulturhistorischen Sinn. Beide Aspekte hängen zusammen: Im rechtlichen Sinn bedeutet Heimatlosigkeit Ausschluss von sozialer Fürsorge; sie stellt eine konkrete Realität dar oder auch die latente Angst, von ihr betroffen $\mathrm{zu}$ werden. Die kollektive soziale Abstiegsangst findet verschiedene kulturelle Ausdrucksformen; der Mythos vom heimatlosen Ahasver (vgl. II.1.3.2) gehört dazu.

Dass die Literatur des 19. Jahrhunderts immer wieder Heimatlosigkeit behandelt - auch in den bisher besprochenen Texten von Reuter, Riehl, Stifter, Gerstäcker und Auerbach spielte sie ja eine Rolle - hat zwei Gründe: Erstens gehen rechtliche Heimatlosigkeit und Nicht-Sesshaftigkeit ${ }^{288}$ der Armen in der gesellschaftlichen Realität der Zeit fast zwangsläufig miteinander einher und wird als solche entsprechend auch von realistischer Literatur abgebildet; zweitens kann die Literatur mit den kulturhistorisch gesättigten Figuren des Vaganten und des ,Zigeuners' - und in diesem Sinn einer historisch konstruierten Semantik wird der Begriff des Zigeuners in dieser Studie verwandt $-{ }^{289}$ auf einen wirkmächtigen Topos zurückgreifen.

286 Auerbach 2014, S. 182.

287 Heinrich Heine an Heinrich Laube, Brief vom 5.4.1847, in: Heine 1972, Brief Nr. 1179, S. 246. 288 Zum Begriff der ,Nicht-Sesshaften` und seinem Verhältnis zum Begriff der Heimatlosigkeit vgl. Meier/Wolfensberger 1998.

289 Zur Nicht-Sesshaftigkeit der Zigeuner und den gegen sie gerichteten sozialdisziplinarischen Maßnahmen des Staates seit der Frühen Neuzeit vgl. sehr informativ Schubert 1988. Zur kulturell konstruierten Semantik des ,Zigeuners', die in verschiedenen historischen Kontexten und Wis- 
Die hier skizzierten Hintergründe beziehen sich zunächst auf die rechtliche Seite von Heimatlosigkeit. In Gottfried Kellers Romeo und Julia auf dem Dorfe hat die Gemeinde dem ,schwarzen Geiger‘ das Heimatrecht verweigert und ihn so unters fahrende Volk getrieben. Diese Vorgeschichte wird am Beginn der Novelle im Gespräch zwischen den Bauern Manz und Marti thematisiert und sie ist der Nukleus des von der Novelle entfalteten tragischen Geschehens. ${ }^{290}$

Die fiktionsimmanente Realität des ,schwarzen Geigers‘ korrespondiert mit einer zeitgenössischen Lebenswelt, in der sich tatsächlich bis zu zehn Prozent der Bevölkerung bestimmter Schweizer Kantone dieser Zeit befanden, und für die zeitgenössischen Leser dürfte das zum Kontextwissen gehört haben. Denn besonders in der Schweiz ist die Heimatlosigkeit in der ersten Jahrhunderthälfte ein drückendes soziales Problem, das zeitgenössisch vielfach als „ein trauriger, fürchterlicher Zustand, der zu den größten Grausamkeiten und Abscheulichkeiten schon Anlaß gegeben hat, von allen Menschenfreunden und wohlgesinnten Männern aufs Tiefste beklagt wird“. ${ }^{291}$ Mitte des Jahrhunderts wird diesem Zustand von Seiten des schweizerischen Bundesstaats mit einer breit angelegten Fahndung, zeitweisen Internierung und anschließenden Zwangseinbürgerung sowie Kindesentzug begegnet. ${ }^{292}$ Die Studie von Meier/Wolfensberger, die u.a. auf dem im Rahmen von Fahndungen angelegten, 506 Personaldossiers umfassenden Aktenbestand „Heimatlose“ im Schweizerischen Bundesarchiv basiert, belegt, dass die Bekämpfung der Heimatlosigkeit dabei nicht primär humanitären Interessen folgte. Nicht die Armut, wohl aber die fahrende Lebensweise der Heimatlosen sollte eingedämmt werden, und zu diesem Zweck wurde Heimat in der zweiten Jahrhunderthälfte wieder zwangsverordnet.

sensdiskursen sehr unterschiedliche Definitionen hervorgebracht hat - ethnographische, soziographische, rassenbiologische - vgl. aus literaturhistorischer Perspektive zuletzt: Bogdal 2011; Patrut 2014.

290 Auch Meier/Wolfensberger 1998 weisen im Kontext von Heimatlosigkeit, die durch unlauteren Ausschluss vom Heimatrecht entsteht, auf Kellers Novelle hin, vgl. Meier/Wolfensberger 1998, S. 68-69.

291 Mügge 1847, S. 270.

292 Versuche zur Lösung der „Heimatlosenfrage“ in der Schweiz gibt es seit Anfang des 19. Jahrhunderts. Über die verschiedenen Heimatlosenkonkordate seit 1812 vgl. Meier/Wolfensberger 1998, ab S. 440. Zum „Heimatlosengesetz“, dem „Bundesgesetz die Heimatlosigkeit betreffend“ von 1850 ab S. 467; zur „Concentration der Heimathlosen in Bern“ ab S. 475, zum Abschluss der Zwangseinbürgerungen ab den 1870er Jahren ab S. 495. Bis 1872 wurden zwischen 25.000 und 30.000 Heimatlose eingebürgert, vgl. Meier/Wolfensberger 1998, S. 495. Das Heimatlosengesetz gewährte nur eingeschränktes Bürgerrecht für die Zwangseingebürgerten, vgl. Meier/Wolfensberger 1998, S. 496. 
Der Fall von Amalie Wehrli, der sich in den von Meier/Wolfensberger aufgearbeiteten Schweizer Akten findet, zeigt, wie die fahrende Lebensweise teils direkt durch die Auswirkungen des Heimatrechts entstand. ${ }^{293}$ Die Armut von Amalie Wehrli zwang sie, für die Suche nach Arbeit als Dienstmagd immer wieder eine nicht-sesshafte Lebensweise anzunehmen. Eine rechtlich legale partnerschaftliche Beziehung konnte sie aufgrund dieser fehlenden Sesshaftigkeit nicht eingehen, mit der Geburt eines unehelichen Kindes fiel sie in die Erwerbslosigkeit und noch größere Armut; Diebstahl aus Not ist die Folge. Die Weigerung der Gemeinde Breisach, sie zu unterstützen, treibt sie in die Lebensweise einer Fahrenden. „Der Zirkelschluss scheint vollkommen: Armut zwingt zu Nicht-Sesshaftigkeit, diese wiederum verunmöglichst in letzter Konsequenz die Rückkehr an den Heimatort und kann Heimatlosigkeit verursachen.“294

Die Schweizer Gemeinden taten bis Mitte des 19. Jahrhunderts viel, um sich ihrer Armen zu entledigen, und nahmen in Kauf, dass die Abgewiesenen zu heimatlosen Fahrenden wurden. Selbst dort, wo ein Heimatrecht legal bestand, wurde den Armen dieses Recht teils verweigert, meist wenn wegen längerer Abwesenheit die Heimatberechtigung, in Vergessenheit' geriet, wie literarisch bei Keller dargestellt. ${ }^{295}$ Als Hauptgrund dafür geben Meier/Wolfensberger das sich

293 „Amalie Wehrlis Vater war Bürger von Breisach in Baden. Seit sie 17 Jahre alt war, arbeitete sie in verschiedenen Anstellungen während jeweils 3-15 Monaten als Dienstmagd. 1847, als sie bei einer Wirtsfamilie in La Chaux-de-Fonds [Schweiz] tätig war, wurde sie unehelich schwanger und versuchte, in ihren Heimatort [Breisach in Baden] zurückzukehren. Auf dem Weg dorthin brachte sie ihr Kind in Reinach BL [Schweizer Kanton Basel-Landschaft bzw. Baselland] zur Welt. Aus Not stahl sie dort in einem Wirtshaus Bettzeug und wurde zu zwei Jahren Gefängnis und zu vier Jahren Landesverweisung verurteilt. Als sie 1850 auf der Rückreise aus dem Kanton Baselland nach Breisach war, verhaftete man sie in Liestal BL erneut und verurteilte sie wegen der Übertretung der Verweisungsstrafe zu einem halben Jahr Kettenstrafe. Bereits 1848 hatte das Bezirksamt Breisach dem Bezirksstatthalter von Arlesheim BL ein Schreiben zukommen lassen, in dem sie als „leichtfertige Dirne, welche zwecklos herumzieht“, bezeichnet wurde. Ihr Vater sei in „gedrängten Vermögensverhältnissen und erklärt sich ausser Stand, für seine Tochter die Verpflegungskosten zu bezahlen und der Gemeinderat hier hält sich zur Zahlung nicht verpflichtet“. Meier/Wolfensberger 1998, S. 81. Dort die entsprechenden Zitatnachweise aus dem Aktenbestand „Heimatlose“ im Schweizerischen Bundesarchiv.

294 Meier/Wolfensberger 1998, S. 81.

295 Ein solches Beispiel für die Verweigerung des Heimatrechts durch die Gemeinden liefern die Akten von Anton Wendelmeyer. Dieser ersucht 1844 die Eidgenossenschaft Luzern um die Zustellung von Dokumenten, die ihm von seinem Heimatort verweigert würden. „Sein Vater, so schrieb er, sei in Leuggern AG [Argau] heimatberechtigt gewesen. Ende des 18. Jahrhunderts hätten seine Eltern das Dorf verlassen, da sie als Spengler, Korber und Pikenmacher aufgrund der innerdörflichen Konkurrenz ihren Unterhalt nicht mehr hätten bestreiten können. Er selbst sei als letzter seines Geschlechts in der Heimat in Vergessenheit geraten, da er sich wegen seines fahrenden Gewerbes - er ist ebenfalls Korbmacher - nur selten dort aufgehalten habe. Ohne die 
seit dem 16. Jahrhundert zunehmend durchsetzende heimatörtliche Prinzip der Armenversorgung $a^{296}$ - die Schweiz unterscheidet sich hier also nicht von Österreich und Deutschland. Und in der Schweiz wie in den anderen deutschsprachigen Gebieten setzen sich auf lange Sicht die Interessen der zentralen Staatsmacht gegenüber denjenigen der Gemeinden durch: Denn lag es im Interesse der Gemeinden, das Gut Heimat zu begrenzen, um die eigenen ökonomischen Ressourcen zu schonen, musste es Anliegen des Staates sein, alle Bevölkerungsgruppen verwaltet $\mathrm{zu}$ wissen. So sind dann auch die Zwangseinbürgerungen in den 1850er und 60er Jahren als Ausdruck der Durchsetzung des Zentralstaats gegenüber den Gemeinden zu deuten.

$\mathrm{Zu}$ den gesellschaftlichen Realitäten der Heimatlosigkeit und Nicht-Sesshaftigkeit gehört auch die massive Stigmatisierung der Gruppe der Heimatlosen in der juristischen, administrativen und kriminalistischen Literatur. So geben $A k$ tenmäßige Nachrichten von dem Gauner- und Vagabunden-Gesindel von $1822 \mathrm{zu}$ lesen, dass „das heimathlose Gesindel“ vornehmlich bestehe aus „gebohrnen Vaganten und Bettlern, ferner entwichene Verbrecher, Deserteure und alle diejenigen, welche Ursach haben, ihre Heimath zu meiden“. ${ }^{297}$ Zwar wird an späterer Stelle kurz auch auf die Unschuld der Kinder, die in diese Situation hineingeboren werden, eingegangen, ${ }^{298}$ aber insgesamt wird Heimatlosigkeit als selbstverschuldeter Zustand der Kriminalität, Asozialität und Arbeitsscheu gewertet: „In allen Ländern hat es von jeher Menschen gegeben, welche, ohne Heimath und Vaterland umherschweifend, lieber betteln und stehlen, als durch Arbeit ihren Unterhalt erwerben mochten.“299 Als Mittel der Bekämpfung und „gänzlichen

erwähnten Ausweisschriften könne er seinem Beruf nicht mehr nachgehen, da er der polizeilichen Verfolgung ausgesetzt sei, als Heimatloser behandelt und dauernd herumtransportiert [also auf den Schub geschickt] würde.“ Meier/Wolfensberger 1998, S. 81-82.

296 „Die Bedeutung des Armenrechts für die Entstehung von Nicht-Sesshaftigkeit und Heimatlosigkeit“ zu Beginn des 19. Jahrhunderts liegt nicht mehr in Heimatlosigkeit als Strafe, „,sondern vielmehr im sich seit dem 16. Jahrhundert allmählich herausbildenden heimatörtlichen Prinzip in der Armenversorgung. Mit dem Beginn der frühen Neuzeit machte die Gesetzgebung in den meisten Kantonen die Gemeinden in steter Wiederholung und mit erhöhtem Nachdruck für die Unterstützung ihrer Angehörigen verantwortlich und animierte sie dadurch zur Vertreibung der Armen und zur Unterschlagung derer Heimatrechte. Die im 16. Jahrhundert beginnende Abschliessung der Gemeinden, die potentiellen Neuzuzüglern den Eintritt ins Bürgerrecht zunehmend verwehrten oder durch die Erhebung hoher Einzugsgelder erschwerten, korreliert denn auch zeitlich mit den ersten armenrechtlichen Erlassen, durch die eine heimatörtliche Armenpflege eingeführt werden sollte." Meier/Wolfensberger 1998, S. 69.

297 Beide Zitate Schwencken 1822, S. 1. Zum Phänomen umhervagabundierender Arbeitsloser im Zeitalter der Industrialisierung vgl. Althammer 2017.

298 Vgl. Schwencken 1822, S. 66-67.

299 Schwencken 1822, S. 1. 
Vertilgung des Gauner- und Vagabundengesindes ${ }^{\text {“300 }}$ werden drakonische Strafen gefordert. Es sollten alle Mittel aufgeboten werden zur „Besiegung dieser innern Feinde“. ${ }^{301}$ Dabei werden die als innere Feinde wahrgenommenen Heimatlosen anscheinend deshalb als besonders bedrohlich empfunden, weil es nicht gelingt, sie als solche einwandfrei zu identifizieren: Immer wieder fänden die Heimatlosen Mittel und Wege, die Obrigkeit hinters Licht zu führen, deren Aufgabe es doch sei, „den Unverdächtigen vom Verdächtigen, den rechtlichen Bürger vom landflüchtigen Verbrecher, vom Gauner und Landstreicher $\mathrm{zu}$ unterscheiden“. ${ }^{302} \mathrm{Zu}$ diesen „Auswürflingen““303 gehörten „ehemals vorzugsweise die Zigeuner“, deren Anzahl durch strengere „Polizeymaßregeln“ etwas reduziert worden sei, und auch die Juden werden selbstverständlich mit dem „heimathlosen Gesindel“304 in Verbindung gebracht, wie eine zeitgenössische Karikatur aus der schweizerischen satirischen Zeitschrift Der Postheiri zeigt (Abb. 37).

Hier greift der zweite oben genannte Aspekt, der den Zusammenhang von rechtlicher Heimatlosigkeit und Nicht-Sesshaftigkeit für die Literatur relevant werden lässt: Beides, Heimatlosigkeit und Nicht-Sesshaftigkeit, sind auch Merkmale der Vaganten- und Zigeunerfiguren, deren kulturhistorische Semantik ein nur noch sehr bedingt mit den Realitäten zusammenhängendes Eigenleben führt. Die Topik der Fahrenden ohne festen Wohnsitz, der ,Kinder des Waldes‘ oder der ,Leute aus dem Walde ${ }^{305}$ umfasst Wilderer, Schmuggler und marodierende Räuberbanden genauso wie Korbflechter und Vogelfänger, wahrsagende Zigeunerinnen und Bettler, ${ }^{306}$ teilweise auch Juden. ${ }^{307}$

In einigen literarischen Texten ist auch von den ,Jenischen' die Rede (in den hier behandelten Texten bei Hermann Kurz). In der Schweiz sind die Jenischen seit 2016 als nationale Minderheit anerkannt. Die Ausbildung der Gruppe der Jenischen seit der Frühen Neuzeit lässt sich jedoch nicht mit ethnischen, sondern mit sozio-ökonomischen Prozessen erklären, die bestimmte Bevölkerungsgrup-

300 Schwencken 1822, S. 62.

301 Schwencken 1822, S. 62.

302 Schwencken 1822, S. 63.

303 Schwencken 1822, S. 1.

304 Alle Zitate Schwencken 1822, S. 2.

305 Der Ausdruck ist Titel eines Romans von Raabe, aber auch stehender Ausdruck der Zeit, vgl. die abgebildete Illustration. Der „deutsche Wald“ - insgesamt ein Topos, der eng mit Heimat verbunden ist (vgl. Zechner 2016) - gerät in Bezug auf die Heimatlosen, deren Heimat topisch an den Wald geknüpft ist, in ein deutliches Spannungsverhältnis.

306 Zur Problematik der Begriffsabgrenzung vgl. die Einleitung in Althammer/Gerstenmayer 2013, S. 13-26 mit weiterführenden Literaturhinweisen.

307 Vgl. Patrut 2014, die vor allem das Paradigma des Orientalismus als gemeinsame Grundlage für die soziale Konstitution des Juden und des Zigeuners beschreibt. 


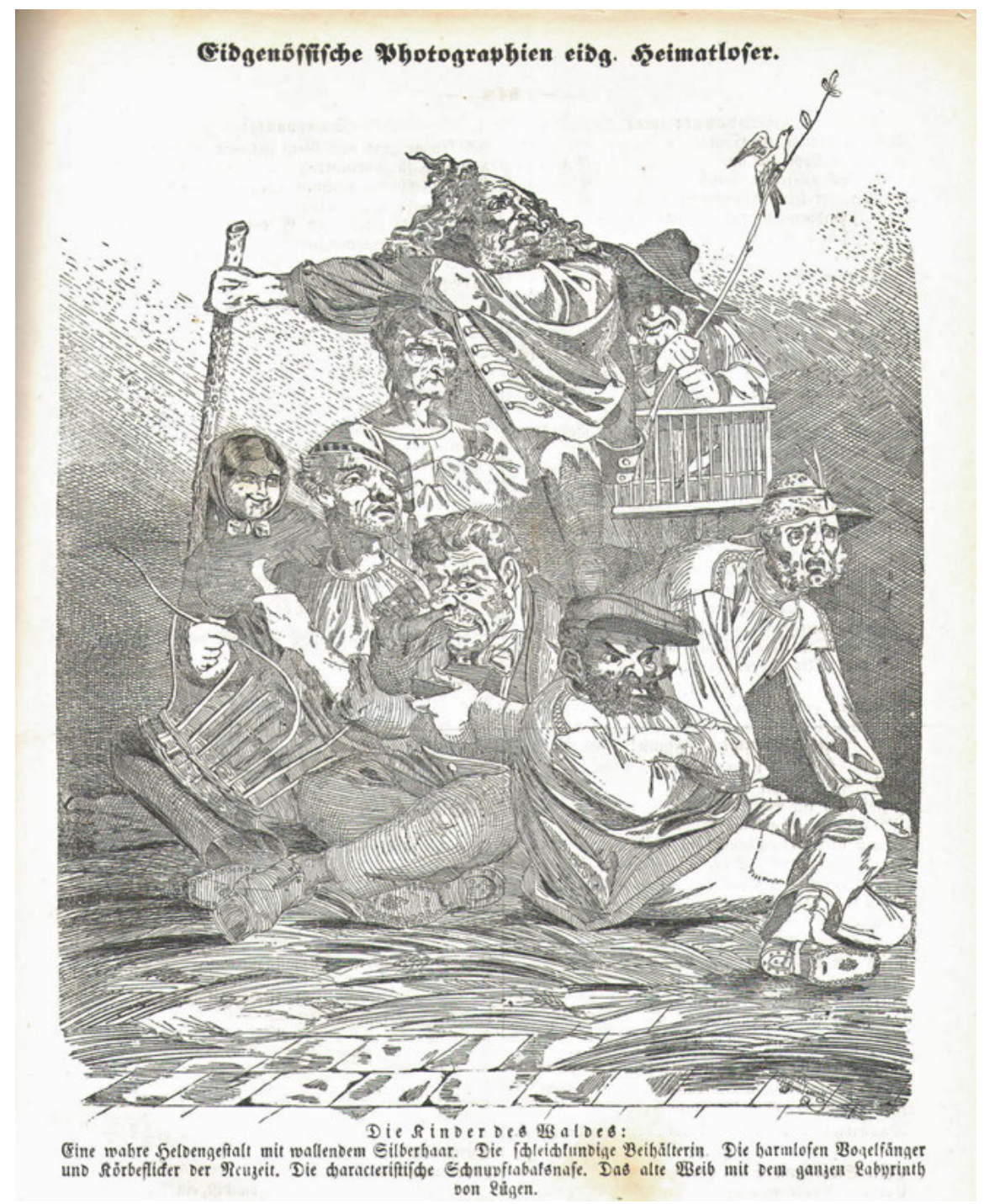

Abb. 37: „Die eidgenössischen Photographien eidg. Heimatloser“: „Die Kinder des Waldes: Eine wahre Heldengestalt mit wallendem Silberhaar. Die schleichkundige Beihälterin. Die harmlosen Vogelfänger und Körbeflicker der Neuzeit. Die characteristische Schnupftabaksnase. Das alte Weib mit dem ganzen Labyrinth von Lügen“. In: Der Postheiri. Illustrirte Blätter für Gegenwart, Öffentlichkeit und Gefühl, Bd. 8, Nr. 29, 1852 (Schweizerisches Sozialarchiv, Zürich) 
pen in die vagierende und durch ihren ökonomischen, sozialen und rechtlichen Ausschluss meist notgedrungen in eine kriminelle Lebensweise trieben. Das Jenische ist ähnlich wie das Rotwelsch eine eigene Sprachvarietät, die diese Gruppe ausbildete. Im 19. Jahrhundert begann man, diese Sprache zu archivieren und zu erforschen, etwa in einem Wörterbuch der Gauner- und Diebs-vulgo Jenischen Sprache von $1832 .^{308}$

Der innerlich und äußerlich freie und unbeschwerte Vogelfänger Papageno, den Emanuel Schikaneder 1791 für Mozarts Zauberflöte entwarf, hat genauso seinen Anteil an der Topik der Heimatlosigkeit wie die mythisch-düstere Figur des Fliegenden Holländers, die Richard Wagner in seiner Oper zeichnet (vgl. II.1.3.3). Die literarischen Figurationen der Heimatlosen bewegen sich im Feld zwischen Romantisierung und Dämonisierung, immer funktionieren sie dabei antipodisch zum Heimat-Komplex, der die rechtliche Heimat umfasst, aber darüber hinaus auch für Bürgerlichkeit und Ordnung in einem sehr viel umfassenderen Sinn steht.

Heimatlosigkeit bezeichnet in den hier behandelten Texten daher zugleich einen Rechtszustand und eine Metapher des Ausgestoßenseins oder zumindest der Nicht-Zugehörigkeit. Die Kulturwissenschaft arbeitete ausgehend von Edward Saids für die Postkolonialismusdebatte maßgeblichem Buch Orientalism (1978) über mehrere Jahrzehnte hinweg intensiv an der Idee, dass erst in der Differenz zum ,Anderen' das Eigene entsteht und in diesem Sinn das Andere die Konstitution von Identität ermöglicht. Julia Kristeva stellt fest: „Das Fremde ist in uns selbst. Und wenn wir den Fremden fliehen oder bekämpfen, kämpfen wir gegen unser Unbewußtes - dieses ,Uneigene“ unseres nicht möglichen ,Eigenen‘.“309 Auch ,Zigeuner‘ und Juden wurden mit diesem Zugriff als ,Grenzfiguren“ der Nation und des Deutschen beschrieben. ${ }^{310}$ Über die kulturelle Konstruktion von

308 Vgl. Train 1832; Wittich/Günther 1915, 1916, 1917.

309 Kristeva 1990, S. 209.

310 ,Juden und ,Zigeuner wurden schon in der Frühen Neuzeit als Grenzfiguren der Nation konstruiert, und dies, obwohl sie alles andere als homogene Gruppen waren und sich in mehr als einer Hinsicht deutlich voneinander unterschieden. Ihre Repräsentationen sagen nichts über die tatsächlichen Juden sowie über Sinti und Roma aus, dafür aber viel über die konstitutiven Gleichungen der ,deutschen Nation“ als einem in sich kohärenten und abgrenzbaren Gebilde. Dies zeigt sich vor allem an den im 19. Jahrhundert immer häufiger werdenden Vergleichen zwischen beiden Gruppen, die offenkundig keiner anderen Logik folgen als jener eines ,deutsch-bürgerlichen' Selbstentwurfs. Im Wissensdiskurs, der dem Narrativ der deutschen Nation plausible Bausteine lieferte, erfüllten Juden und ,Zigeuner` eine überaus wichtige Funktion: Sie stehen, wie Giorgio Agamben die ,Grenzfigur‘ auffasst, innerhalb und außerhalb der rechtlichen Ordnung, um die sich die Nation im 19. Jahrhundert formiert. Erst solche Grenzfiguren ermöglichen den Bestand und die Stabilität von Normen und Herrschaft, und erst die Auseinandersetzung mit der Gewalt, 
Juden und Zigeunern schreibt Iulia-Karin Patrut: „Sie sind nicht in der denkbaren Welt lokalisierbar, sie stehen im Außen der Nation - auch und gerade der deutschen, die sich konstituiert, indem sie ihr unmarkiertes Anderes ausgrenzt.“311 Nicht nur die deutsche Nation, so wäre hinzuzufügen, konstituiert sich im Lauf des 19. Jahrhunderts, sondern auch die bürgerliche Gesellschaft, die sich nicht nur massiv nach oben - vom kosmopolitischen Adel - abgrenzen will, sondern auch nach unten. Der Heimatlose ist also in diesem Sinn auch das ,Andere“ des Bürgers mit seiner ökonomischen Maxime der Arbeitsamkeit und seiner moralischen der Triebunterdrückung. Er kann faszinieren, weil er die bürgerlichen Maximen durchbricht, er kann bedrohen, weil er die Möglichkeit des Abgleitens aus der Bürgerlichkeit vor Augen führt. ${ }^{312}$ Juden und Zigeuner lassen sich in diesem Sinn als Grenzfiguren des Bürgerlichen und der bürgerlichen Heimat beschreiben.

Die literarischen Texte, die im Folgenden behandelt werden und die unter der Vorgabe ausgewählt wurden, dass sie Heimatlosigkeit auch als rechtliche Kategorie begreifen, thematisieren die Störung von (bürgerlicher) Ordnung. Und ob bei Kinkel (1849), Kurz (1855), Keller (1856) oder Schweichel (1858), immer geht es um eine Liebe, die innerhalb der bürgerlichen Ordnung nicht durchgesetzt werden kann und in die Heimatlosigkeit führt oder, um dieser zu entgehen, mit dem Tod endet.

Bedrohung geht von der bürgerlichen Ordnung aus, insofern sie nicht alle in diese Ordnung aufnehmen will, Bedrohung geht von den Heimatlosen aus, insofern sie die Ordnung in Frage stellen. Die Störung wird überwunden, indem die Heimatlosen in die bürgerliche Ordnung integriert werden oder aber diese Ordnung zugunsten einer klassenlosen Gesellschaft überwunden wird - zumindest in der utopischen Vision. Dies ist in den Texten Kinkels und Schweichels der Fall. In den Texten von Kurz und Keller gelingt diese Harmonisierung nicht. Das tragische Ende der Helden, die an der bürgerlichen Ordnung zerbrechen bzw. sich ihr um den Preis des eigenen Todes unterwerfen, kann dabei sehr unterschiedlich als

die die Konstruktion solcher ,Grenzfiguren‘ prägt, ermöglicht ein Verständnis der strukturellen und epistemischen Gewalt, die für den Selbstentwurf und Fragen des Regierens insgesamt konstitutiv ist." Patrut 2014, S. 275.

311 Patrut 2014, S. 281.

312 Der Heimatlose ist nicht einfach nur Gegenfolie des ,Eigenen', sondern kann vielmehr in der Trias ,Eigenes - ,Fremdes‘ - ,Drittes‘ wechselnd alle Positionen innehaben. Gerade durch diese Möglichkeit des Standortwechsels kann Heimat in ihrer (brüchigen) Konstitution beleuchtet werden. Die Rede oder Vorstellung von Zigeunern als ,internen Fremden', die nicht schlicht Gegenfolie des ,Eigenen` sind, lässt sich nach Patrut deshalb nicht als bloße Spielart des Diskurses von den ,edlen Wilden' um 1800, von den ,Primitiven“ um 1900 oder auch von den ,Asozialen Anfang des 20. Jahrhunderts erklären. Vielmehr generiere sie in sehr viel stärkerem Maß „deutsche Selbstentwürfe“. Patrut 2014, S. 441. 
Infragestellung oder Bestätigung dieser Ordnung interpretiert werden. Die folgenden Texte behandeln im Kontext von Heimatlosigkeit und Heimatrecht daher auf sehr verschiedene Weise die Frage nach Macht und Ohnmacht bürgerlicher Ordnung.

\section{Gottfried Kinkel: Die Heimatlosen}

Gottfried Kinkel (1815-1882), eigentlich evangelischer Theologe, der wegen einer Heirat mit einer geschiedenen Katholikin nicht mehr in der theologischen Fakultät tätig sein durfte und ab 1846 eine außerordentliche Professur für Kunstund Literaturgeschichte in Bonn bekleidete, wandelte sich politisch vom konstitutionellen Liberalen zum sozialistischen Republikaner, der an den Aufständen von 1848 teilnahm und dafür zu lebenslanger Festungshaft verurteilt wurde. Seine Erzählung Die Heimatlosen entstand im Zuchthaus von Rastatt, kurz nach Kinkels Gefangennahme im Juni 1849 und vor der Urteilsverkündung am 3. September, ohne dass Kinkel wissen konnte, ob ein Todesurteil auf ihn wartete; die Erzählung wurde zur Publikation aus dem Gefängnis geschmuggelt. ${ }^{313}$ Auch Kinkels weitere Biographie enthält spektakuläre Ereignisse: Sein Freund und früherer Schüler, der Bonner Student Carl Schurz, der sich selbst nach revolutionären Umtrieben und Verhaftung durch eine berühmt gewordene Flucht durch einen Abwasserkanal vor dem eventuell drohenden Todesurteil retten konnte, gelang später die Befreiung seines ehemaligen Professors aus der Haft in Berlin-Spandau und beide flohen ins Exil: Schurz stieg zum Innenminister der Vereinigten Staaten auf; Kinkels Weg führte nach London, Paris und New York und dann wieder nach London zurück, wo er als Professor für Literaturgeschichte wirkte, bevor er später eine Professur für Kunstgeschichte in Zürich annahm.

Gottfried Kinkels Erzählung Die Heimatlosen. Erzählung aus einer armen Hütte (1849) enthält offenkundig viele Parallelen zur eigenen Politisierungsgeschichte. Der Protagonist wandelt sich vom unpolitischen Bauernsohn zum Vorkämpfer der revolutionären Aufstände und am Ende zum politischen Exilanten. Der zunächst anonym erschienene Text beginnt mit den Verstrickungen des badischen Heimatund Eherechts und endet mit einer Revolution, die als nur vorerst gescheitert erklärt wird. Die Auswirkungen des Heimatrechts führen zur Politisierung des Helden: Der aus Kriegsdiensten entlassene Valentin lernt 1844 auf der Durchfahrt die Zugezogene Sabine in einem Dorf in Baden kennen. Er will in ihrer Nähe

313 Vgl. Walcher 2009, das Kapitel zu Die Heimatlosen S. 130 - 161, hier S. 131. Walchers Studie zu Kinkel enthält die bisher einzige ausführlichere Interpretation und historisch-sozialgeschichtliche Kontextualisierung der Erzählung. Den hier interessierenden Aspekt der Verknüpfung von Heimatrecht und Zigeuner-Metaphorik behandelt Walcher nicht. 
bleiben, verdingt sich als Knecht, die beiden verlieben sich und wollen schließlich heiraten. Sie sind mittellos, aber hoffnungsvoll, auf gepachtetem Land ihre Existenz zu begründen. ${ }^{314}$ Alle Formalitäten zur Heirat werden mit dem Pfarrer besprochen, ${ }^{315}$ wobei dieser auf die fällige Entrichtung von hundertfünfzig Gulden hinweist (in der badischen Gemeindeordnung von 1831 tatsächlich so festgesetzt $\left.{ }^{316}\right)$ : „Sie kennen doch unsere badische Gemeindeordnung? Wer sich in einer Gemeinde verheirathen will, muß zuvor Bürger sein und zu diesem Zweck ein Grundstück oder eine Geldsumme aufweisen.“317 Valentin stammt aus dem „Oberland an der Schweizer Grenze“ von Bauersleuten ab, war Knecht dort und anderswo, bevor er zum Militär ging, ${ }^{318}$ Sabines Vater kommt aus Böhmen, sie selbst ist im Hessischen geboren, bevor die Familie in das badische Dorf zog, ohne dort das Bürgerrecht $\mathrm{zu}$ erlangen. ${ }^{319}$ So haben weder Valentin noch Sabine Heimatrecht, und da sie mittellos sind, können sie es sich auch nicht erkaufen. Der Pfarrer sagt über Sabines Familie, sie sei „brav“, „arbeitsam“ und „fromm“, aber sie seien eben zugleich auch „fremd“ und „arm“: Geht nach einer Heirat etwas „mit der Wirthschaft schief, so fallen die Kinder der Gemeinde zur Last“. ${ }^{320}$ Valentin insistiert: „[S]oll ich denn, weil ich arm bin, keine Frau nehmen dürfen?“ Der Pfarrer beharrt: „Jede Gemeinde sucht sich zu hüten, daß nicht arme Leute in sie hineinheirathen, Kinder zeugen und so in das Vermögen der Gemeinde sich breit hineinsetzen. “321 Alle weiteren Versuche des Paars, finanzielle Hilfe zu erhalten, um die geforderte Summe bezahlen zu können, scheitern. Schließlich geben sie sich ohne institutionellen Beistand das Jawort. Diese ,wilde Ehe‘ ist der Gemeinde nun vollends ein Dorn im Auge, auch dies mehr unter ökonomischen als unter moralischen Gesichtspunkten: „Die wackern Gemeindevorsteher grämten sich bitter über die Möglichkeit, daß nun doch die Zigeunerhaushaltung, wie man sie nannte, sich um Sprossen vermehren könne, denen sich das Heimatsrecht nicht absprechen lasse.“ Um sie „zum Wegziehen nach einem andern

314 Vgl. Kinkel 1849, S. 409-410.

315 „In Baden haben die Geistlichen noch die Führung der Civilstandsregister, und die kirchliche Trauung schließt die bürgerliche in sich.“ Kinkel 1849, S. 411.

316 Vgl. das Gesetz über die Rechte der Gemeindebürger und die Erwerbung des Bürgerrechts von 1831, in: Weiske 1848, S. 235-250; Walcher diskutiert die Einzelheiten der genauen Summe, vgl. Walcher 2009, S. 149.

317 Kinkel 1849, S. 412.

318 Kinkel 1849, S. 395.

319 „Diese Stellung zur Gemeinde hatte Mutter Wlaska, als der Mann starb und sein ältestes Kind erst zwölf Jahr alt war. Sie war eine Fremde, hatte keinen Grund und Boden und somit kein Bürgerrecht am Orte.“ Kinkel 1849, S. 385.

320 Alle Zitate Kinkel 1849, S. 414.

321 Beide Zitate Kinkel 1849, S. 413. 
Orte zu veranlassen“, ${ }^{322}$ ist niemand bereit, sie zu unterstützen, so dass alle Anstrengungen Valentins und Sabines scheitern, durch Arbeit doch schließlich das geforderte Geld aufzubringen. Sabine wohnt weiter bei der Mutter, auch noch, als zwei Kinder gekommen sind, Valentin findet kein Unterkommen und keine Arbeit mehr im Dorf und verdingt sich schließlich als Arbeiter beim Eisenbahnbau. Fernab der Familie wird er in seinem neuen Umfeld zum Sozialisten, beteiligt sich an den 1848er-Aufständen und muss am Ende mit der finanziellen Hilfe eines von ihm während der Unruhen geretteten Aristokraten nach Amerika auswandern, um der Haft oder sogar dem Todesurteil zu entgehen. Den „großen Kampf der Zeit“, den Kampf der Proletarier gegen die Besitzenden, wird er, so die utopische Perspektive, auch dort führen können. Valentin weiß, „daß der Kampf, den er führte, der Kampf der Besitzlosen gegen die erdrückende Geldmacht der Gegenwart überall seine Streiter finde dießseits und jenseits des Meeres““.323

Was als Kritik am Rechtssystem und seinen engstirnigen geistlichen und weltlichen Handlangern beginnt - dem evangelischen Pfarrer, der sich weigert, dem Paar die nötige Summe vorzustrecken, um es sich nicht mit der Gemeinde zu verderben, dem katholischen Pfarrer, der Hilfe nur für den Fall anbietet, dass die potentiellen Kinder des Paares katholisch getauft werden, der Gemeinde, die dem Paar Hilfe verweigert -, endet mit der Emanzipation des Proletariers. Der Eisenbahnbau bringt ihn mit einer internationalen Arbeiterschaft in Berührung, die an die kommunistische Lehre glaubt: „Sie waren aus aller Welt zusammengeströmt, und viele trugen in ihrem Kopfe über die deutsche Grenze die neue Lehre, welche bestimmt ist, in der nächsten Zukunft die Gestalt unseres alternden Welttheils noch einmal zu verjüngen.“ Valentin begreift, „daß aller Reichthum des Volkes allein auf der Arbeit ruht, und daß das Kapital selbst nur das Kind der Arbeit ist“ und dass es Recht eines jeden sein müsse, ,ein Weib rechtmäßig zu besitzen, satt an einem eigenen Herde auszuruhen und Kinder ohne Schamgefühl und Seelenqual an sein Herz zu drücken“.324

Mit historischem Abstand kann man sagen, dass die (von Kinkel auch in einer Streitschrift schon ein Jahr vor Erscheinen der Erzählung analysierten und kritisierten) $)^{325}$ Zwänge des Heimatrechts und der Kapitalismus tatsächlich eher gegenläufige Tendenzen waren. Denn während Mobilität und Flexibilität der Arbeitskräfte im ökonomischen Interesse waren und Unternehmer daher tendenziell zu den Befürwortern von Niederlassungsfreiheit (Freizügigkeit) und Unterstüt-

322 Alle Zitate Kinkel 1849, S. 425.

323 Beide Zitate Kinkel 1849, S. 159.

324 Alle Zitate Kinkel 1849, S. 429-431.

325 Vgl. Kinkel 1848; zum sogenannten ,Heimatzwang“ vgl. Kinkel 1848, S. 25. 
zungswohnsitz gehörten, ${ }^{326}$ entsprang das Heimatrecht einer vorkapitalistischen Welt und die Beharrungskräfte, die es entfaltete, waren insofern auch antikapitalistische. In der zeitgenössischen Perspektive erschienen die Auswüchse des Heimat-, Armen- und Eherechts allerdings als Teil des Pauperismus. Rechtliche Heimatlosigkeit und das Aufbegehren des Vierten Standes sind daher miteinander korreliert.

Neben den rechtlich Heimatlosen und den Proletariern bildet die Figur des Zigeuners eine dritte Komponente dieser narrativen Korrelation. Jenseits der ökonomischen Logik, dass das arme Paar mit seinen Kindern der Gemeinde zur Last fallen könnte, gibt es nämlich noch andere Gründe für den Ausschluss von Sabines Familie durch die Gemeinde: Ihr Vater, Joseph Jelinecz, stammt aus Böhmen, ihre Mutter Wlaska ist geboren ,ganz tief in Ungarn, nahe bei der türkischen Grenze“ ${ }^{\text {‘327 }}$ und beider Lebensweise war immer schon unstet: Joseph war „Hornist bei einem österreichischen Regiment“, ${ }^{328}$ Wlaska „diente bei seiner Compagnie als Marketenderin“, nach abgelaufener Dienstzeit ließ sich Joseph nieder und verdiente sein Geld damit, im Sommer als „wandernder Musikant“3329 unterwegs zu sein; auch die musikalisch begabten Kinder begleiten ihn in seinem „Leben des fahrenden Musikanten“. ${ }^{330}$ Der Vater stirbt früh, und was mit seinem vagantenhaften Leben sich schon assoziierte, wird nun durch die ins Zentrum der Erzählung rückende Mutter vollends repräsentiert: Die Mutter Wlaska ist Zigeunerin und ihre Beschreibung bedient viele Facetten des populären Repertoires: Sie ist dunkel und feurig; ${ }^{331}$ sie ist Matriarchin;; ${ }^{332}$ sie ist Heilerin und Wahrsagerin, ${ }^{333}$ dabei katholisch und ,eine insbrünstige Verehrerin der Jungfrau Maria“ - in einer rein protestantischen Gegend eine zusätzliche Fremdheitsmarkierung: Sie und ihre Familie sind „die einzigen Katholiken in ihrem Orte““.334 Sie wird mit dem Orient assoziiert ${ }^{335}$ und mehrfach mit dem Jüdischen, ${ }^{336}$ u.a. mit dem Ahasver-

326 Vgl. Lerche 2009.

327 Kinkel 1849, S. 376.

328 Kinkel 1849, S. 373.

329 Beide Zitate Kinkel 1849, S. 374.

330 Kinkel 1849, S. 375.

331 Vgl. Kinkel 1849, S. 376-377.

332 Das wird schon darin deutlich, dass dem Vater wenige Zeilen der Erzählung, ihrer Beschreibung als dem neuen Zentrum der Familie hingegen lange Passagen gewidmet sind; auch ihr Name verweist auf den Kampf der Frauen um Vorherrschaft: „Schon der Name war auffallend; sie hieß Wlaska, ihre Patronin war also jenes furchtbare Weib, auf welches die Sage den Ursprung des in Böhmen mährchenhaft berühmten Mägdekriegs zurückführt.“ Kinkel 1849, S. 376.

333 Vgl. Kinkel 1849, S. $380-381$.

334 Beide Zitate Kinkel 1849, S. 379-380.

335 Vgl. Kinkel 1849, S. 376-377. 
Mythos (vgl. II.1.3.2). Ihren Kindern erzählt sie „die rührende Legende von der Missethat, die ihr Volk gleich Juden und Armeniern zu rastlosem Wandern verdamme“..37 Die mythologische Heimatlosigkeit der Zigeuner wird als heimatrechtliche Situation Valentins und Sabines aktualisiert, die ihnen ihr Glück verwehrt, und auf diese Weise mit der Ohnmacht des Vierten Standes im Ganzen in Verbindung gebracht.

Die Erzählstrategie zielt auf eine Solidarisierung mit all diesen Ausgegrenzten und sie erreicht sie auch, indem sie um Sympathie mit Mutter Wlaska wirbt. Dabei werden verschiedene Strategien gewählt. Erstens die der Rationalisierung: Die von den Dorfbewohnern empfundenen Ängste gegenüber der Zigeunerin erweisen sich alle als unbegründet - das Gerücht von den Zauberkünsten basiert auf einem Scherz der Kinder, das Unheimliche der Aussprache auf dem tschechischen Zischlaut. $^{338}$ Zweitens die Inklusion in die bürgerliche Wertewelt: Ostentativ werden Arbeitsamkeit, Frömmigkeit, Sauberkeit und Fleiß als Charaktereigenschaften Wlaskas herausgestellt. Drittens aber auch das Beharren auf der eigenen Andersartigkeit. Über Wlaska heißt es, dass sie „mit dem vollen Stolze einer Baronin, die ihre sechzehn Ahnen an den Fingern herrechnet“",339 ihre fremdländische Herkunft betont. Auch wenn der Stolz aus einer Mischung aus „Hirngespinst“ und „Legende“ herrührt, die wiederum die „Einbildungskraft“ ihrer Töchter so anregt, dass auch diese sich „höher und stolzer empfanden als die deutschen flachshaarigen Bauernmädchen ihrer Nachbarschaft“, 340 und damit die Distanz weiter vergrößert, wird das Selbstwertgefühl der von der Gemeinschaft Ausgestoßenen von der Erzählerstimme immer wieder positiv betont. Dies schließt zum einen an den Topos des stolzen Zigeuners an. Zum anderen ist das Selbstbewusstsein der Ausgegrenzten so wichtig, weil sich in diesem Punkt die Figur des Zigeuners, rechtlich Heimatlose und der Vierte Stand überblenden lassen, ja die Zigeuner Vorbild und Vorläufer des Proletariats werden: als Teil einer unterdrückten Klasse, die zu begreifen beginnt, dass sie ihren Stolz gerade aus ihrer Unterdrückung ableiten muss. Valentin, der erst durch die Abwärtsspirale, in die er gerät, zum Sozialisten wird, bedarf in dieser Phase der proletarischen Selbstbewusstwerdung der Mutter Wlaska als Geburtshelferin des neuen Bewusstseins. Mutter Wlaska „verstand das Feuer, mit welchem Valentin seine Lehren vortrug, und sie gab ihm zu seinen Lehrsätzen die Summe der Erfahrung“. Dies wird dann ins Allgemeine gehoben: „Tüchtige Weiber sind das feine reinliche

336 Vgl. Kinkel 1849, S. 376-377.

337 Kinkel 1849, S. 378.

338 Vgl. Kinkel 1849, S. 378.

339 Kinkel 1849, S. 377.

340 Alle Zitate Kinkel 1849, S. 379. 
Linnen, durch welches ein Heilkünstler die Arznei fließen läßt, um sie zu klären: was noch trüb und wirr im Tiegel des menschlichen Geistes kocht und brodelt, das nöthigen sie ihn durchsichtig und krystallen ans Licht zu treiben. “341 Frauen also als den Verstand und die Einsicht des Mannes klärendes Sieb - hier repräsentiert die Erzählerstimme ein zeitgenössisch übliches Frauenbild. Wlaska repräsentiert aber nicht nur die (in ihrem Emazipationsstatus für die Erzählung unproblematische) Frau, sondern auch die Zigeunerin und insofern das Bewusstsein einer notwendigen Emazipation. Die Figuren des Zigeuners, des rechtlich Heimatlosen und des Proletariers werden von der Erzählung überblendet: als Unterdrückte, die aus ihrer Unterdrückung zur Selbstbewusstwerdung kommen und zu den Vorboten einer neuen, utopischen Zukunft werden.

\section{Robert Schweichel: Heimathlos}

Auch der wie Kinkel zu den Unbekannten zählende Autor Robert Schweichel (1821-1907) ist Kommunist; 1868, im Erscheinungsjahr seiner Novelle Heimathlos, ist er eines der Gründungsmitglieder der sozialistischen Arbeiterpartei. Als enger Freund der Sozialdemokraten August Bebel und Wilhelm Liebknecht (des Vaters von Karl Liebknecht) lebt er aus politischen Gründen zeitweise im Schweizer Exil. In seiner fast romanlangen Novelle verarbeitet er die rechtliche Situation der Heimatlosen in den 1850er Jahren, die sich zum Entstehungszeitpunkt des Textes durch die massive Bekämpfung der Heimatlosigkeit zwischen den 1850er und 60er Jahren schon grundlegend geändert hatte. „Das Elend, dem diese Heimathlosen ausgesetzt waren, ließ ihre Zahl freilich nie hoch anschwellen, trotzdem betrug sie um die Mitte des vorigen Dezenniums noch über zweitausend. Alle Versuche, diese Unglücklichen in den Gemeinden einzubürgern, scheiterten zur Zeit, von der wir sprechen, noch an dem Widerstande der Kantone.““342 Die Zahlen, die hier von der Erzählerstimme angegeben werden, sind nach heutigem Kenntnisstand weit untertrieben. Bis zum Abschluss der Zwangseinbürgerungen, die zwischen den 1850er und 1870er Jahren stattfanden, wurden zwischen 25.000 und 30.000 Heimatlose eingebürgert. ${ }^{343}$ Abseits dieser Frage nach der Anzahl der Nullen hinter den Zahlen - als Erzähler spricht, so viel wird schon zu Beginn deutlich, eine solidarische Stimme der Heimatlosen.

Die schöne Oze gehört zu diesen Heimatlosen, „die seit undenklicher Zeit heimathlos in der Schweiz umher irrten, und wieder in diese heimathlose

341 Kinkel 1849, S. 431- 432.

342 Schweichel 1868, S. 10.

343 Vgl. Meier/Wolfensberger 1998, S. 495. 
Heimath zurückgewiesen wurden, wenn sie auf ihren Wanderzügen deren Grenzen überschritten“. ${ }^{344}$ Oze bezieht mit ihrer Mutter eine verlassene Hütte im Gebirge nahe dem Dorf Valorbe in der romanischen Schweiz, nicht weit von der französischen Grenze. Die beiden Frauen ernähren sich vom Schmuggel nach Frankreich. Aus einer Liebesbeziehung zu dem wohlhabenden Bauern Offenge geht ein Sohn hervor, der vom Vater nie öffentlich anerkannt wird. Oze versucht immer wieder vergeblich, dem Sohn Konstantin die Aufnahme in die Gemeinde zu ermöglichen. Ihr Kind soll nach ihrem Willen „in dem Boden, auf dem seine Wiege gestanden, einwurzeln gleich den Föhren, die sich dem Sturm beugen, aber von ihm nicht fortgerissen werden. Ihm eine Heimath zu schaffen, war die Aufgabe ihres Lebens geworden“ und das heißt, ihm „den Weg in das bürgerliche Leben zu bahnen“. ${ }^{345}$ Obwohl sie dem Kind eine Schulbildung ermöglicht und seine Konfirmation durchsetzt, will ihm niemand eine Lehrstelle geben und damit den „Eintritt in das bürgerliche Leben“ und die Gründung von „Heimath“ ermöglichen. ${ }^{346}$ Die Meinung der Leute richtet sich nicht gegen die Person Konstantins, aber die ökonomischen Interessen überwiegen; die „zukünftige Last“, die sich die Gemeinde damit aufhalsen könne, will niemand riskieren. ${ }^{347}$ Die sich anbahnende Zuneigung Offenges zu seinem verleugneten Sohn wird von dessen falschem Freund Corsant hintertrieben. Während Offenge nur aus Mutlosigkeit die Verbindung zu Oze und Konstantin leugnet, ${ }^{348}$ unterstützt ihn Corsant darin aus Berechnung. Corsant profitiert von dem durch den Verrat an der Geliebten gebrochenen Offenge; es gelingt ihm, ihn von sich abhängig zu machen. In einem Streit der beiden kommt es zum tödlichen Schlaganfall Offenges, Corsant vernichtet das Testament, das Konstantin als Alleinerben einsetzt, und alle Schuldscheine, die er selbst bei Offenge hat, und stiehlt sämtliches im Haus aufbewahrtes Geld. Damit kauft er wenig später den Hof seines Opfers auf. Der perspektivlose, unwissentlich um sein Erbe und den Namen seines Vaters betrogene Konstantin will in die Fremde ziehen, wird aber von der Mutter immer wieder zurückgehalten. Was ihn schließlich hält, ist die Liebe zu Corsants Tochter Germaine. Sie und ihr Vater sind selbst - auf andere Weise - von der Gemeinschaft Ausgestoßene. Während der amoralische Corsant seine Außenseiterrolle

344 Schweichel 1868, S. 10.

345 Alle Schweichel 1868, S. 13.

346 Beide Zitate Schweichel 1868, S. 50.

347 „Und endlich bürdete man mit der Annahme eines solchen Lehrlings nicht wahrscheinlich der Gemeinde eine zukünftige Last auf? Es war nicht gut thunlich, den beiden Frauen die Unterstützung der Gemeinde zu versagen, wenn der Sohn bei einem Bürger derselben in der Lehre sich befand." Schweichel 1868, S. 15.

348 Vgl. Schweichel 1868, S. 28. 
selbst verschuldet hat, ist seine Tochter Germaine nur in unverdiente Sippenhaft genommen. Nachdem sie entdeckt hat, dass Konstantin der Sohn Offenges und von ihrem Vater um sein Erbe betrogen worden ist, bittet sie den Vater um Wiedergutmachung, die dieser aber verweigert. Eine Ehe zwischen Konstantin und Germaine ist unter diesen Bedingungen für Germaine nicht möglich. Corsant, in Angst, dass sein Verrat ans Licht kommt, begeht einen Mordversuch an Konstantin, in dessen Folge er selbst stirbt. Erst jetzt ist Germaine von ihren Tochterpflichten entbunden und darf die Wahrheit ans Licht bringen. Konstantin und Germaine, die offizielle Erbin des Hofes, heiraten und Konstantin gelangt so wieder in den Besitz seines rechtmäßigen Erbes: „Die Gemeinde von Valorbe nahm den erklärten Bräutigam der Germaine Corsant gern unter sich auf, und nach Konstantin's Hochzeit zogen Mutter und Großmutter zu ihm auf seines Vaters Hof. Sie waren nicht mehr heimathlos.“" ${ }^{349}$ Die rechtliche Heimatlosigkeit der Ausgestoßenen ist beendet und die Aufnahme in die bürgerliche Gesellschaft besiegelt. Zugleich wird Heimat nicht nur über das Recht, sondern auch über Gemeinschaft und Genealogie konstituiert: Es ist eben auch der Hof, auf dem nun drei Generationen gemeinsam leben.

Interessant an der Konstruktion der Novelle ist die Konstellation der Ausgestoßenen, zu denen Konstantin mit seiner Mutter Oze und seiner Großmutter auf der einen, Corsant mit seiner Tochter Germaine auf der anderen Seite gehören. Rechtlich heimatlos sind Konstantin und seine Familie, Corsant und Germaine sind es nicht. Corsant verhindert, dass Konstantin seine rechtliche Heimat gewinnt, und nur sein Tod ermöglicht die Integration aller anderen Ausgestoßenen. Aufgenommen werden die (integrationswilligen) Zigeuner, ausgeschlossen wird der (die Gemeinschaft untergrabende) Jude, wie zu zeigen sein wird.

Die rechtliche Heimatlosigkeit von Großmutter, Mutter und Sohn ist mit deren Zigeunerdasein verknüpft. Während sich Mutter und Sohn nichts dringlicher wünschen, als in die bürgerliche Gesellschaft aufgenommen zu werden, repräsentiert die aus der Hand weissagende, abergläubische Großmutter das Vagantenleben: „Wer unstät geboren ist, der bleibt auch unstät.“ Sie habe sich immer „wie in einem Gefängniß gefühlt, so daß sie wieder hätte zum Wanderstab greifen müssen, um frei zu werden“. ${ }^{350}$ Trotz Armut und Perspektivlosigkeit bleibt Konstantin aber schließlich, sein Name ist Omen, standhaft und wählt das Leben eines Almhirten, nicht das eines Schmugglers. Nach verschiedenen Bewährungen kann er in die Gemeinschaft aufgenommen werden und Heimat erlangen. Auch

349 Schweichel 1868, S. 157.

350 Beide Zitate Schweichel 1868, S. 67-68. 
die zigeunerische Großmutter darf dann auf den nun rechtmäßig besessenen Hof ziehen.

Konstantins Antagonist ist Corsant. Bei der ähnlichen Namenswahl fällt auf, dass Konstantin, der Standhafte, mit dem deutschen $\mathrm{K}$ und nicht mit dem lateinischen $\mathrm{C}$ geschrieben ist wie Corsant. Konstantin ist moralisch integer, Corsant ist amoralisch: Er wird als Spinne bezeichnet, die ihre Opfer aussaugt, ${ }^{351}$ als verschlagen, geldgierig und egoistisch. Auch wenn sein Verhalten teilweise biographisch begründet ist - als Kind erlittene Armut und erlittener Spott -, wird er dadurch kaum entlastet. Als Vermittler von unsauberen Geldgeschäften, von denen ihm solche am liebsten waren, „welche mit dem Ruin des Schuldners endeten“, als Schnüffler, der sich in aller Leute Angelegenheiten auskennt, um sie zum eigenen Vorteil auszunutzen, erhält die nie explizit als Jude bezeichnete Figur doch im historischen Kontext eindeutig jüdisch konnotierte Eigenschaften. Spekulation ist sein Steckenpferd. ${ }^{352}$ Er hat mehr Verstand als alle anderen, setzt diesen aber nur eigennützig ein. Er hat einen hinkenden Fuß und wird daher mit dem Teufel assoziiert. Zusammen mit den Stereotypen der Geldgier, Gewissenlosigkeit, Verschlagenheit, Spekulation, der Spinnen- und Teufelhaftigkeit, dann dem physiognomischen Kennzeichen der „scharfgebogene[n] Nase““353 wird Corsant auch mit dem assimilierten Juden assoziiert, der so lange Christ sein und so viel zur Kirche gehen kann, wie er will, und doch nicht zur Gemeinschaft gehört: „[E]s half ihm auch nichts, daß er an den Sonntagen regelmäßig zur Kirche ging [...]. Er blieb ein Ausgestoßener.“354 Alle Dorfbewohner ahnen, dass er den Tod Offenges auf dem Gewissen hat und dessen Hof nicht rechtmäßig in seinen Besitz gekommen ist. Er wird durch diesen Verdacht zum Geächteten - er „wurde von ihnen in die Acht gethan“ - und verliert mit dieser Gemeinschaft auch seine Heimat: „Dieser Ausschluß von dem Orte, wo er seit undenklicher Zeit seine eigentliche Heimath gehabt und wie ein König geherrscht hatte, war für Corsant empfindlicher als alles Andere.“355

Heimatlosigkeit ist in Robert Schweichels Erzählung somit eine tief ambivalente Kategorie. Einerseits wird sie als rechtlicher Missstand gebrandmarkt, um für die Assimilation des ,Fahrenden Volkes` zu werben, die ja tatsächlich zur Veröffentlichungszeit der Erzählung gerade als Zwangsmaßnahme durchgeführt worden war. An verschiedenen Stellen der Erzählung wird der soziale und ökonomische Druck deutlich, der einer Veränderung der Zustände entgegensteht

351 Vgl. Schweichel 1868, S. 37.

352 Schweichel 1868, S. 79.

353 Schweichel 1868, S. 78.

354 Schweichel 1868, S. 79.

355 Beide Zitate Schweichel 1868, S. 57. 
(Offenge hat Angst, selbst zum Ausgestoßenen zu werden; die Dorfbewohner zögern, Konstantin als Lehrling anzunehmen). Aber im Ganzen ist die Dorfgemeinschaft positiv gezeichnet, voll Mitgefühl für Oze, Konstantin, Offenge - und voll Haß auf Corsant. Corsant ist es, der alle negativen Entwicklungen zu verantworten hat. Die Schuld an dem Leid ist in der Logik der Erzählung keine strukturelle, sondern eine personalisierbare. Und deswegen wird Corsant seitens der anderen Dorfbewohner sein moralisches Recht auf Heimat streitig gemacht; im moralischen Sinn wird er zum Heimatlosen, und das als gerechte Strafe, vergleichbar dem Ahasver-Mythos (vgl. II.1.3.2). Erst mit seinem Tod können Gemeinschaft und Heimat im moralischen wie juristischen Sinn für alle anderen hergestellt werden.

Wie bei Kinkel werden Zigeuner und rechtlich Heimatlose miteinander assoziiert oder sogar zur Deckung gebracht, ihr Ausschluss wird angeprangert und ihre Beheimatung zumindest als Utopie imaginiert. Bei Kinkel gelingt in der utopischen Abschlussszene sogar die Verbrüderung des Vierten Standes mit dem Ersten. Bei Schweichel gibt es einen Preis für die Integration: Der Preis ist in der Logik der Erzählung der Ausschluss des nicht assimilierbaren Juden.

Allerdings gilt dieser Ausschluss nur für Corsant, nicht für dessen Tochter Germaine. So wie Konstantin und Corsant antipodisch aufeinander bezogen sind, gibt es eine starke Parallelisierung zwischen dem erst in Hass, dann in Liebe aufeinander bezogenen Paar Konstantin und Germaine: Beide sind Ausgestoßene nicht aufgrund eigenen Verschuldens, sondern weil sie die Kinder von Ausgestoßenen sind. Der Weg zurück zur Gesellschaft gelingt ihnen durch hohe Moralität und Integrität. Das Abstreifen des alten ungeliebten Lebens als Ausgestoßene und der Aufbruch in ein neues gemeinsames Leben innerhalb einer Gemeinschaft wird durch eine umständlich in die Erzählung eingeführte Episode symbolisch verdichtet, in der Konstatin nachts in eine Felsengrotte klettert, dort die Orientierung verliert und meint, sterben zu müssen. Er wird von Germaine gerettet und sie gestehen sich ihre Liebe, die am Ende der Erzählung ja in die bürgerliche Ehe überführt werden wird. Schon beim Heraustreten aus der Grotte Grab und Liebesgrotte zugleich - wird der Blick frei auf eine Zukunft, die Heimat verspricht: „wie froh sein Auge auf das heimathliche Thal schaute!“356 Konstantin dem Standhaften und Germaine der Deutschen ist es also möglich, sich aus ihrer Außenseiterrolle zurück in die Gemeinschaft $\mathrm{zu}$ arbeiten. Die zigeunerische Großmutter darf mitgenommen werden ins neue Leben, der jüdische Vater muss sterben. Eine Erzählung, die mit dem offensiven moralischen Anspruch antritt, das Vorurteil gegenüber einer gesellschaftlich marginalisierten Gruppe zu be-

356 Schweichel 1868, S. 124. 
kämpfen, löst dies erzählerisch intrikaterweise durch den Ausschluss einer anderen unterdrückten Gruppe der Gesellschaft.

\section{Hermann Kurz: Der Sonnenwirth}

Das literarische Werk von Hermann Kurz (1813-1873) wird heute höchstens noch regional erinnert. Das konnte auch Fritz Martini nicht ändern, der ihm 1962 einen Abschnitt seiner Literaturgeschichte des Realismus widmet, in dem er ihm eine „Modernität“ attestiert, „die an Georg Büchner erinnert“. 357

Der schwäbische Regionalbezug der Texte von Hermann Kurz mag biographische Gründe haben, ergibt sich bei ihm aber vor allem aus dem Anspruch auf Konkretion. Denn sein Realismus erfordert die Bezugnahme auf den konkreten kulturhistorischen und sozialpolitischen Raum und sein Humanismus zielt auf den konkreten Menschen mit seiner konkreten Sprache: „Schwaben ist ein gut Land, ich will aber nit wieder heim: grob Brot, dünn Bier und große Stunden!“‘, ${ }^{358}$ sagt eine seiner Figuren - und ist damit denkbar weit entfernt von Heimattümeleien.

Symptomatisch ist, dass Kurz den Titel seines Romans Schillers Heimathjahre. Ein vaterländischer Roman (1843) nicht selbst verantwortet, sondern sein Verleger - wäre es nach Kurz gegangen, hätte der Roman den Namen des Protagonisten „Heinrich Roller“ getragen. Schon mit der Wahl des (erfundenen) Lehrers von Schiller als Hauptgestalt, die Schiller zu einer Nebenfigur macht, wird deutlich, dass Kurz nicht an Dichterkult gelegen ist. Genauso wenig geht es um Heimatkult, vielmehr um ein kulturhistorisches Panorama des Großherzogtums Württemberg zu der Zeit Herzog Karl Eugens.

357 Martini 1974, S. 442. Anders Ernst Alker, der in seiner zuerst 1949/1950 erschienenen Literaturgeschichte des 19. Jahrhunderts Hermann Kurz’ Leistungen abwertet: „Er war in stärkster Weise an heimatliche Stoffe gebunden, nicht infolge freier Entscheidung wie Alexis, sondern durch Verwurzelung im Mutterboden.“ Auch sonst meint Alker, literarisches Unvermögen beobachten zu können. Alker 1981, S. 299. Wie die auch noch in der dritten veränderten Auflage von 1969 insgesamt in ihrem herabwürdigenden Ton und ihren unbelegten Wertungen kaum erträgliche Literaturgeschichte - Höhepunkt in diesem Sinne ist das vor antisemitischen Stereotypen triefende Kapitel zu Heinrich Heine - noch 1981 ohne kontextualisierendes Vorwort neu aufgelegt werden konnte, bleibt unverständlich. Jüngere Literaturgeschichten erwähnen Hermann Kurz nur noch als Mitherausgeber des Deutschen Novellenschatzes; Paul Heyse war der Hauptherausgeber dieser 1871 erschienenen Sammlung und schrieb das für die Novellentheorie programmatische Vorwort, vgl. Brenner 1996, S. 165; Sprengel 1998, S. 396 oder Beutin/Beilein/Ehlert 2019, S. 310. 358 Kurz 1980, S. 239-240. Hier wird mit einer Neuauflage des Romans von 1980 gearbeitet, die mit einem die künstlerische Leistung Kurzens würdigenden Vorwort von Peter Härtling versehen ist, vgl. Härtling 1980. 
Auch der Roman Der Sonnenwirth hat die Region Schwaben als Schauplatz, ohne an deren Verklärung zu arbeiten. Die ersten vier Kapitel des Sonnenwirths wurden 1846 im Morgenblatt für gebildete Leser veröffentlicht; 359 erst 1855 lag der ganze Roman vor, wobei die Fertigstellung der letzten Romankapitel unter belastenden familiären Umständen und ökonomischem Druck stattfand. ${ }^{360}$ Das Vorhaben einer Überarbeitung, zu der ihn sein Herausgeber Paul Heyse immer wieder ermutigte, wurde nie umgesetzt. ${ }^{361}$ Obwohl der Roman mit seiner schonungslosen und doch empathischen Menschenzeichnung und seinem komplex entwickelten sozialhistorischen Panorama aus heutiger Perspektive zu den großen erzählerischen Leistungen der Zeit gezählt werden müsste, hatte er keinen zeitgenössischen und auch keinen posthumen Erfolg.

Betrachtet man etwa Philipp Walburg Kramers noch im Jahr 1855 erschienene (wohl nicht zur Aufführung gekommene) ${ }^{362}$ Bühnenfassung, die den knapp 800seitigen Roman auf 70 Seiten komprimiert und ihm abweichend vom tragischen Romanende einen alternativen guten Ausgang gibt, ${ }^{363}$ wird die Tragweite des zeitgenössischen Missverständnisses deutlich. Denn der Roman von Kurz zeichnet gerade keine Welt, in der, wie bei Kramer, das Gute siegt.

Die Handlung ist im Schwaben der 1750er Jahre angesiedelt und basiert auf dem aktenkundig gewordenen Fall Friedrich Schwahns, Sohn des Sonnenwirths Schwahn, der vorher schon Schiller als Vorlage für seinen Verbrecher aus verlorener Ehre diente. Wie Schiller geht es auch Kurz nicht um moralische Demonstration, ${ }^{364}$ sondern um eine psychologisch-soziologische Perspektive auf das Verbrechen. ${ }^{365}$ Was bei Schiller nur angedeutet ist, wird bei Kurz breit entfaltet: eine Charakter- und Gesellschaftsstudie, in der individuelles Versagen aus per-

359 Vgl. Morgenblatt für gebildete Leser 40 (1846), Nr. 42-46, 48-54, 270-275, 281-283. Zu dieser Zeit wurde das Morgenblatt von Hermann Hauff geleitet, zuvor von seinem bekannteren Bruder Wilhelm Hauff zusammen mit Gustav Schwab.

360 So der Bericht der Tochter Isolde Kurz in ihrer Biographie des Vaters im Kapitel Neue Schaffensperiode, vgl. Kurz 1906.

361 Vgl. Kurz 1906.

362 Vgl. Kurz 1906.

363 Der Herzog Karl erscheint als Deus ex machina, begnadigt den schon zum Tod Verurteilten und ermöglicht ihm die Auswanderung nach Amerika. Vgl. Kramer 1855.

364 „Wenn ich auch keinen der Vorteile hier in Anschlag bringe, welche die Seelenkunde aus einer solchen Behandlungsart der Geschichte zieht, so behält sie schon allein darum den Vorzug, weil sie den grausamen Hohn und die stolze Sicherheit ausrottet, womit gemeiniglich die ungeprüfte aufrechtstehende Tugend auf die gefallne herunter blickt [...]." Schiller: Verbrecher aus Infamie, in: Schiller 2002, S. 565.

365 Die Verknüpfung von psychologischem und kulturhistorischem Interesse stellt schon Hermann Kurz' Tochter Isolde Kurz im Kapitel Neue Schaffensperiode in ihrer Biographie des Vaters heraus, vgl. Kurz 1906. 
sönlichen Dispositionen sowie familiären und institutionellen Verhältnissen hervorgeht, die Täter- und Opferrollen bei genauerem Hinsehen verschwimmen lassen. Schiller und Kurz wählen einen Fall, in dem es um eine zunächst harmlose Verletzung des Gesetzes geht, die in letzter Konsequenz zum völligen Ausschluss aus der bürgerlichen Gesellschaft führt. Der Geächtete nimmt diese Rolle in beiden Versionen schließlich für sich an und lebt ein kurzes Leben außerhalb der bürgerlichen Gesellschaft, bevor ihn das Gesetz einholt und er zum Tod verurteilt wird.

Bei Kurz wird im Gegensatz zu Schiller der Protagonist bei allen problematischen Charakterzügen nicht nur mit analytischem Interesse, sondern auch mit Empathie betrachtet; die gewählte Innensicht verstärkt das Identifikationsangebot. Der Antrieb für seine Verstöße gegen das Gesetz rührt bei Kurz’ Figur Friedrich Schwan (in der literarischen Fiktion Schwan, nicht Schwahn), genannt Frieder, anders als bei Schiller, aus wirklich empfundener Liebe und deren emotionalen Konflikten her. Die unauflösliche Situation, in die Frieder gerät, entspringt der Unvereinbarkeit dieser Liebe zu Christine mit einem bürgerlichen Leben. Aber auch in dem heimatlosen Leben außerhalb der bürgerlichen Gesellschaft, in das er getrieben wird oder sich treiben lässt, scheitert die Liebe. In dieser Welt der Heimatlosen ist es die schwarze Christine, Zigeunerfrau und Spiegelfigur der blonden Namensschwester, der Frieder in Anziehung und Abstoßung verbunden ist. Heimat und Heimatlosigkeit werden durch diese Frauenfigur bei Kurz zu zentralen komplementären Prinzipien.

Der Roman beginnt mit der Entlassung Frieders aus der Haft und seiner Rückkehr nach Hause. Auf seinem Heimweg trifft er einen ebenfalls entlassenen Häftling, einen Zigeuner, dessen Weg in die erneute Kriminalität dieser selbst als unabwendbar ansieht: „Wie kann der Zigeuner, dem ihr mit Verachtung die Türe weiset, sein ehrlich Brot bei euch verdienen?“366 - Damit setzt eine den ganzen Roman beherrschende Auseinandersetzung mit dem Schicksal der heimatlosen Zigeuner ein; es wird auf seine historischen und soziologischen Ursachen hin befragt ${ }^{367}$ und die drakonischsten Maßnahmen werden ausgemalt, etwa ein Kreispatent, nach dem Zigeuner ohne jedes Vergehen und ohne Verhör und Urteil „aufs Rad“ gelegt werden können. ${ }^{368}$ - Angeregt von der moralischen Belehrung des Gefängnispfarrers, gute Werke zu tun, und beschwingt durch die Aussicht auf das „Ziel ihrer Reise“, das sich „freundlich und heimatlich““369 vor den beiden

366 Kurz 1980, S. 23.

367 Vgl. Kurz 1980, S. 462.

368 Kurz 1980, S. 462-464. Die Stelle wird von Philipp Walburg Kramer als so wichtig erachtet, dass sie auch in seiner Bühnenfassung nicht fehlt; vgl. Kramer 1855, S. 45-46.

369 Kurz 1980, S. 26. 
Wanderern ausbreitet, fasst Frieder den Entschluss, bei seinem Vater, dem Sonnenwirth, für seinen neuen Bekannten um Aufnahme ins elterliche Haus zu bitten: „Vater, ich hab Euch einen Menschen mitgebracht, der keine Heimat hat, eine vater- und mutterlose Waise, denn das ist er, und wenn auch seine Eltern noch leben." ${ }^{370}$ Frieder erntet nur Hohn für sein Ansinnen und muss den Zigeuner wegschicken - aber er wird ihn im weiteren Verlauf der Handlung immer an entscheidenden Wendepunkten seines Lebens wiedertreffen und schließlich selbst zu den Heimatlosen zählen und keine Aufnahme mehr in einem ,ehrlichen“ Haus finden. Schon der Romanbeginn verweist also auf die Komplementarität von Heimat und Heimatlosigkeit, und von Anfang an ist dabei sowohl die juristische als auch die emphatische Bedeutung der Begriffe im Spiel: Denn was sich für den Rückkehrer mit Sentimentalität verbindet, hat für den Zigeuner einen rechtlichen Sinn. Am bürgerlichen Anspruch, dass beides in eins falle, wird Frieder zugrunde gehen.

Frieders Weg in die Katastrophe beginnt mit dem frühen Tod der Mutter und der daraus erwachsenden Haltlosigkeit, wird beschleunigt durch die Missgunst der Stiefmutter, die sein Ansehen beim Vater mit allen Mitteln schmälert, durch seinen im Zuchthaus endenden jugendlichen Versuch, mit dem heimlich entwendeten mütterlichen Erbe nach Amerika auszuwandern, und schließlich durch die Verweigerung der Ehe mit der von ihm geliebten Christine durch den Vater. Da der Vater ihm das Erbteil seiner Mutter nicht auszahlt, steht der an sich nicht arme Bürgersohn in der Macht des Vaters. Frieder will sich nun außerhalb des Geburtsdorfes ansässig machen, um mit selbstverdientem Geld die Ehe zu ermöglichen. Er verlässt ein Umfeld - sein Elternhaus, die Dorfbewohner, die amtlichen Vertreter seiner Gemeinde -, das sich als menschlich niedrig erwiesen hat, ohne damit Maßstäbe bürgerlicher Moral zu verletzen. Die Menschen, mit denen Frieder zu tun hat, sind, so die Erzählerstimme, „gewiß lauter ,ehrliche Leute““, und doch habe Frieder viel Gelegenheit gehabt, „die mehr oder minder klare Betrachtung anzustellen, daß Achtbarkeit und guter Ruf in dieser Welt sehr oft weniger von einem streng ehrlichen und sittlichen Wesen, als von Klugheit und zufälligen Umständen abhängen““. ${ }^{371}$ Obwohl Frieder in seinem Umfeld vor allem Missgunst, Opportunismus und Bigotterie erfahren hat, ist er wehmütig, als er „sein väterliches Haus“ verlässt. Diese erste wichtige Wegmarke, der Aufbruch aus dem Haus, in dem er geboren wurde, wird zum Anlass einer ausführlichen Reflexion des Erzählers auf Heimat:

370 „Man hat gegen diese Leute manches einzuwenden, und das ist auch kein Wunder, denn man behandelt sie auch danach." Kurz 1980, S. 59. Identisch für das Bühnenstück verwendet, vgl. Kramer 1855, S. 19.

371 Beide Zitate Kurz 1980, S. 89-90. 


\begin{abstract}
Aber auch von diesem, so wenig Gutes er in letzter Zeit daselbst erlebt zu haben meinte, fühlte er sich noch eine geraume Weile festgehalten und starrte mit feuchten Augen nach den Fenstern hinauf, hinter welchen seine Mutter ihn geboren und mit so unendlicher Liebe aufgezogen hatte, hinter welchen der Mann waltete, der doch immer sein Vater war. Sein rauhes Herz war von einer unsäglichen Wehmut ergriffen, in welcher die innerste Seele des Volksstammes, dem er angehörte, sich spiegelte. Der Schwabe, obgleich er eines der unstätesten Völker ist und vielleicht sogar seinen Namen vom Schweben und Schweifen hat, ist doch darum dem Heimtum nicht minder als dem Wandertriebe verfallen. ${ }^{372}$
\end{abstract}

Frieders ,Wehmut' beim Abschied von dem Haus, in dem er geboren und aufgezogen wurde, hat nur einen positiven Bezugspunkt, die früh gestorbene Mutter. Schnell wird die Reflexion vom Individuell-Biographischen ins Allgemeine gehoben, zunächst ein spezifisch schwäbischer Hang zum ,Heimtum‘ behauptet, der mit dem ,nicht minder ${ }^{\star}$ ausgeprägten Hang zum ,Wandertrieb` wieder relativiert wird. Die Reflexion wird ein weiteres Mal ins Allgemeine gehoben, indem die widerstreitenden Gefühle von Fern- und Heimweh (vgl. I.2.5) nicht als Spezifisches, sondern als Allgemeinmenschliches behandelt werden:

Während viele jahraus, jahrein entlegene Länder durchziehen, kleben andere an ihrer Heimstätte fest, als ob sie mit ihr verwachsen wären, - ja, man erzählt von einer alten Frau, die in Tübingen auf der Ammerseite wohnte, sie habe nie in ihrem Leben den Neckar gesehen -, und selbst von jenen reißt sich mancher erst nach vergeblichen Versuchen und nur um den Preis des bittersten Heimwehs von der heimischen Scholle los, mag aber auch freilich, wenn einmal das Heimweh überwunden ist, an sich erleben, daß die Heimat, die er nicht entbehren zu können glaubte, jahrelang fern und tot und seinem Herzen als etwas Fremdes hinter ihm liegt. Doch wird es kaum einen geben, den nicht wenigstens im Alter wieder die Sehnsucht nach den heimischen Bergen, Tälern und Gewässern befinge. Freilich werden diese widersprechenden Triebe der Wanderlust und der Heimseligkeit, die bei dem Schwaben nur mit besonderer Stärke hervortreten, in jedem Menschenschlage wahrzunehmen sein. ${ }^{373}$

Es bleibt damit ein ,Trieb` von anthropologischem Format, der sich mit einem ihm „widersprechenden Triebe“ wieder aufhebt und so am Ende nicht viel erklärt. Der sich anschließende Dialog zwischen Frieder und einem alten Invaliden bricht die Bedeutung von Heimat ein weiteres Mal, diesmal durch den Wechsel vom Sentimentalen ins Witzige des ,Volksmunds': „Übrigens sagt man: Die Fremde macht Leut. [...] Ich streit's nicht. Wer nie hinauskommt, kommt auch nie hinein. Und was das Heimweh betrifft, so hat selbiger Schwab in der Fremde gesagt: Schwaben ist ein gut Land, ich will aber nit wieder heim: grob Brot, dünn Bier und große

372 Kurz 1980, S. 237.

373 Kurz 1980, S. 237-238. 
Stunden!“374 Die im 19. Jahrhundert omnipräsente Dialektik des In-die-FerneGehens, um bei der Rückkehr Heimat erneut zu erlangen, wird hier in Frage gestellt. Besser ist es vielleicht, einfach dort zu bleiben, wo es mehr zu essen und weniger $\mathrm{zu}$ arbeiten gibt: Die sentimentale wird hier mit einer pragmatischen Perspektive konfrontiert. Die sehr verschiedenen Blickwinkel auf Heimat, die der Roman bietet, werden hier um einen für das 19. Jahrhundert ziemlich radikalen Blickwinkel ergänzt, dem zufolge Heimat eigentlich gleichgültig ist.

Frieders Versuch, sich außerhalb des Geburtsdorfes ansässig zu machen, scheitert - alles sei zünftig, so Frieders Erkenntnis, „da kann man nicht so hineinsitzen, wie man will“, das könne nur einer, „der ein Geschäft ererbt oder so viel Geld hat, um sich eins zu kaufen“. ${ }^{375}$ Ohne Kapital hat man keine Möglichkeit, außerhalb der Heimatgemeinde legal einem Erwerb nachzugehen. Und ist man einmal in die Fremde gegangen, ist dem Rückkehrenden ohne Geld auch „die Heimat zugeschlossen“. ${ }^{376}$

Von dieser Erfahrung ausgehend trifft Frieder dann die Aussage, „die Heimat [sei] halt doch das Beste in der Welt“377 - eine Aussage, die also rein pragmatische und keine sentimentalen Ursachen hat. Die Stiefmutter hintertreibt den Ehewunsch des zurückgekehrten Frieder mithilfe des Amtmanns, der seinerseits an die potentiellen Lasten für die Gemeinde denkt, ${ }^{378}$ und bringt schließlich die in Vergessenheit geratene Tatsache ins Spiel, dass die Familie der Christine Müller sich nominell noch im Verhältnis der Leibeigenschaft befindet. Die Summe, die zur „Leibeigenschaftsablösung“379 nötig wäre, wird zum unüberwindlichen Hindernis für die Heirat. Frieder kann seinen Schwur, Christine treu zu bleiben, nur halten, indem er die Regeln der bürgerlichen Ordnung durchbricht und eine ,wilde Ehe' mit der Frau eingeht, die er nicht heiraten darf. Er bleibt „bei dem Weibe, um dessen Besitz er so lange mit der Welt gestritten hatte, bis ihm selbst jeder Anspruch auf ein Eigentum und eine Heimat in der Welt verloren gegangen war“. ${ }^{380}$ Es kommen Kinder und es ist kein Bleiben mehr im Dorf. Frieder bezahlt das Kostgeld für die provisorische Unterbringung Christines abseits der Dorfgemeinschaft mit dem Ertrag seiner Wilderei, aber die ärmliche Unterkunft gewährt

374 Kurz 1980, S. $239-240$.

375 Beide Zitate Kurz 1980, S. 270.

376 Kurz 1980, S. 271.

377 Kurz 1980, S. 273.

$378 \mathrm{Er}$ „schalt die Regierung, welche viel zu liberal sei und das junge Volk [...] ins Blaue hinein heiraten und den Gemeinden zur Last fallen lasse“. Kurz 1980, S. 361.

379 Kurz 1980, S. 365.

380 Kurz 1980, S. 552. 
den beiden nur einen „,vorübergehenden Schein von Haus und Heimat““. ${ }^{381}$ Das armselige Leben am Rande der Gesellschaft, die immer wieder sich zerschlagenden Hoffnungen auf Wiedereintritt ins bürgerliche Leben, Frieders zunehmender Kontakt mit den Jenischen und Zigeunern, eine Verwicklung in einen Raubüberfall und seine Beziehung zur schwarzen Christine führen zu einer Entfremdung zwischen ihm und Christine, die für Frieder auf einen endgültigen Bruch mit einer der beiden Welten hinausläuft. Dabei geht es schon lange nicht mehr um eine Wahl zwischen einem Leben in der Heimat oder in der Heimatlosigkeit, sondern zwischen einem Leben in der Heimatlosigkeit oder dem Tod in der Heimat. ${ }^{382}$

An dieser zweiten Wegmarke, an der Fragen nach dem Verhältnis zur bürgerlichen Gesellschaft und nach Heimat überblendet werden, geht Frieder mit der schwarzen Christine durch ein bergiges Waldstück, das sich ganz in der Nähe seines Geburtsdorfes befindet: „Eine kurze Wanderung auf der sich gegen den Talrand senkenden Anhöhe würde ihm sein Heimattal gezeigt haben. [...] Er warf einen finsteren Blick nach der Stelle, wo unsichtbar für das Auge sein Vaterort drunten lag [...].“383 Nach einem Gewitter erleben die beiden ein Lichtschauspiel in der Gebirgslandschaft, das ihm das Vertraute fremd und das Fremde vertraut macht; es ist wie ein erster, unverstellter Blick auf die alte Heimat und die neue Gefährtin. Die schwarze Christine und die Landschaft verschmelzen im Licht und auch er selbst ist Teil dieser kurzzeitigen Synthese:

Er wußte nicht, ob er wachte oder träumte; die Welt war ihm neu, und er glaubte, sie, obgleich kaum eine Stunde von seinem Geburtsorte entfernt, zum erstenmal zu sehen. Er heftete den Blick wieder auf seine Genossin, durch deren Augen er dieses Liebesspiel der Sonne mit einem Fleck der Erde, den er seine Heimat nannte, erschaut hatte, und siehe, auch sie hatte der Lichtstrahl in seinen blendenden Bereich gezogen. Er hing bewundernd an ihrem Anblick, da kehrte sie ihm das braune, in rötlichem Schimmer strahlende Antlitz zu und rief: „Du bist ja ganz von Glanz umflossen!“

„Auch ich?“ fragte er verwundert.

„Wir sind bei der Frau Sonne zu Gaste“, sagte sie, „wir Kinder des Waldes haben darin viel vor den anderen Menschen voraus.“384

381 Kurz 1980, S. 553.

382 Es ist die gleiche Entscheidungssituation, in der bei Gottfried Keller die Liebenden Vreni und Sali stehen: Der schwarze Geiger will sie auf die Seite der Heimatlosen ziehen. Die Alternative ist für Vreni und Sali aber nicht mehr die bürgerliche Heimat, sondern nur der Tod - sie wählen ihn. Auch auf Frieder wartet, wie die Szene zeigt, in der Heimat nur der Galgen. Was bei Keller der schwarze Geiger repräsentiert, verkörpert bei Kurz die schwarze Christine: die Möglichkeit, sich nicht als Opfer der bürgerlichen Gesellschaft zu verstehen, sondern als ihr Verächter.

383 Kurz 1980, S. 636.

384 Kurz 1980, S. 637-638. 
Sie setzen ihren Weg fort, bis sie in der Nähe des Hofes angelangen, in dem Frieder die blonde Christine untergebracht hat. Er will sie auffordern, mit ihm sein Leben im Wald zu teilen, nachdem er an einem Überfall beteiligt war und die Gegend verlassen muss. Die schwarze Christine macht ihm kurz vor dem Abschied klar, dass er an einer Wegscheide steht und seine Entscheidung über das Leben, das er führen will, mit der Entscheidung für eine der beiden Frauen zusammenhängt: „In ihr hast du nur dich selbst geliebt, deinen eigenen Willen, in ihr hast du nur dir selbst Wort gehalten. In mir liebst du etwas anderes. “385 Die Entscheidung für eine Frau, die Frieder zu fällen hat, ist zugleich die Entscheidung für ein selbstgewähltes Leben in Heimatlosigkeit oder ein Leben am Rand der Gesellschaft, die Heimat verwehrt. Die schwarze Christine lockt ihn damit, dass er in ihr ,das Andere' und nicht nur sich selbst, seinen eigenen Willen, liebe. In der blonden Christine liebt er, so ließe sich der von der schwarzen Namensschwester ausgesprochene Gedanke weiterentwickeln, ein bürgerliches Ideal der Ehre, Treue und Heimat, das nicht lebbar ist. Die schwarze Christine zeigt Frieder, dass die von ihm hochgehaltenen Werte sich gegen ihn selbst gewandt haben und er zum Opfer des ,Eigenen“ geworden ist. Die Wahl der schwarzen Christine und der von ihr repräsentierten Heimatlosigkeit verheißen dagegen als Wahl des ,Anderen` auch Selbstermächtigung.

Das Wiedersehen mit der blonden Christine bringt keine Annäherung; Christine will Frieder nicht in die Heimatlosigkeit folgen. Sie gelangen während ihres Gesprächs zu derselben Stelle, an der sich zuvor das Lichtschauspiel mit der anderen Christine ereignet hat:

Nun saß sie an derselben Stelle, wo kurz zuvor ihre Namensschwester gesessen. Welch ein ganz anderes Bild bot sich ihm jetzt in den grauen Schatten des Abends dar! Die Waage mußte zuungunsten des armen, bleichen, vor der Zeit alternden Weibes hoch emporsteigen, wenn er sie mit jenem von Schönheit und Jugend strahlenden Geschöpfe der Wüste verglich. Er fühlte dies und kämpfte dagegen an. Er wollte dem Weibe seiner Jugend Wort halten, und wenn er die Unmöglichkeit selbst überwinden müßte. Leidenschaftlich rang er mit ihrem Entschlusse, bat, drohte, tobte, fluchte. Sie blieb fest. „Du kannst mich erschießen“, sagte sie, ,aber ich tu's meinem rechtschaffenen Vater unter dem Boden nicht zuleid, daß ich zu dem Gesindel ging.“386

385 Kurz 1980, S. 638.

386 Kurz 1980, S. 647. 
Christine sieht, dass der Ursprung von Frieders Handeln gut war und er doch in eine Lage gekommen ist, aus der höchstens der Tod rettet. ${ }^{387}$ Tatsächlich führt der Blick von der Bank nicht mehr ins heimatliche Dorf Ebersbach, wie es Frieder noch beim Zusammentreffen mit der schwarzen Christine schien, sondern auf den Ebersbacher Galgen. ${ }^{388}$ Während Frieder verzweifelte Pläne schmiedet, als Soldat eine Zeit in die Fremde zu ziehen, um danach doch noch ein gemeinsames Leben beginnen $\mathrm{zu}$ können, werden die beiden von Frieders Häschern überrascht. Frieder kann fliehen, aber Christine nicht aus der Gefangenschaft befreien; sie kommt in Haft und wird wegen unterstellter Komplizenschaft „zur Ausstellung auf dem Hochgerichte und hierauf zu erstehender vierjähriger Zuchthausstrafe“389 verurteilt.

Die dritte Station auf dem Weg in das völlige Zerwürfnis mit der Gesellschaft, liegt kurz vor dem Mord Frieders an dem Mann, der wesentlich Schuld an Frieders Konflikten mit der Obrigkeit trägt. Die Nacht vor dem Mord verbringt Frieder schlaflos in der Nähe des Dorfes versteckt. Die ausführliche Schilderung des nächtlichen Naturerlebnisses geht bei Tagesanbruch in die Darstellung der Gefühle von Wut und Hass über. Zunächst aber findet wieder eine Reflexion des Erzählers auf das statt, was das Heimatgefühl ausmacht. Zunächst ist es ein Duft, der Kindheitserinnerungen weckt: „Tau im Heu [...] jener Duft, der vor allen anderen den Menschen mit heimatlichen Empfindungen erfüllt. Der Geächtete sog ihn gierig ein, und Tränen traten in seine müden Augen. Wie oft hatte er da unten als Knabe mit anderen Knaben [...] in dem aufgeschichteten Heu sich gewälzt.“ Dann ist es der Anblick des Geburtshauses, „das Haus, das ihn geboren, das nach dem rechten Laufe der Dinge ihn als Erben hätte behalten sollen“. Aber auch das ist noch nicht der Kern des Heimatgefühls: „Doch war es nicht dies allein, was seinen Blick an die grauen Giebel fesselte: es war der wunderbare Zug nach der Heimat, den seine heimatlosen Gesellen nicht verstanden. Seltsamer Drang des Herzens!“390 Seltsam deswegen, weil sich dieser „Zug nach der Heimat“391 nicht durch positive Bindungen erklären lässt:

387 Vgl. Kurz 1980, S. 647-648. Bei Keller entscheiden sich Vreni und Sali beide gegen das Leben mit den Heimatlosen und gehen lieber in den Tod, als deren Welt zu teilen; bei Kurz ist es die blonde Christine, die eben diesen Weg gehen will.

388 Vgl. Kurz 1980, S. 648.

389 Kurz 1980, S. 749.

390 Alle Zitate Kurz 1980, S. 660 - 661.

391 Der ,Zug‘ oder das ,Ziehen“ nach Gott ist ein oft in pietistischen Kontexten verwendeter Begriff und verweist hier möglicherweise auch auf eine religiöse Dimension des Heimatverhältnisses. „Eine der pietistischen Kernvorstellungen ist die, daß Gott die in Welt und Sünde versunkene Seele zu sich ,zieht'. Sie hängt eng zusammen mit der Grundhaltung der Passivität: die Seele, die aus sich heraus nichts als Böses ,wirken` kann, die sich der ,Eigenheit‘ entäußern muß, 


\begin{abstract}
Keine heimische Geschichte, vom Mund des Großvaters auf den Enkel fortgepflanzt, keine alte Volkssitte lebte in diesem nüchternen Orte, woraus das Gemüt des Knaben Nahrung und dankbare Anhänglichkeit hätte schöpfen können, und doch zog es den reifenden Mann aus der Öde der Verbannung immer wieder nach der kargen Heimat zurück. Sie hatte ihn ausgestoßen und von sich gespien, sie fürchtete sich vor ihm wie vor dem wilden Tiere, das aus den Wäldern hervorbricht; er fluchte ihr und drohte ihr mit Mord und Brand: und doch kam er immer wieder nach ihr zu schauen, und in seiner kindisch unverdauten Weise war er mehr als auf jede Kriegs- oder Friedensneuigkeit darauf erpicht, zu wissen, was man in Ebersbach von ihm sage $[. ..] .^{392}$
\end{abstract}

Das Heimatgefühl ist ambivalent: „dankbare Anhänglichkeit“ lässt sich für Frieder weder aus Kindheitserlebnissen noch aus den Erfahrungen des Erwachsenen schöpfen. Obwohl sich seine Heimatbezogenheit nicht durch Menschen rechtfertigen lässt, die ihm Gutes taten, bleibt sie auf die Menschen bezogen: Mehr als auf alles andere sei er darauf erpicht zu wissen, was man in Ebersbach von ihm sage. Diese Bezogenheit auf Heimat wird nun zum Hauptunterscheidungsmerkmal zwischen ihm und den immer schon rechtlich Heimatlosen, auf deren Seite er mit seinem Mord dann endgültig stehen wird.

Der steckbrieflich Gesuchte wird einige Jahre mit der schwarzen Christine und den gemeinsamen Kindern in der Heimatlosigkeit leben. ${ }^{393}$ Ihre Verhaftung und das sich anschließende Todesurteil führt zur vierten Wegmarke der Auseinandersetzung zwischen Frieder und der bürgerlichen Ordnung. Während die schwarze Christine, „Tochter eines heimatlosen Stammes“, „die über den Gräbern ihrer geschlachteten Verwandten im Kriege mit der Gesellschaft aufgewachsen war" 394 die bürgerliche Gesellschaft immer schon als natürlichen Feind betrachtete, bleibt ihr Frieder auch als Delinquent verbunden. Die schwarze Christine erlebt ihre Todesstunde im Hass auf die Gesellschaft, Frieder schließt seinen Frieden mit ihr, auch wenn er, wie der Erzähler befindet, von dieser „fast ge-

überläßt sich tatlos dem ,Zug“ der Gnade.“ Langen 1968, S. 45; vgl. insgesamt den Eintrag ,zieh, reißen, führen“ in Langen 1968, S. 45-54.Vgl. aber auch Jung-Stillings Einschätzung, nach der das Bild des ,Zugs‘ typisch für die Mystik sei: Die „erste Periode des christlichen Lebens, nennen die Apostel Sinnesänderung; und die neue Geburt, Wiedergeburt folgt unmittelbar darauf; die christlichen orthodoxen Theologen geben ihr den Namen Buße, Bekehrung und Wiedergeburt, die Pietisten nennen sie die Erweckung, und der Mysticker den Zug des Vaters zum Sohn; im Grund aber ist das alles Eins.“ Johann Heinrich Jung-Stilling: Berichtigung der gewöhnlichen Begriffe von der Mystik (1799), in: Albrecht-Birkner/Breul/Jacob 2017, S. 149-177, hier S. 166.

392 Kurz 1980, S. 661.

393 Auch die Ehe mit der schwarzen Christine kann aus rechtlichen Gründen nicht geschlossen werden: Es fehlt ein Taufschein, vgl. Kurz 1980, S. 696-697.

394 Alle Kurz 1980, S. 702. 
waltsam unter die Räuber gestoßen worden“395 ist. Es ist eine Gesellschaft, der auch in der Todesstunde der Protagonisten seitens des Erzählers keine Kritik erspart wird: Sie ,schlachtet' Zigeuner und verurteilt neben Frieder und der schwarzen Christine auch eine Magd zum Tod, deren Vergehen darin besteht, „zwei Hemden, einige Tischmesser und Zinnlöffel und eine Semmel“396 gestohlen zu haben. Es ist eine Gesellschaft, deren Pfarrer nur das Todesdatum der Delinquenten verzeichnen, statt sie zu schützen, wie es mit deutlichen Worten heißt, ${ }^{397}$ und die angesichts des bevorstehenden qualvollen Todes auf dem Rad das christliche Martyrium beschwören, statt Humanität zu üben. Der Roman gibt die in den Akten des real zugrundeliegenden Falls von der „Heimatbehörde“398 festgehaltenen Worte der letzten Tage und Stunden des Todeskandidaten wieder und kommentiert sie kritisch: Es sei zu bezweifeln, dass Frieders Hoffnung auf den Himmel christliches Märtyrertum ausdrücke, wie der anwesende Geistliche glauben wolle, wahrscheinlicher sei sie schlicht der Angst vor der Marter entsprungen. Nicht Heroisierung, sondern ein humanes Menschenbild, das die Glücksbedürftigkeit und Schwäche des Menschen einbezieht, liegt diesem Anliegen zugrunde. Kirchenkritik ist hier Kritik am Verrat an der Humanität und an der Teilhabe an staatlicher Repression. ${ }^{399}$

Die Kritik an verlogener religiöser und bürgerlicher Moral - und dass diese auch noch in der zeitgenössischen Gesellschaft zu finden sind, daran lässt die Erzählerstimme keinen Zweifel ${ }^{400}$ - tangiert bei Kurz jedoch nicht den Glauben an

395 Kurz 1980, S. 761.

396 Kurz 1980, S. $748-749$.

397 Vgl. Kurz 1980, S. 759.

398 Kurz 1980, S. 755.

399 Die Gottessehnsucht, als welche der „Geistliche Krippendorf“ Frieders Freude über die bevorstehende Hinrichtung deutet, wird von der Erzäherstimme ironisch relativiert als schlichte Hoffnung auf den Zeitpunkt, an dem die Todesqualen überstanden sein werden: „An diesem christlichen Heldentum, das die Geschichte in unschuldigen Märtyrern wie in reuigen Verbrechern tausendfach als unverfälschte Gesinnung aufgewiesen hat, soll niemand mäkeln. Wohl aber hat jedes Heldentum, nicht bloß für die gemeine Anschauung, die es niedriggesinnt in den Staub $\mathrm{zu}$ ziehen sucht, sondern auch für eine würdigere Betrachtung, die aber nicht anders als mit menschlichem Maße messen mag, seine menschliche Seite, und es kann der Menschenwürde des Bekehrten, den wir hier durch seine letzten Stunden begleiten, keinen Eintrag tun, wenn wir aus den Worten, die seinen Beichtvater beseligten, doch auch den menschlichen Seufzer heraushören, daß die scheußliche [...] Marter, die in den ersten Frühstunden beginnen sollte, um die Zeit, wo glücklichere Menschen ihrem Schöpfer danken und seine Gaben genießen, doch hoffentlich überstanden sein werde.“ Kurz 1980, S. 753-754.

400 Auch wenn das gegenwärtige „Ringen nach Licht und Recht“ (Kurz 1980, S. 762) ein Stück weitergekommen sei - die erzählte „Volksgeschichte“ (Kurz 1980, S. 763) gehe immer noch alle an. Auch Fritz Martini deutet den Sonnenwirth als „eine Warnung an die Gegenwart“. Die „,soziale und 
eine davon unberührt bleibende, positive Beziehung zu Gesellschaft und Religion. In beiden Beziehungen fungiert Heimat als positiv bestimmter Nukleus. Heimat ist für Frieder, selbst wo alle äußeren Umstände dagegen sprechen, das Band zwischen ihm und der bürgerlichen Gesellschaft. Die gleiche Funktion nimmt Heimat für die Religion ein. Die Religion, so heißt es, war bis zum Ende „die Heimat seines innersten Gemüts geblieben“, ${ }^{401}$ und der Roman endet auf dem Weg zum Henker mit einer Begegnung mit dem Invaliden, der schon beim ersten Auszug aus dem Geburtsort fragte: „wo 'naus?“ und als Antwort erhielt: „In die Fremde“. ${ }^{402}$ Jetzt fragt der Alte wieder: „Oh, wo 'naus, Frieder, wo 'naus?“ „Dem Himmel zu!“, antwortet Frieder „mit der hellen Kommandostimme, die bei so manchem Einbruch erschollen war“. ${ }^{403}$ - Ob im Himmel Heimat gefunden wird, lässt der Roman offen.

Im dezidiert sozialkritischen Heimatverständnis von Kurz, das die Bedeutung von Heimat als administrative Kategorie gegen deren emotionale Bedeutung setzt und beide als unauflösbar miteinander verknüpft zeigt, wird Heimat als tragisch ausgewiesen. Denn sie vermag - weder auf administrativer noch auf emotionaler Ebene - zu geben, was sie verspricht, und kann doch als Anspruch nicht aufgegeben werden. Die unterschiedlichen, ja widersprüchlichen Heimatauffassungen des Romans lassen am Ende offen, ob der ,Zug zur Heimat“ einem anthropologischen Trieb, einem ökonomischen Pragmatismus oder gesellschaftlicher Konvention entspringt. Den Autor interessiert das tragische Potential, das sich aus Heimat schlagen lässt: Denn die Wünsche und Hoffnungen, die sich mit Heimat als Ort der Gemeinschaft und des Schutzes verbinden, werden allesamt enttäuscht.

\section{Gottfried Keller: Romeo und Julia auf dem Dorfe}

Hermann Kurz behandelt die mit dem rechtlichen Problem der Heimatlosigkeit zusammenhängenden sozialen Fragen in einer Schonungslosigkeit, die die zeitgenössische Relevanz des Themas trotz der historisch entfernten Situierung des Romanstoffs offenlegt. Viele andere literarische Texte des 19. Jahrhunderts verdecken die Brisanz der rechtlichen Heimatlosigkeit, indem sie ihren heimatlosen Helden am Ende doch poetische Gerechtigkeit widerfahren lassen, wie bei Wil-

moralische Anklage gegen eine Gesellschaft, die den Armen entrechtete“ sei nicht zuletzt auch als „aktueller Vorwurf gegen die Dauer der deutschen Misere“ zu interpretieren. Alle Zitate Martini 1974, S. 443.

401 Kurz 1980, S. 694.

402 Beide Zitate Kurz 1980, S. 239.

403 Alle Zitate Kurz 1980, S. 772. 
helm Heinrich Riehl, Friedrich Gerstäcker oder Robert Schweichel gesehen. Bei Johanna Spyri, der Heidi-Autorin, ist das Schweizer Heimatrecht gar nur noch Anlass, die Rückkehr in die - nur durch unglückliche Umstände zeitweilig entzogene - Heimat umso glücklicher feiern zu können. In einer Erzählung von 1878 glaubt der heimatlose Geiger Rico, es sei Gottes Wille, dass es für ihn keine Heimat gebe: ,[W]enn der liebe Gott eine Heimat in seinem Reich für mich hätte und auch die Kraft hat, daß er mir sie geben könnte, so will er nicht [...]“. Diese Ansicht wird im Lauf der Erzählung dahingehend korrigiert, dass Rico erst zurück zu Gott finden muss, ehe sein sehnlicher Wunsch nach Heimat erfüllt wird. Ob es dann tatsächlich der „liebe Gott“404 ist, der - wohlgemerkt die irdische! - Heimat schenkt, oder doch nur der Blick ins Taufbuch, der Rico als rechtmäßigen Erben eines Hofes ausweist, bleibt offen: Alles kommt jedenfalls im Kapitel In der Heimat zu seinem Recht, ausnahmslos alle Dorfbewohner freuen sich für den bisherigen armen Schlucker und man „konnte gar nicht begreifen“, daß es bisher niemandem aufgefallen war, wie ähnlich Rico seinem taufbuchlich nachgewiesenen Vater sieht. ${ }^{405}$

Die Parallelen wie der Kontrast zu Gottfried Kellers über zwanzig Jahre früher erschienener Novelle Romeo und Julia auf dem Dorfe, um die es hier nun gehen soll, könnten auffälliger nicht sein: Hier wie dort findet sich ein rechtlich Heimatloser, der sich als Geiger in Wirtshäusern verdingt, hier wie dort eine auffällige Ähnlichkeit zum Vater, die seine rechtmäßigen Ansprüche auf Heimat nahelegt. Nur fehlt bei Keller der Taufbucheintrag und es fehlen die Menschen, die die Ansprüche gutheißen würden, es fehlt der liebe Gott, an den man nur wieder glauben muss, und es fehlt das gute Ende. Nicht nur erhält der Geiger keine Heimat, sondern darüber hinaus werden zwei ganze Familien ausgelöscht. Die Entwicklung ist damit genau andersherum als bei Spyri: Während bei Spyri die Heimat des (vermeintlich) Heimatlosen wiederhergestellt wird, werden bei Keller die, die (vermeintlich) Heimat haben, zu gesellschaftlich Ausgestoßenen. Dabei erweist sich Kellers hochkomplexe Seldwylaer Novelle nicht nur als sozialkritische Gegenwartsdiagnose (wie etwa Fritz Reuters Heimathloser in Mecklenburg), sondern mehr noch als Diagnose der zutiefst ambivalenten Faszination, die Heimatlosigkeit als Gegenmodell zur bürgerliche Ordnung repräsentierenden Heimat in sich birgt.

In Kellers Romeo und Julia auf dem Dorfe, dessen erste Fassung von 1856 stammt, löst der heimatlose ,schwarze Geiger‘ beim Liebespaar Sali und Vrenchen

404 Alle Zitate Spyri 1920, S. 112. Die Erzählung Am Silser- und am Gardasee wurde zusammen mit einer zweiten Erzählung unter dem Titel Heimathlos. Zwei Geschichten für Kinder und solche, die Kinder lieb haben 1878 veröffentlicht. Heidi’s Lehr- und Wanderjahre folgen 1880.

405 Alle Zitate Spyri 1920, S. 122. 
zugleich Angst und Anziehung aus. Diese Mischung der Gefühle ist ebenso dunkel wie die Funktion, die der schwarze Geiger für die Novelle hat. Seine Heimatlosigkeit, so die hier und etwas anders bereits von Herbert Uerlings vertretene These, ist die verdrängte Ursache des tragischen Geschehens und bildet damit das geheime Zentrum des gesamten Textes. ${ }^{406}$ Das verweigerte Heimatrecht bildet die Vorgeschichte des Rechtsstreits der Familien, in dessen Folge die unglückliche Liebe ihrer Kinder diese zu ,Romeo und Julia auf dem Dorfe' macht. Es geht anders als bei Shakespeare ${ }^{407}$ nicht um die ungünstige Verkettung von äußeren Umständen, durch die die Liebe der Kinder zweier verfeindeter Familien im Tod endet, sondern um die verinnerlichten Zwänge einer bürgerlichen Ordnung, deren verdrängtes ,Anderes‘ die Heimatlosigkeit ist. Das Liebespaar vollstreckt das Recht, das zwischen denen unterscheidet, die Heimat haben, und denen, die sie nicht haben, an sich selbst und wählt den Tod als Bürger statt das Leben als Heimatlose. ${ }^{408}$

Im berühmten Anfangsbild der Erzählung ist die wohlgefällige geometrische Ordnung der Landschaft, in die sich drei Äcker „gleich drei riesigen Bändern“409 einfügen, zu einer schon hyperrealistischen Symmetrie übersteigert. So wie die Namen der beiden pflügenden Bauern Manz und Marti alliterieren, vollzieht sich auch ihre Arbeit als absolut symmetrische Bewegung entlang der Pfluglinien, der

$406 \mathrm{Zu}$ Kellers Romeo und Julia auf dem Dorfe unter dem Aspekt von Heimatlosigkeit und Heimatrecht vgl. neben Uerlings 2007 auch Carsten Rohde, der im Rahmen einer konstellativen Lektüre von Auerbachs Barfüßle und Kellers Romeo und Julia auf dem Dorfe auch kurz auf die rechtliche Dimension von Heimat eingeht; vgl. Rohde 2014. Uerlings' Argumentation folge ich in vielen Aspekten, allerdings verschleiert seine Rede von der „Scheinhaftigkeit des Gegensatzes von Heimat und Heimatlosen“ an einigen Stellen seiner Argumentation, dass dieser Gegensatz eben nicht nur eine kulturelle Semantik ist, die es zu dekonstruieren gilt, sondern dass ihr rechtliches Fundament auch soziale Realitäten schuf. Obwohl Uerlings selbst diese rechtliche Dimension starkmacht, unterscheidet er in der eigenen Begriffsverwendung nicht hinreichend zwischen rechtlicher und übertragener Bedeutung, etwa wenn er Vrenchen und Sali zu Heimatlosen erklärt (Uerlings 2007, S. 175), obwohl sie es im rechtlichen Sinn ja gerade nicht sind.

407 Ausführlich zu den Shakespeare-Bezügen vgl. Saul 2003.

408 Die sich nach dem Verkauf des Ackers entfaltenden erbitterten Streitigkeiten zwischen den Bauern um die genaue Grenzziehung zwischen ihren Gebieten, die in kostspielige und jegliche Verhältnismäßigkeit verlierende Rechtsstreitigkeiten münden, führen schließlich zum gänzlichen Ruin beider Bauernfamilien. Im Unrecht, das im Ausschluss des schwarzen Geigers aus der Dorfgemeinschaft liegt und an dem sich die beiden Bauern als Repräsentanten der Gemeinde zu bereichern versuchen, liegt die verborgene, von der Erzählung gleichwohl deutlich markierte Ursünde der Gemeinde und Ursache der sich entfaltenden Katastrophe. Die Katastrophe legt die dialektische Gebundenheit bürgerlicher Ordnung an ihr antagonistisches Gegenteil, die Heimatlosigkeit, frei.

409 Keller 1989, S. 69. 
selbst die Zipfel ihrer Kappen zu unterliegen scheinen. Manz und Marti werden mit den Attributen der Unbescholtenheit und Solidität ausgestattet: Sie ,verkündeten auf den ersten Blick den sichern, gutbesorgten Bauersmann“, ihre Äcker sind „prächtig[ ]“, ihre Pferde „stattlich“, ihre Gesichter „wohlrasiert[ ]“ und jede Falte ihrer Kniehosen hat „ihre unveränderliche Lage“ und sieht „wie in Stein gemeißelt" aus. ${ }^{410}$

Schon ins Anfangsbild der pflügenden Bauern, auch dies wurde schon bemerkt, ist die antagonistische Kehrseite dieser nur scheinbar Biederen, in Wahrheit ins Groteske kippenden bzw. petrifizierten Ordnung (Zipfelmützen einerseits, „wie in Stein gemeißelte“ Hosenfalten andererseits) mit einbezogen, denn zwischen den zwei symmetrisch bearbeiteten Äckern befindet sich ein mittlerer, „brach und wüst“411 liegender Acker. Der wilde Acker ist die Bedingung für die Ordnung auf den beiden bewirtschafteten. Zunächst im ganz gegenständlichen Sinn: „Wenn sie einen Stein in ihren Furchen fanden, so warfen sie denselben auf den wüsten Acker in der Mitte mit lässig kräftigem Schwunge, was aber nur selten geschah, da derselbe schon fast mit allen Steinen belastet war, welche überhaupt auf den Nachbaräckern zu finden gewesen.“412 Aber auch in einem übertragenen Sinn steht der wilde Acker für das die Ordnung bedingende ,Andere‘: Gleich im ersten Gespräch der Bauern Manz und Marti geht es um die Vorgeschichte des herrenlosen Ackers. Den wenigen Andeutungen entnimmt die Leserin, dass dieser Acker ursprünglich dem ,Trompeter gehört habe, dessen als ,verdorben` bezeichnete Kinder in den Wäldern gelebt hätten und dort ein Kind auf die Welt gebracht hätten. Die Geburt dieses Kindes, des späteren schwarzen Geigers, sei entsprechend nicht beurkundet. Obwohl die Ähnlichkeit des schwarzen Geigers mit dem Großvater frappierend und die Verwandtschaft auf diese Weise bezeugt ist, wird ihm der Anspruch auf sein Erbe mit Hinweis auf die fehlenden Papiere verweigert. Die beiden Bauern rechtfertigen dies unter anderem mit der finanziellen Last, die die Gemeinde sonst tragen müsse:

„[W]ir haben so genug zu tun, diesem Geiger das Heimatsrecht in unserer Gemeinde abzustreiten, da man uns den Fetzel fortwährend aufhalsen will. Haben sich seine Eltern einmal unter die Heimatlosen begeben, so mag er auch dableiben und dem Kesselvolk das Geigelein streichen. Wie in aller Welt können wir wissen, daß er des Trompeters Sohnessohn ist? Was

410 Alle Zitate Keller 1989, S. 69.

411 Keller 1989, S. 69.

412 Keller 1989, S. 70. Der Acker wird also nicht nur für ein Jahr, sondern immer brach liegen gelassen. Insofern zeigt der Hinweis auf die Dreifelderwirtschaft von Alexander Honold nur, dass die Literaturwissenschaft ihr landwirtschaftliches Grundlagenwissen verbessern könnte; vgl. Honold 2004. Honold geht es eigentlich um das brach liegende Feld als Feld der Vermittlung, das im strukturalistischen Sinn selbst frei bleibt von dem, was es organisiert. 
mich betrifft, wenn ich den Alten auch in dem dunklen Gesicht vollkommen zu erkennen glaube, so sage ich: irren ist menschlich, und das geringste Fetzchen Papier, ein Stücklein von einem Taufschein würde meinem Gewissen besser tun, als zehn sündhafte Menschengesichter!“ [...] „,E]r sagt zwar, er sei nicht Schuld, daß man ihn nicht getauft habe! Aber sollen wir unsern Taufstein tragbar machen und in den Wäldern herumtragen ${ }^{413}$

So wie der Acker im ganz handgreiflichen Sinn Bedingung für die Ordnung auf den anderen Feldern ist, so ist er es auch in einem symbolischen Sinn: Die bürgerliche Ordnung des Gemeinwesens basiert auf (ökonomisch motiviertem) Ausschluss: „Wir sind schon übervölkert im Dorf [...]!“414 Der Besitz der einen basiert auf der Besitzlosigkeit der anderen.

Die Schieflage, in die sich die bürgerliche Ordnung mit dieser Diskrepanz zwischen ökonomischer Moral und Humanität begibt, wird auch im weiteren Verlauf der Novelle in Bilder der sich selbst untergrabenden Ordnung gefasst: Mittig zwischen den beiden bestellten Äckern gelegen, wird der wilde Acker zum Ort, an dem verschwiegen Raubbau betrieben wird. Beide Bauern schlagen Stück um Stück Furchen in den herrenlosen Acker und verleiben ihn dem eigenen ein wieder geschieht dies in Bildern der Ordnung, wird mit der Arbeit von „Weberschiffchen“ verglichen. ${ }^{415}$ Als der wilde Acker - in, so heißt es, Ermangelung von rechtmäßigen Erben - verkauft wird, bieten beide und Manz erwirbt ihn schließlich. Manz und Marti handeln rechtmäßig und vollziehen doch ein „Unrecht“, das von der gesamten Dorfgemeinschaft diffus als solches empfunden wird - allerdings hätten wohl „zwei Drittel der übrigen unter diesen Umständen“ dasselbe getan, merkt die Erzählerstimme an. ${ }^{416}$ Der Streit der Bauern entbrennt über Fragen der „Symmetrie“,417 einen „lächerlichen und unvernünftigen Schnörkel“, einen „krummen Zipfel“, den der eine Bauer vom neuerworbenen Feld des anderen abzuzweigen sucht. Dabei müsse doch alles „zuletzt eine ordentliche grade Art haben“. ${ }^{418}$ Der übersteigerte Ordnungssinn führt zum erbitterten, jede Verhältnismäßigkeit überschreitenden Streit und am Ende dazu, dass die durch die Rechtskosten verarmten Bauern selbst zu ,verwilderten Männer[n] “419 werden, deren Äußeres genauso herunterkommt wie ihre Sitten. Ihre

413 Keller 1989, S. 72-73.

414 Keller 1989, S. 73.

415 Keller 1989, S. 77.

416 Beide Zitate Keller 1989, S. 78.

417 Keller 1989, S. 81.

418 Alle Zitate Keller 1989, S. 79.

419 Keller 1989, S. 94. 
selbst wild gewordenen Äcker unterscheiden sich schließlich kaum mehr vom einstigen herrenlosen Acker. ${ }^{420}$

Die Novelle bietet viele Anhaltspunkte, solche sich selbst zerstörende Ordnung als schicksalhaft bzw. als Ausdruck einer höheren Gerechtigkeit zu deuten: Mehrfach ist von Gestirnen, Sternbildern und Schicksalsgestirnen die Rede. ${ }^{421}$ Ebenso naheliegend ist es, auf Theorien des Verdrängens zurückzugreifen, um den Vorgang der sich gegen sich selbst kehrenden Ordnung zu erklären. W.G. Sebald hat der Assoziation von Heimat und Unheimlichem einen ganzen Essayband über die österreichische Literatur gewidmet. Er basiert auf der freudschen Annahme, dass das Unheimliche immer zugleich das Vertraute und das Unvertraute ist und sich die Angst aus der Wiederkehr des Verdrängten speist. ${ }^{422}$

Auch der wilde Acker Kellers lässt sich als solche ,unheimliche Heimat‘ lesen, in der sich Verdrängtes unfreiwillig Bahn bricht. Auf dem wilden Acker findet das Spiel der Kinder statt, in dem sie eine Puppe zerstören, sie zum „Marterleib“ und zum „ausgequetschten Leichnam“ machen und in ihren hohlen Kopf eine Fliege einsperren, um diese darin lebendig zu begraben. Die lustbesetzte Grausamkeit der Kinder und ihr späteres „Grauen“ vor der eigenen Tat verwandeln den wilden Acker für sie in eine „unheimliche Stätte“. Dem zum Gefängnis der Fliege gewordenen Puppenkopf wird von den Kindern eine Art Altar errichtet: „[S]o glich der Tönende jetzt einem weissagenden Haupte und die Kinder lauschten in tiefer Stille seinen Kunden und Märchen, indessen sie sich umschlungen hielten.“423 Der ,Marterleib‘, der Altar, auch die topisch mit dem Bösen oder dem Teufel verbundene Fliege ${ }^{424}$ machen das ausführlich geschilderte Kindheitserlebnis zu einer Art kultisch-religiöser Handlung, die um ein Böses und zugleich Lustvolles kreist. Auch später bleibt der Acker schuld- und lustbesetzter Ort der GegenOrdnung oder vielmehr des Außer-der-Ordnung, etwa wenn das Jäten des inzwischen verkauften wilden Ackers orgiastische Züge annimmt: „Denn da es eine außerordentliche gleichsam wilde Arbeit war, bei der keine Regel und keine Sorgfalt erheischt wurde, so galt sie als eine Lust.“ Das „wilde Zeug“ wird „mit großem Jubel verbrannt, daß der Qualm weithin sich verbreitete und die jungen Leutchen darin herumsprangen, wie besessen.“425

420 Vgl. Keller 1989, S. 98.

421 Vgl. Keller 1989, S. 70, S. 102.

422 Vgl. Sebald 2004. Zum Themenkomplex Heimat und Heimweh in Sebalds eigenem Werk vgl. Weber 1993.

423 Alle Zitate Keller 1989, S. 75.

424 Vgl. den Artikel ,Fliege‘ in Butzer/Jacob 2008, S. 107, in dem die Fliege u.a. als Symbol des Bösen beschrieben wird.

425 Alle Zitate Keller 1989, S. 80. 
Genauso wie am wilden Acker zeigt sich an der Figur des heimatlosen schwarzen Geigers selbst, dass sich das Unheimliche dort einstellt, wo ein verdrängtes Eigenes in Form des Anderen wiederkehrt. ${ }^{426}$ Der erste Auftritt des schwarzen Geigers findet zu dem Zeitpunkt statt, als sich die inzwischen älter gewordenen Vreni und Sali ihre Liebe gestehen. Der ehemals wilde Acker ist lange verkauft und bestellt. Die Szene ereignet sich an der Stelle, an der er gelegen hatte. Hier erscheint nun dessen verhinderter Besitzer, der schwarze Geiger, und nennt das ihm geschehene Unrecht beim Namen. Nach „ihrem Gewissen“ hätten die Väter von Vreni und Sali ihn, den schwarzen Geiger, als „den rechten Erben“ anerkennen müssen. Aber sie haben nicht moralisch gehandelt, sondern sich hinter der Rechtsprechung versteckt, um Unrecht tun zu können:

„Eure Väter kennen mich wohl und Jedermann in diesem Dorfe weiß wer ich bin, wenn er nur meine Nase ansieht. Da haben sie vor Jahren ausgeschrieben, daß ein Stück Geld für den Erben dieses Ackers bereit liege; ich habe mich zwanzigmal gemeldet, aber ich habe keinen Taufschein und keinen Heimatschein und meine Freunde, die Heimatlosen, die meine Geburt gesehen, haben kein gültiges Zeugnis, und so ist die Frist längst verlaufen und ich bin um den blutigen Pfennig gekommen, mit dem ich hätte auswandern können! Ich habe Eure Väter angefleht, daß sie mir bezeugen möchten, sie müßten mich nach ihrem Gewissen für den rechten Erben halten; aber sie haben mich von ihren Höfen gejagt und nun sind sie selbst zum Teufel gegangen! Item, das ist der Welt Lauf, mir kann's recht sein, ich will euch doch geigen, wenn Ihr tanzen wollt!“427

426 Wildheit und Ordnung, Heimatlosigkeit und Heimat bedingen einander. Das Eigene entsteht durch die Ausgrenzung des Anderen, das aber im Zentrum des Eigenen angesiedelt wird und sich durch diese Inversion schließlich selbst zugrunde richtet. Die unauflösliche Bedingtheit von Ordnung und Wildheit, Heimat und Heimatlosigkeit kommt nach Uerlings hier als das (verdrängte) Fremde, das zugleich Teil des Eigenen ist, zum Ausdruck. Der Acker als das Fremde wird okkupiert, damit dringt das Andere in das Eigene ein: „Aber wie der verwilderte Acker nicht das unmoralische Gegenbild zur Ehrbarkeit der Bauern, sondern das Abbild einer schon vorhandenen moralischen Verwilderung ist, so ist die Tugend der Sesshaften in dieser Erzählung nicht denkbar ohne die Behauptung der Untugend der Heimatlosen“ (Uerlings 2007, S. 166). Auch Saul interpretiert den schwarzen Geiger als das Fremde des Eigenen: „This outsider is indeed the outcast logically required to promote internal coherence of a closed, non-pluralist society or culture. But he comes, or came, from inside. In all members of the community, Keller seems to be saying, is an inner Gypsy, in all those secure in their unreflected homely identity lies hidden the exotic other. And this is the inner structure of identity formation. A sense of the intertextuality of Keller's figure thus not only leads the reader backwards to the literary pre-text, but also outwards to the extratextual referent (reality, that is) with a profound critique of the received, provincial Heimat mentality. “ Saul 2003, S. 139. Ob der ausgesprochen vieldeutige Text wirklich so eindeutig eine profunde Kritik der provinzellen Heimat-Mentalität darstellt, wie Saul argumentiert, sei dahingestellt. Er lässt jedenfalls auch diese Deutung zu.

427 Keller 1989, S. 103. 
Von der Gemeinde um seine Heimatrechte und damit um seinen Besitz betrogen, mit dessen Erlös er ein neues Leben hätte beginnen können, zeigt sich der schwarze Geiger nicht als bemitleidenswertes Opfer, sondern als rächender Geist mit allen Merkmalen des Unheimlichen; selbst ungreifbar wie ein Gespenst, scheint sogar sein Hut „alle Augenblicke seine Gestalt zu verändern“. ${ }^{428}$ Die dominante Schwarz-Rot-Farbigkeit ${ }^{429}$ gibt der Figur etwas Teuflisches und die mehrfach hervorgehobene Größe der Nase gibt ihm ein Attribut des Juden und des Zigeuners. Die Prophezeihung des schwarzen Geigers gegenüber dem in einen „seltsamen Bann“430 geratenen Paar, sie würden vor ihm „den Weg alles Fleisches“431 gehen, nimmt die Kindheitsszene wieder auf, die an derselben Stelle, und ebenfalls umgeben von Mohnblumen, stattfand und in der sich der Puppenkopf zu „einem weissagenden Haupte“432 verwandelte und die schaudernden Kinder mit dem Gefühl ihrer Schuld zurückließ. - Auch in Der Grüne Heinrich ist es übrigens eben diese Mischung aus Schauder und Faszination, die der Anblick von Heimatlosen auslöst. ${ }^{433}$

Der heimatlose schwarze Geiger ist zu Unrecht um seinen Besitz betrogen, aber trotzdem keine Identifikationsfigur, wie schon Berthold Auerbach in seiner Rezension von Kellers Novelle ausführt. Der Stoff wäre von der Romantik noch

428 Keller 1989, S. 103. Es geht ständige, unberechenbare Bewegung und ein nicht einzuordnendes Geräusch von ihm aus: Er taucht „plötzlich“, wie aus dem Nichts auf und „plötzlich“, „mit einem Satze“ springt er auf den „ungerechte[n] Steinhaufen“, der den streitbaren Acker markiert. Von seinen Augen sei „fast nichts als das Weiße zu sehen, da die Sterne unaufhörlich auf einer blitzschnellen Wanderung begriffen waren und wie zwei Hasen im Zickzack umhersprangen“, sein „kleines rundes Löchelchen von einem Munde“, das „sich seltsam stutzte und zusammenzog“, „pustete, pfiff und zischte“ unaufhörlich. Alle Zitate Keller 1989, S. 102-103.

429 Auch farblich im Kontrast zur freudvollen Situation vorher mit goldener Sonne, gelbem Kornfeld, weißen Wolken und blauen Kornblumen wird beim Erscheinen des Geigers alles schwarz: Sein Haar ist „pechschwarz“, seine Kleidung ist schwarz gefärbt und zugleich schwarz von Schmutz, der mit seinem Handwerk - Kesselflicken, Kohlenbrennen und Pechsieden in den Wäldern - erklärt wird. Die Dunkelheit vom „schwärzlichen Kerl“ wird, als er auf den mohnbedeckten, „feuerrot“ wirkenden Steinhaufen springt, mehrfach mit dem leuchtenden Rot der Blumen kontrastiert. Alle Zitate Keller 1989, S. 102. Die Mohnblumen werden in der folgenden Szene zusammen mit den roten Lippen von Vreni zuerst zum erotischen Symbol; direkt im Anschluss deckt Vreni ein Mohnblumenblatt auf den niedergeschlagenen Vater, um festzustellen, ob er noch lebt.

430 Keller 1989, S. 102.

431 Keller 1989, S. 103.

432 Keller 1989, S. 75.

433 Mit den Gefühlen von Schauder und Faszination begegnen Heinrich und Anna einer fahrenden Familie, die als eine „Bande Heimatloser“ abgeschoben werden soll, deren Versteck sie aber aus Mitleid mit dem „unglücklichen Volke“ nicht verraten. Beide Zitate Keller 1985, S. 282. 
ganz anders ausgeführt worden, argumentiert er: „Ein Romantiker hätte in der Lust an dem Vagabundarischen den schwarzen Geiger, der als Heimathloser um sein Vatergut betrogen wird, zum Helden gemacht. Der realistische Dichter wählt das Liebespaar, das sich bürgerlich und gemütlich retten will und doch in den Untergang verfällt." ${ }^{434}$ Heimatlosigkeit versus Bürgerlichkeit, das ist auch für Auerbach das die Novelle charakterisierende Gegensatzpaar.

Das zentrale Symbol der gefährdeten bürgerlichen Ordnung ist das Haus. ${ }^{435}$ Der Niedergang der Familien bedeutet auch einen Niedergang ihrer Häuser. Am Ende muss Salis Familie ihr Haus verlassen, um vom Dorf in ein heruntergekommenes Wirtshaus in der Stadt zu ziehen. Von dort aus erscheint Sali die „alte[] Heimat“ als „himmlisches Jerusalem“.436 Das zurückgelassene Zuhause verschmilzt für Sali mit dem religiösen Bild zukünftiger Heilserwartung. Vrenchen ist ihrerseits gezwungen, in der Stadt eine Dienststellung anzunehmen. Das Haus der Familie von Vrenchen wird zwangsversteigert, nachdem die Mutter gestorben und der verwirrte Vater im städtischen Armenspital untergebracht ist, als letzter symbolischer Akt wird die „Bettstelle“437 Vrenchens verkauft. Die letzten gemeinsamen Stunden, die dem Liebespaar bleiben, bevor ihm der Kahn „schwimmende Bettstelle“ und „Brautbett“438 wird, von dem aus es seinen Selbstmord verübt, flüchtet es sich in die Traumwelt eines unmittelbar bevorstehenden bürgerlichen Glücks, in der „die Ehre ihres Hauses“439 wiederhergestellt ist. Auf dem Kirchweihfest kauft Sali Vrenchen ein Lebkuchenhaus: „[U]nser Herz ist jetzt unser Haus, darin wir wohnen, und wir tragen so unsere Wohnung mit uns, wie die Schnecken! Andere haben wir nicht!“440 Das Lebkuchenhaus wird beim letzten Tanz zerdrückt, in einem Wirtshaus mit dem Namen Paradiesgärtlein. Dieser zwischen christlichem Elysium und heidnisch-dionysischer Welt angesiedelte Ort, ${ }^{441}$ an dem am Ende der Nacht nur noch die „kleine Gesellschaft der

434 Berthold Auerbach: Gottfried Keller von Zürich [Rezension], in: Beilage zu Nr. 108 der Augsburger Allgemeinen Zeitung, 17. April 1856, S. 1721-1723, hier zitiert nach dem Teilabdruck in Hein 1987, S. 36-40, hier S. 40.

435 Zur Symbolik des Hauses und ihrem Zusammenhang mit Heimat vgl. auch Uerlings 2007, S. 172-174; Kultermann 1956, S. 94-96; Rohde 2014, S. 61-90.

436 Keller 1989, S. 97. Zur christlichen Symbolik der Novelle vgl. Kaiser 1971. Die mehrfachen Evokationen einer Heimat im Himmel verweisen nach Rohde weniger auf einen der Novelle inhärenten Heilsglauben als vielmehr auf die Unmöglichkeit, Heimat sozial zu verwirklichen, vgl. Rohde 2014, S. 70.

437 Keller 1989, S. 119.

438 Beide Zitate Keller 1989, S. 143.

439 Keller 1989, S. 137. Vgl. auch die Interpretation bei Uerlings 2007, ab S. 172.

440 Keller 1989, S. 130.

441 Vgl. Koebner 1990. 
Heimatlosen“442 zurückbleibt, das „Hudelvölkchen, welches nirgends zu Hause war“, ${ }^{443}$ findet die zweite Begegnung mit dem schwarzen Geiger statt, dessen ambivalente Zeichnung ihn zugleich als dionysischen Anführer eines Bacchantenzugs und als Tod, der zum letzten Tanz aufspielt, zeigt. Er bleibt auch in dieser Szene eine uneindeutige Gestalt. Seine Stimme ist ,schrill‘, dann wieder ,aufrichtig' und ,gemütlich', ${ }^{444}$ und sein Angebot an die Liebenden, sich den Heimatlosen anzuschließen, wird zur kurzfristigen Verlockung: „Kommt mit mir und meinen guten Freunden in die Berge, da brauchet Ihr keinen Pfarrer, kein Geld, keine Schriften, keine Ehre, kein Bett, nichts als Eueren guten Willen! [...] [D]ie grünen Wälder sind unser Haus, wo wir uns lieb haben, wie es uns gefällt [...]. “445

Der „tolle nächtliche Zug“, dem sich das Liebespaar erst mehr gebannt denn willig anschließt, hat in seiner Kontrastierung mit dem zur Kulisse werdenden „Heimatdorf“446 etwas Karnevaleskes, auch Gespenstisches. Ihr Haus und Bett in den Wäldern zu finden, ist das Paar nicht bereit. Mit dem Freitod entziehen sie sich der für sie ausweglosen Lage. Der Tod der Liebenden wird nicht als Akt der Freiheit gezeigt, sondern als Unterwerfung unter eine bürgerliche Ordnung um den Preis des eigenen Lebens. Dies heißt nicht, dass das Ordnungsprinzip der Heimat und mit ihr verbundene Ehrvorstellungen als überspannt kritisiert werden sollen, ${ }^{447}$ sondern dass der Preis aufgezeigt wird, den es kostet. Heimat ist so darin vergleichbar dem Grünen Heinrich ${ }^{448}$ - zugleich höchster Wert und größte

442 Keller 1989, S. 139.

443 Keller 1989, S. 134.

444 Vgl. Keller 1989, S. 137-138.

445 Keller 1989, S. 137.

446 Beide Zitate Keller 1989, S. 140.

447 Dies ist auch ein wichtiger Punkt für Eva Geulen; vgl. Geulen 2010, S. 261. Der Tod des Liebespaars sei eben nicht „das bedauerliche Resultat unemanzipiert-naiver Bürgerlichkeit“ (Geulen 2010, S. 262), sondern das notwendige Telos einer Novellenkonstellation im rechtlichen und ästhetischen Spannungsfeld zwischen Besitz und ,Herrenlosigkeit‘.

448 Die starke affektive Bindung des Helden Heinrichs an Heimat - verstanden als Ort seiner Herkunft, als Beziehung zur Mutter und als Ausdruck bürgerlicher Ordnung - ist zugleich Grund seiner Überforderung und seines Scheiterns. Die Ambivalenz der Zugehörigkeit zu Heimat im Grünen Heinrich arbeitet Verena Ehrich-Haefeli heraus. In einer kontrastiven Lektüre von Wilhelm Meisters Lehrjahren und Grünem Heinrich stellt Ehrich-Haefeli zunächst fest, dass es das „Begriffspaar Heimat und Fremde“ im Gegensatz zu Keller bei Goethe „überraschenderweise“ noch nicht gebe (Ehrich-Haefeli 1991, S. 352). Fortunatus verwandt, der das frühbürgerliche Modell des Aufbruchs des Helden prägt, stehen auch Wilhelm Meister Welt und Zukunft völlig offen. Das einzige Mal, wo Goethes Roman das Wort Heimat verwende, sehe Wilhelm Heimat für sich in der Zukunft, nämlich in einer Gemeinschaft von Menschen, die wie er nach dem Schönen und Guten strebten (vgl. Ehrich-Haefeli 1991, S. 353). Demgegenüber füllen Erinnerungen an die Heimat über die Hälfte des Romans von Keller. Sie sind nach Ehrich-Haefeli u.a. durch Geschlossenheit des 
Last. Eine moralische Eindeutigkeit in der Bewertung des Endes von Romeo und Julia auf dem Dorfe gibt es nicht, und Kellers eigene Streichung des ursprünglichen Schlusses im Zuge der Überarbeitung zeigt die zeitgenössische Schwierigkeit, diese Uneindeutigkeit zuzulassen. ${ }^{449}$ Wie auch immer die dargestellte Gefährdung der bürgerlichen Ordnung zu bewerten ist, die Darstellung arbeitet sich jedenfalls an den Realitäten der Zeit ab. Uerlings nennt die bei Keller dargestellte bürgerliche Ordnung eine phantasmatische, ${ }^{450}$ doch die Erzählung zeigt, insbesondere im Hinblick auf das Heimatrecht, dass Heimat, Haus und Bürgertum nicht einfach nur zu entlarvende Konstrukte sind, sondern innerlich wie äußerlich, symbolisch wie rechtlich bestehende Ordnungskategorien, die nicht als reines Phantasma wegzuwischen sind.

\section{Heimatlosigkeit als Gegenordnung zur bürgerlichen Gesellschaft}

In den hier um das Thema des Heimatrechts versammelten Texten repräsentieren die Heimatlosen eine Gegenordnung zur bürgerlichen Gesellschaft. Bei den Texten von Kinkel und Schweichel liegt eine bestimmte Autorintention ziemlich klar auf der Hand: Kinkels Text wirbt für eine Solidarisierung mit dem vierten Stand; dieser wird mit den rechtlich Heimatlosen assoziiert. Die Selbstbewusstwerdung dieser Entrechteten, die gerade aus ihrer Außenseiterstellung Kraft schöpfen sollen, um sie im Klassenkampf letztlich zu überwinden, ist das erzählerische Telos.

Schweichels Intention ist wie die Kinkels eine emanzipatorische, und hier wie dort ist es das Anliegen, wenigstens in der erzählten Welt den Heimatlosen gewissermaßen ihre Heimat zurückzugeben. Auf der Textoberfläche geht es bei Schweichel um die Überwindung von Vorurteilen gegenüber den ins rechtliche Abseits geschobenen Zigeunern. Der Subtext der Erzählung spricht allerdings eine andere Sprache, denn die erzählerische Rücküberführung der Zigeuner in die Gemeinschaft wird in der narrativen Logik erst durch den Ausschluss des Juden

\footnotetext{
Raums, Geschlossenheit der bürgerlichen Welt, Geschlossenheit einer Kleinstfamilie und Sakralisierung des Interieurs gekennzeichnet. Die Ausfahrt des Schweizers in die ,Fremde‘ Deutschland erhält vor dem Hintergrund der stark affektiven, aber eben ambivalenten Bindung an die Heimat eine ganz andere Bedeutung als die Ausfahrt Wilhelm Meisters. Während Wilhelm leicht reise, so Ehrich-Haefeli, reise Heinrich gebunden und beschwert durch Liebe, Sehnsucht, geschuldete Verpflichtung und einen riesigen Holzkoffer der Mutter (vgl. Ehrich-Haefeli 1991, S. 360).

449 Keller strich die letzten beiden Absätze in seiner Überarbeitung von 1874, in denen die Erzählerstimme die Geschehnisse kommentiert.
}

450 Vgl. Uerlings 2007, S. 184. 
möglich. Das narrative Telos der Inklusion bleibt also versteckt an die Exklusion einer anderen gesellschaftlichen Gruppe gebunden.

Die Texte von Kurz und Keller, die - bisher nicht beachtet - vielfältige Parallelen aufweisen, stellen die Unentrinnbarkeit der Heimatlosigkeit radikal dar. Heimatlosigkeit zeigt sich als Gegenordnung der Bürgerlichkeit; die schwarze Christine bei Kurz und der schwarze Geiger bei Keller repräsentieren solche Heimatlosigkeit als geradezu notwendige Gegenordnung. In beiden Texten geht es um eine die bürgerlichen Normen verletzende Liebe, die aber außerhalb dieser Normen nicht bestehen kann. Auch die Freiheit von diesen Normen erweist sich als nur vermeintlich bzw. nicht akzeptabel. Die blonde Christine entscheidet sich gegen das ,Gesindel' und geht lieber in den Tod, als deren Welt zu teilen. Frieder versucht es, kann die bürgerliche Welt aber nie ganz hinter sich lassen und endet auf dem Rad. Sali und Vrenchen wählen genau wie die blonde Christine lieber aus freien Stücken den Tod, als die Normen der bürgerlichen Welt zu verletzen und sich dem ,Hudelvolk“ anzuschließen. „Diesen sind wir entflohen, sagte Sali, aber wie entfliehen wir uns selbst?“451 Das Leben mit den Heimatlosen können sie ablehnen, aber den Normen ihrer bürgerlichen Ordnung, die ihnen ein Leben nicht ermöglicht, können sie nicht entgehen. Heimatlosigkeit verhält sich in beiden Fällen antagonistisch zu einer Heimat, die Geborgenheit nur denen verheißt, die sich ihrer Ordnung unterwerfen. Der Preis, der für Heimat zu zahlen ist, ist in beiden erzählerischen Gestaltungen der Tod, und dass dieser Preis hoch, möglicherweise $\mathrm{zu}$ hoch ist, zeigen beide Erzählungen eindringlich. Die Verbindung von Tod und Heimat wird indes nur verständlich, wenn man sich mit der Geschichte des Heimatrechts klarmacht, wie grundsätzlich der Ausschluss aus der bürgerlichen Ordnung war, wo Heimat verwehrt wurde.

451 Keller 1989, S. 140. 